\title{
New Products, New Programs, and Prices: Measuring Consumer Benefits to Changes in Cable Television Choices, 1989-1995
}

\author{
Gregory S. Crawford* \\ Department of Economics \\ Duke University
}

September 1997

Draft - Please do not cite or quote

\footnotetext{
* This paper is based on Chapter 2 of my Ph.D. Dissertation at Stanford University. I would like to thank Tasneem Chipty for making available some of the data for this paper. I would also like to thank Roger Noll, Tim Bresnahan, and especially Frank Wolak for their many comments, as well as their patience and guidance. I have additionally benefited from the comments of Raphael Bostic, Raj Gangadean, Scott Stern, Bill Vogt, and seminar participants at Stanford University, Duke University, the University of Michigan, the University of Maryland, and the Federal Trade Commission. Financial support from the National Science Foundation, the Olin Foundation, and the Lynde \& Harry Bradley Foundation is gratefully acknowledged. Correspondence may be sent to Gregory S. Crawford, Department of Economics, Duke University, Durham, NC 27707-0097, phone 919-660-1828, email gsc@econ.duke.edu.
} 


\begin{abstract}
This paper evaluates the economic consequences of quality change and new service introductions in the cable television industry over the period 1989-1995. The analysis is motivated the recent widespread introduction of new, Expanded Basic, cable services and the associated addition and reallocation from existing services of some of the most popular cable programming to these services. These phenomena constitute increases in the variety and quality of cable television, the benefits of which to consumers is unknown.

To address these issues, we develop and estimate a discrete-choice, differentiated product model of the United States cable television industry. On the demand side, we depart from existing models of the industry and specify that the building blocks of individual utility in the model are the individual programming networks selected by systems and bundled into services for sale to consumers. To the extent individuals value quite highly certain programming networks - ESPN and The Discovery Channel for example - and less highly others, those services containing more valued networks will command greater demand. Individual demand is given by the maximization of utility over the (discrete) combinations of services offered in each cable market. Under the assumption that unobserved consumer tastes are distributed as a Type I Extreme Value, these demands are then aggregated over both individuals and unobserved service combinations - only total service market shares are observed - to yield market demands for a panel dataset of heterogeneous cable markets.

This framework is sufficiently flexible to measure the impact of changes over time in both the services offered by systems and the programming offered on those services. New services simply changes the set of choices available in each market, while changes in the programming offered simply change the value to consumers of the services which make up those choices. As such, the model permits us to evaluate the utility, and thus the demand, to consumers given any program selection and bundling changes undertaken by systems. In addition, we are able to use all the information available in each market and avoid the unpalatable aggregation over services frequently employed by existing models of the industry. On the supply side, cable systems are modeled as multi-product monopolists.

Our focus is measuring the benefits of changes in the choice set facing consumers over time. Our principal application is the construction of a quality-adjusted price index for cable television service for the period 1989 - 1995. In addition to measuring the total change in prices over this period, we decompose changes in this index to changes in the set of services offered, in the programming offered on those services, in the prices of those services and in demographic and market characteristics. We then compare this index to that obtained by the Bureau of Labor Statistics as part of the Consumer Price Index. Our principal finding is that failing to account for the benefits of increased quality and variety in cable television services yields an index which largely duplicates the 15\% price increase reported by the Cable CPI between January, 1989 and July, 1995. However, incorporating consumer benefits from the addition of new services, the addition of programming to all services, and increased quality of existing programming yields an aggregate index which suggests a slight decrease of $1.1 \%$ in cable prices.
\end{abstract}




\section{Introduction}

Accounting for the benefits to consumers from the introduction of new goods and services or from changes in the quality of existing goods and services has always been a bit awkward. This issue, historically the provenance of the price index literature, is extremely important, however. To give a single prominent example, the Consumer Price Index is used as an economic indicator and guide to the development of monetary policy, as a deflator of economic time series and an indicator of productivity trends, and as a means of adjusting consumer and worker income and wage payments through indexing. Recent analysis of the CPI by an panel of economists has suggested, however, that failure to adequately account for the economic benefits associated with new products and quality change has led to an overestimation of the true cost of living by over $1 \%$ per year. ${ }^{1}$ The savings in social security payments alone from a readjustment of the index accounting for this overestimation are projected to exceed $\$ 700$ billion over a 12 year period. ${ }^{2}$

These same issues present themselves in the analysis of the cable television industry. In a practice known as bundling, cable television systems select and package programming networks into services for sale to consumers. As they have since the 1970's, cable systems in the last decade have increased the quality of these services: the number of channels provided by the system, the programming provided on those channels, and the cost of that programming have all grown considerably in this time. ${ }^{3}$ More recently, however, systems have also begun to increase the number of services that they provide, largely by splitting into multiple services the bundle of programming provided on the lowest level of service. ${ }^{4}$ These increases in both the quality and the diversity of cable services have in turn fueled comparable increases in subscriber growth - despite accompanying increases in prices - so much so that the industry now approaches its broadcast counterpart in economic importance.

Accounting for the benefits to consumers from changes in cable prices, programming, and services is of central importance as a guide to regulatory policymaking in the industry. A recent

1 [CPI panel cite]

Feldstein (1997)

3 Owen and Wildman (1992) and Crandall and Furchtgott-Roth (1996).

4 In addition to reallocating programming among services, systems have tended to simultaneously introduce new 
survey of industry regulatory activity highlights this point. Cable systems have been deregulated (1984 Cable Act), re-regulated (1992 Cable Act) and partially deregulated again (1996 Telecommunications Act). At cause has been the persistent growth in cable television prices since the '84 Act and debate over the extent to which regulation can protect consumers from this growth.' That prices for cable television services are high, however, does not imply that consumer welfare is correspondingly low. As emphasized above, associated increases both in the quality and diversity of the portfolio of services offered surely offset, and may indeed outweigh, the loss in welfare associated with high prices. The rationale for regulation at all, as well as the form that it should take, depends on the extent to which consumers value product and quality changes at the expense of price changes as well as the extent to which government policies can affect these gains. ${ }^{6}$ The measurement of these gains is the purpose of this paper.

The measurement of the value to consumers of the quality and diversity of cable television services is not an obvious undertaking, however. In the case of valuing quality change in computing or cars, other markets for differentiated products where this issue has received considerable attention, increased quality is easily quantified - greater CPU speed and larger disk space or more horsepower and better gas mileage, for example. ${ }^{7}$ Converting such 'quality units' into economic value can then be made by modeling the demand for the products embodying these characteristics. ${ }^{8}$ The comparable 'product characteristics' for cable services are program networks. Unlike disk space, however, where a gigabyte is a gigabyte, not all networks are created equally. The value to consumers of an additional program network depends critically on the type and quality of programming it provides. In a phrase: $\mathrm{CNN}$ is not the Cartoon network. An accurate measure of the value to consumers from changes in the programming provided by cable systems over time must therefore reflect these differences in the

programming.

See, inter alia, Mayo and Otsuka (1993), Rubinovitz (1994), Johnson (1994), Crandall and Furchtgott-Roth (1996), and Crawford (1997). [Other sources] See Johnson in particular for the recent regulatory history of the industry and Crandall and Furchtgott-Roth for an analysis of the consequences of these regulations and a position on the proposed scope for future government involvement in the industry. In a companion paper, Crawford (1997), we analyze in detail the benefits to consumers associated with the '92 Act.

6 The motivation for the partial deregulation of cable services in the 1996 Telecommunications Act was, in part, due to the widespread belief that price cap regulation had not yielded substantial consumer benefits. See Crawford (1997) for more. 7 See Brown and Greenstein (1994), for models of demand for mainframe computers and Bresnahan, Stern, and Trajtenberg (1997), etc. for models of demand for personal computers. See also the related hedonic literature relating the price of computers to their associated attributes exemplified by Griliches and Cockburn (1994). [Other cites] 
underlying value of individual networks.

The case of valuing diversity in the cable industry presents different obstacles. As consumers have heterogeneous tastes for programming, the introduction of a new service with associated new networks by a system, will, ceteris paribus, increase aggregate consumer benefits by satisfying some consumers with tastes for the new programming. If a new service is introduced, however, and networks are shifted to it from existing services - a common practice during this period - the benefit to consumers is not clear-cut. Those with tastes for the networks provided on the new service should benefit, but those which now must purchase a larger bundle to obtain their preferred networks may not.

Few previous studies of the industry have specifically addressed these measurement questions. ${ }^{9}$ Those that have, notably Crandall and Furchtgott-Roth (1996) and Rubinovitz (1993), estimate models of demand that control for quality change over time by comparing the number of program networks provided on Basic cable service. ${ }^{10}$ To the extent individual networks are imperfect substitutes, however, such a measure may over- or understate the benefits of additional program networks as well as the welfare benefits of the reallocation of networks among services. ${ }^{11}$ Moreover, these studies either focus exclusively on Basic Service or on Basic Service plus an aggregate measure of Premium Services. ${ }^{12,13}$ As a consequence, they likely underestimate the value of added diversity associated with new service introductions by cable systems by aggregating over these services.

This paper attempts to avoid these pitfalls by estimating an discrete-choice differentiated product model of demand and supply of cable television services which permit the valuation of both changes in the quality and diversity of cable services over time. On the demand side, consumers are

9 Due to a continued regulatory interest in the industry by the Federal Communications Commission (FCC), the economic literature on the industry has largely focused on particular policy questions of regulatory interest. Representative branches of this literature have addressed (1) the extent of market power held by local monopoly cable systems [Sources], (2) Overbuild, (3) etc.

10 Basic cable service is the most popular service offered by cable systems. It typically contains most if not all of the programming people typically associate with cable television. A more detailed definition is given in Section 2 .

11 These conclusions depend on the value of the networks under consideration relative to the value of a network of 'average' quality.

12 Premium Services typically offer advertising-free entertainment programming on an à-la-carte basis for an additional fee.

${ }^{13}$ Rubinovitz aggregates those markets with multiple Basic Services into a single service using market shares as weights. Crandall and Furchtgott-Roth aggregate subscriptions to multiple premium services into a commonly reported industry aggregate - pay units - and analyze the demand for Basic Service and this aggregate. 
assumed to have preferences for program networks. The bundling strategies undertaken by cable systems, however, restrict consumer choice in two important ways. First, because systems bundle networks into services for sale to consumers, the objects of consumer choice are these services, and not the networks which make them up. This is the no more than the standard characteristic of differentiated products markets. However, systems also require the purchase of Basic Service in order to purchase any other service. This is called a 'tying' arrangement in the economic literature. ${ }^{14}$ Subject to these restrictions, consumers may choose as they please, implying a final choice among all combinations of services offered by systems and the choice of not subscribing to cable at all. The discrete choice model reflects these restrictions by specifying a market-specific choice set consisting of all combinations of services offered in that market and assuming consumers select one element of this set.

Taken together, these elements of the model of individual demand provide a unifying framework for measuring the value of cable television services. ${ }^{15}$ First, the framework builds individual demand for whatever services are offered from tastes for the underlying objects of consumer utility, the programming provided on those services. By separating the link between the convenient institutional definition of a product used in previous studies, i.e. Basic Cable Service, and the different components of that product, the programming provided, we shift the focus of individual choice to its structural foundations. By estimating the value of each of these individual programming networks, the model is able to differentiate between the utility accruing to consumers from the consumption of relatively more valuable and relatively less valuable programming networks. As systems shift programming to new services from existing services or, more generally, change the portfolio of programming provided of any service, the benefit to consumers from those services will change and the model can track that change. Second, the discrete-choice framework provides a natural means of evaluating the benefit to consumers from any additions (or deletions) to this set imposed by cable systems. If a system introduces a new service, the choices available to consumers in that market increase to include all of the existing choices alone and in combination with the new

\footnotetext{
${ }^{14}$ The good which must be purchased - here basic cable service - is generally called the 'tied' good as its purchase is 'tied' to the purchase of all other cable services.

15 The plural, services, is appropriate as the framework permits the valuation of the programming provided on each service offered by a cable system in a cable market.
} 
service. As a consequence, the benefit to consumers from facing this expanded choice set grows and the model can track that growth. In addition, we are able to use all the information available in each market and avoid the unpalatable aggregation over individual services frequently employed by existing models of the industry.

To aid in the estimation and applications, the model of demand is then joined with a model of pricing behavior by the cable system in each market. As the vast majority of cable systems are monopolists, ${ }^{16}$ they are assumed to maximize profits with respect to the price of each of their offered services given the structure of demand described above. ${ }^{17}$

The principal source of data used to pursue this investigation is a database on the population of U.S. Cable systems compiled and maintained by the Television and Cable Factbook, a cable industry reference. ${ }^{18}$ We have drawn information on the price, programming and subscribers to each service provided by each of these cable systems at two points in time: February 1992 and August 1995. ${ }^{19}$ Because the data report market-level demand for individual services, however, we must aggregate over the individual demands for combinations of services predicted by the model. The assumption that the joint distribution of individual, idiosyncratic tastes over the combinations of services available in each market is a Type I Extreme Value permits the former aggregation and yields logit market shares for the service combinations among which consumers choose. Since each of these combinations is mutually exclusive, adding all the market shares predicted by the model for the combination of services containing each particular service yields the market share for that service. These are then taken to the data.

16 What few 'overbuilt' (competitive) markets were in the dataset were excluded from consideration in the empirical implementation of the model.

17 By assumption, this paper will conduct a short-run analysis. In the long-run, the cable supply decision can be adequately described by a three part process. First, systems build capacity by wiring their franchise areas. Next, they choose the number of tiers of service, both expanded basic and premium, to offer as well as the programming to offer on those services. Finally, they choose the price of each service given their physical plant and chosen service portfolio. This section considers only the last, short-run, stage of this trilogy - the pricing decision. The omission from the analysis of the choice of size of cable plant is not unreasonable given that most systems have completely wired their franchise areas and may not expand further. The omission from the analysis of the tiering decision is less reasonable -- in future work, I intend to address this portfolio (tiering/programming) decision in detail.

${ }_{18}$ The data sets used in the analysis and the conditions placed on them are discussed in detail in the next chapter.

${ }^{19}$ Since the number of homes passed by each system defines the set of possible subscribers to cable service and is also reported, we have a very precise definition of the size of each cable market, permitting a natural transformation from the number of subscribers for each reported service to the market shares for those services required by the model. 
Following recent advances in the estimation of discrete-choice models of differentiated product markets, we also permit an unobservable (to the econometrician) attribute - quality - in the demand for each service offered by systems. This induces a correlation between prices and market shares which must be addressed in the econometric estimation. Utilizing techniques introduced in Berry (1994) and modified to accommodate the aggregation over combinations of services described above, we invert the market share equation for each service to equate mean expected consumer utility for that service with a nonlinear function of its market share. ${ }^{20}$ The unobservable quality associated with each service remains as a source of econometric error. Variables which shift the marginal cost of providing cable service serve as instruments for price. Price-cost margins obtain from the solution of the systems first-order conditions for profit maximization yield the estimating equations for the pricing model; variables which shift demand across markets provide instruments for markups.

The results of the estimation indicate that it is cable programming in general - and the most popular cable programming in particular - which largely drives the demand for and cost of cable services. Estimates of mean willingness-to-pay (WTP) in the 1992-1995 sample for ESPN, CNN, WTBS, USA and The Discovery Channel, the five most popular nationally distributed cable television networks, are $\$ 5.02, \$ 0.35, \$ 1.26, \$ 0.96$, and $\$ 0.87$. By contrast, mean WTP for networks outside these five average between $\$ 0.10$ and $\$ 0.26$. By contrast, while cable programming clearly increases demand for cable, we cannot reject the hypothesis that mean WTP for broadcast programming networks not otherwise available over-the-air are zero. Where widely available over-the-air, however, they do tend to decrease demand for cable services, suggesting that they remain a competitive alternative. In comparison with the 1992-1995 sample, estimates for the 1988-1991 sample indicate that average tastes for cable programming have changed significantly over time, no doubt reflecting program expenditure increases by networks, while that for broadcast and premium programming have remained constant..

Our principal practical application of the model is in the development of a quality-adjusted price index for cable television services. ${ }^{21}$ To do so, we rely on the construction of an analogue to an

\footnotetext{
20 It is the aggregation over unobserved elements of the choice set - the combinations of services predicted by the model of demand - that prevent us from exploiting recent advances in permitting more flexible substitution patterns among the elements of choice. This problem and its implications for the estimation and applications are discussed in detail in the paper.

21 The price index literature is vast and varied. The index ...
} 
exact group cost-of-living index in the spirit of Pollak (1980). This, in turn, relies on the characterization of heterogeneous household tastes within markets with the preferences of a representative consumer. As described in recent work by Anderson, de Palma, an Thisse (1993) and Feenstra (1995), the representative consumer's preference map serves as the social welfare function required for the exact group index. We begin by measuring the welfare change to consumers from the observed changes in their choice set over time. As the change in the choice set is a consequence of four separate, component, changes - in the services provided, in the programming provided on those services, in the prices charged for those services, and in characteristics of consumer demographics and cable markets, we disaggregate the welfare change into these four components. Taking these magnitudes as given, we then consider the initial choice set and measure the changes in the price of Basic Service which would yield identical welfare changes. ${ }^{22}$ This disaggregation of the overall index into its component parts has the advantage of illustrating which aspects of changes in the choice set namely changes in diversity, quality, or price - yielded the greatest and least consumer benefit. In a final exercise, we compare our quality-adjusted index with the Consumer Price Index for cable television service maintained by the Bureau of Labor Statistics.

Our principal finding is that failing to account for the benefits of increased quality and variety in cable television services across our sample periods yields an index which largely duplicates the price increases reported by the Cable CPI. In particular, while the Cable CPI reports price increases of $14.8 \%$ over the period January, 1989 to July, 1995, our index accounting only for price increases in cable services yields a comparable estimate of $16.7 \%$. Incorporating consumer benefits from the addition of new services, the addition of programming to all services, and increased tastes for existing programming, however, yields an aggregate index which suggests a slight decrease of $1.1 \%$ in cable prices. Effective price declines due to the introduction of new services and the introduction of new programming to these and existing services account for approximately $60 \%$ and $40 \%$, respectively, of this differential benefit. We conclude therefore that existing price indexes understate the true benefits of changes in cable television services over this period. This conclusion then calls into question the need for further industry regulation.

The balance of this paper proceeds as follows. We first establish the stylized facts which are

22 Since Basic Service is included in all consumer cable purchases, it's price is a natural candidate for indexing. 
the basis of our analysis. In particular, we define the range of contemporary cable television services available and describe the changes in these services over our two sample periods. The model of individual demand for cable services is then specified and the aggregation assumptions required to permit its estimation on a cross-section of market-level data are described. The structure of econometric error is explicitly made and the modifications required to estimate the model by instrumental variables are delineated. The model of pricing is then introduced and the pricing equations derived. The implications of the assumed functional form for individual tastes in cable markets is discussed and the identification of the structure of cost and preferences considered. The estimates are then presented and interpreted and the quality-adjusted price index for cable service derived. A final section considers the implications of our results for industry regulatory policy and discusses possible extensions.

\section{Cable Television Service: An Introduction}

Cable television service is characterized by the provision of a portfolio of programming networks, bundled into one or more services and offered to consumers in local, geographically separate, cable markets by monopoly cable systems. ${ }^{23}$ Systems offer three principal types of networks. Broadcast networks are television signals broadcast in the local cable market by television stations and then collected and retransmitted by cable systems. Obvious examples are the major, national broadcast networks - ABC, CBS, NBC, and FOX - as well the programming broadcast by public and independent television stations. Cable programming networks are advertising-supported general and special-interest networks distributed nationally to systems via satellite. Among these are some of the most recognizable networks associated with cable, including WTBS, CNN, and ESPN. Premium programming networks are advertising-free entertainment networks, typically offering fulllength feature films. Among these are equally familiar networks like HBO, Showtime, and the Disney Channel. $^{24}$ Broadcast and cable programming networks have historically been bundled together by

\footnotetext{
${ }^{23}$ This market structure historically resulted from the granting by local municipalities of exclusive franchises to cable systems in light of the perceived ' $N$ atural $M$ onopoly' features of cable service. The granting of exclusive franchises was annulled by the 1992 Cable Act. For a description of the franchising process, see Prager (1986) and Zupan (1989).

24 In addition, cable systems often offer two other types of program networks: Public, Educational, and Government (PEG) networks and Pay-per-view networks. The former are typically considered in-kind compensation to municipalities for the right to provide cable service and are not typically valued very highly by consumers. The latter are networks devoted to real-
} 
cable systems and offered on what is known as Basic Service while premium programming networks have typically been separated into individual services and sold on an à-la-carte basis as Premium Service(s). ${ }^{25}$ Some systems, however, do elect to split Basic Service and instead offer some portion of their cable programming networks on multiple services. ${ }^{26}$ These are called Expanded Basic Services. ${ }^{27}$ Figure 2-1 summarizes the typical allocation of these different types of programming for systems that do and do not offer Expanded Basic Services.

The introduction of new program networks over time into existing services and the unbundling of the cable programming networks historically provided on Basic Service into new Expanded Basic services are the focus of this paper. As has been the case since the advent of the industry, the former event has largely been driven by increases in system channel capacities. As capacities have risen, from an average of 12 in the mid-1970s to 27 in 1984, 34 in 1991, and 40 in 1995, systems have exploited this capacity to provide more program networks. ${ }^{28}$ Such increases qualify as changes in the quality of cable service. The introduction of Expanded Basic Services, however, is a relatively new phenomenon. These, in turn, qualify as a changes in the variety of cable services. $^{29}$

In this paper, we take a very particular view of how to parameterize the quality of cable services. As we believe consumers purchase cable in order to view programming, the quality of a given service is assumed to depend upon the identities of the individual program networks provided there. In particular, cable services providing more programming, and more importantly, more of the

time purchases of entertainment (typically movies and sporting events). The lack of adequate data on the presence of Payper-view networks in the initial sample considered in this paper precluded their inclusion in the analysis.

25 Note that recently the Disney Channel - a premium programming network - has pursued being carried on basic cable service rather than as an a-la-carte offering. At the time of this study, however, they were uniformly offered on as a premium service.

26 By law, broadcast networks must be offered on Basic Service.

27 In addition, systems have recently begun to introduce Pay-per-view networks. These are very similar to Premium programming networks except that they offer programming on a per-program, rather than per-channel basis.

28 Factbook (1992) and (1995).

29 To be precise, the introduction of Expanded Basic services is really a combination of changes in both the variety and the quality of cable services. The introduction of a new service constitutes an increase in variety. The reallocation of programming among Basic and Expanded Basic services, however, constitutes both an increase in the quality of Expanded Basic services but also a decrease in the quality of Basic Service. Of course, in addition to the introduction of Expanded Basic services and the reallocation of programming among these and Basic services, many systems simultaneously introduced new networks into each, increasing the after-transfer quality of both services. 
most popular programming, are supposed to be valued more highly by consumers. ${ }^{30}$ As such, as an indicator of the quality of programming provided on any given service, we measure the number of the "most popular" cable programming networks provided on that service. The "top 40" such cable programming networks available in the United States as of December, 1992 are listed in Table 2-1. This line of argument appears to suffer from circular logic: consumers attach value to the most popular programming, but of course the most popular programming is that which consumers value most highly. The penetration of networks onto systems, however, takes years to build. ${ }^{31}$ As a consequence, at any point in time, the nationwide popularity of individual program networks is largely fixed and can serve as a good indicator of overall worth to consumers. ${ }^{32}$

This narrow view of the quality of a cable service is predicated on the belief that programming networks, particularly the most popular programming networks, are poor substitutes for each other. There is some justification for this point of view. Networks, particularly cable networks, are differentiated in many ways. First, they tend to differ in the overall category of programming that they provide. ESPN provides 24 hour sports coverage, CNN provides 24 hour news coverage, The Discovery channel provides educational programming, Nickelodeon provides children's programming, and MTV provides music news and videos. Even those networks that provide 'general-content' programming, for instance the USA network, WTBS, and TNT, tend to systematically differ in the type of programming they provide. ${ }^{33}$ The same is true for other networks that compete within the same category. CNN, Headline News, C-SPAN (I and II), and CNBC each

30 This is not a constraint in the empirical estimation, however. The data are free to determine the relative worth of all individually parameterized networks. The only distinction, then, between more and less popular networks are that the former more likely enter the empirical specification with individual impact.

31 Casual observation of the launch dates in Table 2-1 supports this supposition: Among the 15 most popular networks, only one, TNT, was launched after 1985 and they are something of a special case given they share a common owner with both CNN and WTBS. This is true both for institutional as well as economic reasons. Since many systems enter long-term contracts with program suppliers, turnover in the portfolio of programming they offer to consumers is limited. Furthermore, due to economies of scale in program supply, the cost (and by extension the quality) of the programming provided on nascent networks often is inferior to that provided on established networks.

32 To buttress this claim, we note that the overall ranking of cable programming services is quite stable over time, particularly at the top. [Source?]

33 In particular, WTBS and TNT, both owned by Time Warner, tend to offer theatrical films and situation comedies from the last 20 years while USA tends to offer more contemporary fare. In addition, WTBS and TNT join NBC in sharing rights for the NBA (Basketball), WTBS owns the broadcast rights to the Atlanta Braves (Baseball), and USA owns rights to PGA (Golf) and WTA (Tennis) events. [Marketing cites for backup] 
provide news programming, but of varying kinds. ${ }^{34}$

\section{The Cable Industry in the Late 1980's and Early 1990's}

The purpose of this section is to introduce the data used in the analysis and to establish the stylized facts that are the basis of that analysis. In particular, we investigate the extent of service, programming, and price changes undertaken in the industry over the period 1989-1995. In so doing, we pay particular attention to changes in the most popular programming offered to subscribers.

\subsection{Data}

This paper compiles a market-level dataset on a panel of United States cable systems. The primary source of data for these systems is Warren Publishing's Television and Cable Factbook Directory of Cable Systems. The Factbook conducts detailed annual surveys of the population of United States systems and records the information in a database whose contents are published in annual editions. Systems are asked about characteristics of their market, their system, and the services that they provide. In particular, systems are asked to report, for each service offered, the number of subscribers to that service, the monthly fee for that service, and the identities of the broadcast, cable, and premium programming networks provided on that service.

The data for this paper consists of two draws from this database. The first sample was drawn in February 1992 and the second sample was drawn in August 1995, and contains the most recent information available to this paper. ${ }^{35}$ As system responses are continuously entered into the database, the vintage of the information is not the same for each system, however. As a consequence, the data from the first sample spans the period 1988-1991 while the data from the second sample spans the period 1992-1995. While there are over 10,000 cable systems in the United States, only 344 systems were both (1) present in each sample and (2) provided sufficiently reliable information to be used in the study. Appendix A discusses in detail the collection method used for the data and chronicles the conditions required of it to be included in the analysis.

\footnotetext{
34 Headline news is 24 hours of breaking news coverage. CNN varies somewhat from this format by also providing analysis as well as specialty programming such as daily programs devoted to Money and Investing. C-SPAN provides uncut coverage of the U.S. Senate and House of Representatives, while CNBC provides more analysis and also tends more towards entertainment.
} 


\subsection{Changes in Services, Programming, and Prices}

Table 2-2(a) describes the change in the overall quality of the portfolio of programming provided by the cable system between the two sample periods in our panel. As can be seen there, on average, cable system capacity increased by 3 channels, from 32.66 to 35.66 , over 2 of which were devoted to the carriage of additional cable program networks. Furthermore, these channels were largely devoted to the carriage of relatively popular programming. Nearly 1.5 of the $2+$ channels, on average, went to the carriage of previously unavailable top-20 program networks and nearly all, 1.82 on average, went to the carriage of previously unavailable top- 40 program networks.

We focus next on the introduction of new, Expanded Basic Services. While only a handful of systems, 5, elected to partition Basic Service into separate components in the earlier data, by 1995, over 17\%, 60, did. Of these, nearly half, 27, offered two Expanded Basic Services in addition to Basic Service.

The introduction of these new services had an important impact on the distribution of cable programming networks across services. The balance of Table 2-2(a) shows the distribution of program networks by type of service. While the total number of cable programming networks increased on Basic Service as a whole, from 11.62 to 12.30, there was substantial attrition at the top. The average number of top-5 networks declined substantially, from 4.26 to 3.99 , while the number of top-10 networks increased only slightly, from 6.42 to 6.51 networks. As we stated earlier, the total number of top-5 networks offered on cable increased over this span. Where, then, did they go if not to Basic Service? To Expanded Basic Services. For those systems that offered Expanded Services, the first such service averaged a 2.15 top-5 networks, 3.73 top-10 networks, and 7.87 total cable networks. In addition, the second such service, where offered, averaged another top-5 network and another 3 total networks.

The introduction of new services also had strong impacts on the penetration across services for given networks. Table 2-2(b) describes the percentage of systems that carried each of the top-20 networks and the service that they carried them on. While ESPN, the most popular cable network, increased its penetration on the cable systems in the data from $97.7 \%$ to $99.1 \%$, penetration on Basic

\footnotetext{
35 I would like to thank Tasneem Chipty for providing me with the 1992 data.
} 
Service fell to 93.9\%, the balance being offered on Expanded Services. Even stronger effects were seen for CNN and WTBS. In each such instance, over $10 \%$ of cable systems in the sample shifted these networks from Basic to Expanded Basic services. ${ }^{36}$ As emphasized later in the paper, the incidence of networks on different services is critical to their identification in the empirical estimation.

The introduction of Expanded Basic Services by a subset of systems suggests that the experience of consumers in these markets might differ significantly from those in markets that didn't introduce Expanded Basic Services. To investigate this issue, we consider the experiences of each of these subsets individually. Tables 2-3 through 2-5 describe changes in the services, programming, prices, and market shares for those systems that (1) Did not introduce Expanded Basic Services, (2) Introduced one Expanded Basic Service, and (3) Introduced two Expanded Basic Services. In the balance of this section, we will refer to the latter two sub-samples according to the number of services that they introduced. ${ }^{37}$ Thus, there were 281 systems that did not introduce new services, 31 oneservice markets, and 26 two-service markets. ${ }^{38}$

We consider first changes for those systems that did not introduce new services. These changes are easily summarized: such systems witnessed slight increases in programming, prices, and market shares. In Tables 2-3(a) and 2-3(b), we see that total capacity increased 2.3 channels, of which over $70 \%, 1.6$, were allocated to top-40 cable programming. Increases in carriage were distributed across the range of networks offered. Prices for Basic Service increased slightly, from $\$ 12.90$ to $\$ 13.43$ as did market share of Basic service, from $64.0 \%$ to $66.3 \%$.

Very different results obtain, however, for those systems which did introduce Expanded Basic Services. Focusing first on the total programming offered, Tables 2-4(a) and 2-5(a) show that such systems were more likely to increase their channel capacities as well as offer more programming on that capacity. The introduction of Expanded Basic Services also had a significant impact on the allocation of that programming across services. While such systems offered over 4 of the top-5 networks on Basic prior to their introduction of Expanded Basic Services, this figure dropped to 2.03

\footnotetext{
36 Note that this is out of a possible $17 \%$ as that is the percentage of systems that offered Expanded Basic Services.

37 This is most appropriate for the latter two categories, which we call 'One-Service' and 'Two-Service' markets. This should not be taken literally, however, as these systems were among the most diverse, offering over 5 services on average.

38 The remaining 6 systems were those that offered Expanded Basic Services in the earlier sample. Including these in the tables yields nearly identical results and only complicates the exposition.
} 
for one-service markets and to 1.58 for two-service markets afterwards. ${ }^{39}$ Similar results, although not as severe, obtain when we expand the analysis to top-40 networks. Here, the number of networks on Basic falls from 17.0 and 15.9, respectively, to 9.2 and 11.8.

While programming was lost on Basic Services, it was gained on Expanded Basic Services. In one-service markets, 9.9 total cable networks were added, over 2.5 of which, on average, were top- 5 networks. In two-service markets, 5.2 and 2.9 total networks were added, 1.8 and 1.1 of which, respectively, were top-5 networks.

While many networks were transferred, however, prices for these new Expanded Basic Services did not reflect these moves. For instance, in one-service markets, while more than half of the total cable programming offered by systems was done so on Expanded Basic Services, its incremental price was half that of Basic Service (\$5.81 v. \$11.00). This was true even though an even greater percentage of the most popular programming was offered on Expanded Basic Service. Similar results obtain in two-service markets. As a consequence of being offered so much for so little, the vast majority of consumers who elected to buy Basic also purchased Expanded Basic Services. Penetration of Expanded Basic among Basic subscribers was over 90\% (57.5\% / 62.9\%) in one-service markets and over $90 \%$ and $80 \%$, respectively, in two-service markets. In addition, despite aggregate price increases, market shares for all services grew.

In contrast to Basic Service changes, Premium Service changes were limited. ${ }^{40}$ Across all markets, prices fell slightly and market shares declined.

\section{Implications}

The implications of these service, program, and price adjustments can be summarized in the following list:

1. 'Top' networks do appear to be relatively important in driving demand.

While this is an empirical issue, there is some evidence here to support the contention that the carriage of the most popular networks and not total networks, is the more important determinant of demand. For support we turn to two facts. First, systems were more likely to provide top-5

39 As noted in footnote 34, 'one-service' markets are defined as those markets where systems introduced one Expanded Basic Service, not as those markets that offered only one service.

40 This, in part, reflects a weakness in the data: the identities of the Premium Services in the 1988-1991 sample was only possibly by inference from the 1992-1995 sample. As a consequence, those markets where systems introduced premium services had to be excluded as matching the services was no longer possible. 
networks on Expanded Basic Services. ${ }^{41}$ While we are not in this paper analyzing system bundling decisions directly, the move to provide relatively more top-5 networks on Expanded Basic Services when compared to Basic Services suggests their relative importance. We also note that these services had very high subscription rates as a percentage of Basic Service. This too suggests the high value placed on these services by subscribers. ${ }^{42}$

2. Consumers appear to have valued the program and service changes by systems.

While the distribution of programming across services differed somewhat for systems that did and did not introduce new Expanded Basic Services, on two points did all markets agree: (1) on average, prices for Basic Service(s) increased, and (2) on average, market shares for Basic Service(s) increased. While perhaps the magnitudes of these increases were unremarkable for systems that maintained a single Basic Service, the same is assuredly not true for those that introduced new services. Given the remarkable percentage of Basic subscribers who also subscribed to the these new services (where offered), the relevant price to the vast majority of these consumers is the sum of the Basic Service prices. ${ }^{43}$ In one-service markets, for instance, the total price for all Basic plus Expanded Basic Services increased, on average, from $\$ 13.46$ to $\$ 16.81$. In two-service markets, the gain was from $\$ 14.02$ to $\$ 19.31$. Yet despite these substantial increases, market shares, at least for Basic Service, actually increased. Taken at face value, these results indicate strong tastes for the changes introduced by systems in the variety and quality of cable service as measured by the services offered and programming offered there.

3. The tie of Basic Service to other cable services is extremely important to account for observed prices and market shares.

Understanding the structure of choice decisions in cable markets is critical to rationalizing the difference in per-channel prices for Expanded Basic Services relative to Basic Services. We consider one-service markets as an example. In these markets, consumers paid, on average, $\$ 1.19$ for each cable network offered on Basic Service. The comparable figure for Expanded Basic Services: \$0.59. This despite average quality - as measured by the number of top networks offered - being higher on the latter service. Of course, the presence of other programming on Basic Service can probably rationalize some of this price difference, but not all. It is easily done, however, by considering that consumers are not able to buy Expanded Basic Services (or any other than Basic service) directly, but are first required to buy Basic. For those that particularly valued Basic, the relevant price for Expanded Basic Services is indeed the incremental price; however, for those that do not, the relevant price is the total (Basic plus Expanded Basic) price. ${ }^{44}$

Taken together, these results suggest both that the welfare reduction associated with system price increases may have been offset by increases in the variety and quality of the services offered. In

41 In particular, 56\% and 64\% of the networks offered on Expanded Basic Service by systems which introduced such services were top-5 networks. That against $51 \%$ and $39 \%$ of the total networks offered were offered on Expanded Basic Services.

${ }_{42}$ We recognize that this is only indirect evidence, however, particularly given the discussion in the following points.

43 These are given in tables 2-1 through 2-4.

44 This is in the extreme case that the consumer values Basic Service not at all. In the general case, the implicit price for Expanded Basic services is its incremental price plus the difference between the price of Basic Service and its reservation 
addition, it suggests that the modeling of consumer choice needs to reflect both the tie of Basic Service to other service purchases as well as the differential importance of individual program networks. In the next section, we introduce an equilibrium model of the industry that can address all of these issues.

\subsection{The Model}

\subsubsection{The Demand for Cable Television Services}

The model of demand developed in this paper is designed to accommodate multiple service offerings by cable systems and the measurement of the demand for the programming provided on any of those services. As such, we rely on recent models developed in the Discrete-Choice, Differentiated Products demand literature and extend them to the case of tied products and unobserved elements of the choice set. The salient features of these models as applied to cable television can be summarized as follows.

First, drawing on the Differentiated Products literature introduced by Lancaster (1966) and Rosen (1974), we specify that the building blocks of individual utility, and thus demand, for cable television services in the model is the programming network. To the extent individuals value quite highly certain programming networks and less highly others, those services containing more valued networks will command greater demand. ${ }^{45}$

The bundling strategies undertaken by cable systems, however, restrict consumer choice in two important ways. First, because systems bundle networks into services for sale to consumers, the objects of consumer choice are these services, and not the networks which make them up. Because different systems offer different services and individual systems offer different services at different points of time, the size and composition of this set varies in both the cross-section and the time series. $^{46}$ As a consequence, if the system offers only a single, basic cable service, then consumer

price to the individual. If an individual would not purchase Basic Service on its own, this magnitude is positive.

45 The merits of this assumption in the context of the cable industry were considered in the last section.

46 Discrete choice models are adept at accommodating both heterogeneity in the choice set as well as changes in the choice set over time. For a survey of the discrete-choice, or Qualitative Response, literature, see McFadden (1984), Maddala 
choice in the market is binary: to buy this service or not. ${ }^{47}$ If, however, as is more likely the case, the system offers multiple services, both expanded basic and premium, then consumer choice in this market is more complicated. In principal, a consumer could purchase any or all of these services or, alternatively, choose not to subscribe to any cable services. However, systems also require the purchase of Basic Service in order to purchase any other service. In practice, then, consumer choice is multinomial: to buy nothing or to buy one of the union of Basic Service with any combination of additional services. ${ }^{48}$

Reflecting this institutional structure, we draw on the discrete choice literature originally developed by McFadden (1974) and posit that an individual purchases one among the set of combinations of cable services available to him. We begin by characterizing individual choice in this context

\section{Individual Choice in Cable Markets}

Consider a cable market, indexed by $n$. Let $S_{n}$ enumerate the set of services offered by the cable system in market $\mathrm{n}$, where $\mathrm{S}$ is indexed by $\mathrm{n}$ to reflect that systems in different markets differ in the number of services they offer. Let $\mathrm{s}$ index the services in $\mathrm{S}_{\mathrm{n}}$ and let $N_{S_{n}}$ indicate the number of such services provided. As described above, consumer choice in market $\mathrm{n}$ consists of the option of purchasing no cable service, or of purchasing Basic Service and any combination of other services offered by the system in market $n$. Let $J_{n}$ enumerate the set of such choices. Similarly, let $\mathrm{j}$ index the choices in $\mathrm{J}_{\mathrm{n}}$ and let $N_{J_{n}}$ indicate the number of such choices.

The relationship between the choice set, $J_{n}$, and the set of services, $S_{n}$, is critical to an understanding of the model. Much of the modeling effort undertaken in this paper arises we observe information about $S_{n}$, the set of services offered in market $n$, while choices are made from $J_{n}$, the set

(1983), or Amemiya (1981).

47 This example is illustrative. No systems in the dataset used in the empirical implementation offered only a single, Basic Service.

48 The user of the word 'combination' is this context is not accidental -- we mean it in its probabilistic sense, namely "any subset of a set considered..." (Webster, 1996) For example, suppose a system were to offer, in addition to Basic Service, HBO and The Disney Channel, two Premium Services. The combination of Basic Service and HBO would then be one element of the choice set. Another would be the combination of Basic Service and the Disney Channel. A third would be the combination of Basic Service, HBO, and the Disney Channel. As can be seen, any individual service can be obtained from more than one choice. 
of combinations of services offered in market $\mathrm{n}$ which include Basic Service. ${ }^{49}$ We discuss this point more fully in the following paragraphs.

Given the market-specific choice set, $\mathrm{J}_{\mathrm{n}}$, we next specify the components of the individual utility to any element of that set. The utility to an individual, $\mathrm{i}$, from the selection of any product, $\mathrm{j} \in$ $\mathrm{J}_{\mathrm{n}}$, is characterized by a vector of attributes of the product, $\left(X_{\mathrm{jn}}, \mathrm{p}_{\mathrm{jn}}, \eta_{\mathrm{jn}}\right)$ and an individual-specific, idiosyncratic taste parameter, $\varepsilon_{\mathrm{ijn}}$. In this notation, $\mathrm{p}_{\mathrm{jn}}$ stands for the price and $\left(\mathrm{X}_{\mathrm{jn}}, \eta_{\mathrm{jn}}\right)$ stand for observed and unobserved attributes of product $\mathrm{j}$ in market $\mathrm{n}$. Since aggregate tastes for cable service may vary across markets and time, we additionally control for this variation by also incorporating a market-specific vector of demographic attributes, $D_{n}$, in the utility specification. ${ }^{50}$ This can be interpreted as the impact to mean utility from the purchase of any cable service accruing to all individuals in market $\mathrm{n}$. Individual differences from this average are then captured by the $\varepsilon_{\mathrm{ijn}}$.

The general form for the utility to individual $\mathrm{i}$ in market $\mathrm{n}$ from the purchase of product $\mathrm{j}$ is then given by

$$
\mathrm{U}_{\mathrm{ijn}}=\mathrm{U}_{\mathrm{ijn}}\left(\mathrm{X}_{\mathrm{jn}}, \mathrm{p}_{\mathrm{jn}}, \mathrm{D}_{\mathrm{n}}, \eta_{\mathrm{jn}}, \varepsilon_{\mathrm{ijn}} \mid \theta^{D}\right)
$$

where $\theta^{\mathrm{D}}$ is a $\mathrm{k}^{\mathrm{D}}$-dimensional vector of parameters representing the utility of each of the observed attributes, $X_{\mathrm{jn}}$ and $\mathrm{p}_{\mathrm{jn}}$, of cable service to individuals in market $\mathrm{n}$ and differences across markets in the tastes for cable service, parameterized by $\mathrm{D}_{\mathrm{n}}{ }^{51,52}$

To provide the reader with some intuition, we briefly discuss the specification of the observable attributes of each cable services, $X_{j}, j \in J_{n}$, in each cable market. The parameterization of $\mathrm{X}_{\mathrm{j}}$ is central to the accurate characterization of individual demand for cable television services. The maintained assumption throughout this paper is that the utility to consumers from the purchase of cable television service in a given market derives solely from the programming offered on that service. Reflecting this belief, $\mathrm{X}_{\mathrm{j}}$ is specified to depend on the identities of the particular programming

\footnotetext{
49 The relationship between the number of such elements is given $\mathrm{by}_{J_{n}}=2^{\left(N_{S_{n}}{ }^{-1)}\right.}+1$.

50 Note, however, that $\mathrm{D}$ does not vary across products within market $\mathrm{n}$.

51 The superscript $\mathrm{D}$ on $\theta$ is chosen to differentiate between parameters in the demand specification from similar parameters is the supply specification, denoted by $\mathrm{S}$.

52 For the balance of this chapter, we will be focusing on an individual cable market, $\mathrm{n}$. As a consequence, for ease of exposition, we will omit the subscript $\mathrm{n}$ from all equations and formula presented in the chapter with the exception of including it when discussing the set of services, $S_{n}=\left\{B, R_{n}\right\}$ and the set of choices, $J_{n}$, offered in each market. $n$ is retained for these variables as a reminder that the set of services, and thus choices, indeed varies across markets.
} 
networks offered on product $\mathrm{j}$.

Because the programming provided on any service may not exhaust all the relevant dimensions of cable service in each market, an unobservable (to the econometrician) attribute is also incorporated into the demand for each service offered by cable systems. We call this attribute the unobservable component of 'quality' of that service, although it could equally well proxy for signal reliability or service record -- anything which would impact the mean utility to consumers for each service which is not measured by the programming provided on it. In the specification above, these unobserved attributes are parameterized by $\eta_{j}$. As it is assumed that $X_{j}$ captures the observable elements of demand for cable television service, for all $\mathrm{j} \in \mathrm{J}_{\mathrm{n}}$, it is assumed that $E \eta_{\mathrm{j}}=0 .{ }^{53}$ Because quality is assumed to be observable to all agents in the market; it enters into each system's profitmaximization problem and is therefore correlated with price. This introduces a source of endogeneity which must be addressed in the econometric estimation in order to identify the structure of consumer tastes for cable service. ${ }^{54}$

To close the model of individual choice, an individual, $i$, is assumed to choose that product which yields to him the greatest utility:

$$
M A X_{j} U_{i j}\left(X_{j}, p_{j}, D, \eta_{j}, \varepsilon_{i j} \mid \theta^{D}\right) \quad j=0,1, \ldots, N_{J_{n}}
$$

Choices $1,2, \ldots, N_{J_{n}}$ index the various combinations of cable service which include Basic Service offered in market $\mathrm{n}$ and product 0 indexes the outside good, $\{\varnothing\}$, that of no cable service.

The advantage of this Discrete-Choice Differentiated Products model of individual choice in cable television markets derives from the unifying framework with which it can evaluate the utility, and thus the demand, for the portfolio of cable television services offered by each system. Individual demand for combinations of cable television services is built from tastes for particular programming networks; the selection among those service combinations is determined by the utility to the

\footnotetext{
53 This is consistent with a model in which the programming networks parameterize the expected quality of each cable service offered in market $\mathrm{n}$, ano $\mathrm{h}_{\mathrm{s}}$ parameterizes market-product-specific deviations from that expected quality.

54 This specification follows recent work on the estimation of product-level demand built from discrete-choice foundations which has emphasized the importance of accommodating such unobserved components of products in the specification and estimation of demand. See Trajtenberg (1991) for an early discussion of the problem, Berry (1994) for a solution for certain demand structures, and Berry, Levinsohn, and Pakes (1995) for an example of its implementation.
} 
programming provided on them. ${ }^{55}$ For given preferences, the model can therefore evaluate the utility to consumers of an arbitrary bundle of programming networks allocated among services in any way. In addition, we can naturally incorporate the tie of Basic Service to the purchase of all other services offered by the system. Individual choice is permitted among all combinations of services which include Basic, but not among any combinations which exclude it. Like in the real world, the model does not permit the purchase of HBO alone.

In the context of the changes in programming, services, and prices observed in the previous section, the implications of this flexibility are as follows. First, we can parsimoniously model demand to depend on the presence of individual networks. To the extent the presence of individual, highly popular networks like ESPN or CNN drive demand for cable, including dummy variables for their presence will measure this effect. Second, the model naturally accommodates the introduction of Expanded Basic Services and the reallocation of programming among these and Basic Service. The introduction of a new service in market $n$ merely adds an element to $S_{n}$, the set of services offered in that market. This in turn implies a corresponding increase, indeed a near-doubling, of the choice set, $\mathrm{J}_{\mathrm{n}}{ }^{56}$ The reallocation of programming among services implies a corresponding recalculation of the utility (and thus the demand) for the offered choices. Those that lose programming, i.e. Basic Service, become less desirable while those that gain, i.e. Expanded Basic Services, become more desirable. Third, the model naturally uses all the information available in the market. Every service offered, every price charged, every network carried, is incorporated into identifying consumer tastes for programming. In contrast to existing models of cable demand, no aggregation across services is required. In the context of identifying tastes for individual networks offered in (nearly) every market, differences in their allocation across services is a (nearly) necessary condition. ${ }^{57}$ Finally, the model is built from strong conceptual foundations. By building demand from the assumption of utility maximizing behavior, we can draw on the tools of applied welfare analysis. In particular, subject to the merits of the assumptions underlying their construction, we can quantify the benefits associated

55 If each of these elements is not clear, return briefly to the first paragraph in the description of this model of demand for a definition of programming network, cable service, and cableproduct.

56 The choice set nearly doubles as every combination of services including Basic is again available, now alone or in combination with the new Expanded Basic Service. Only the tie of Basic to its purchase prevents an exact doubling of the old set as the option of Expanded Basic Service alone is excluded from the new set.

57 Recall that ESPN is available in over $99 \%$ of the sample. It differs, however, in the service on which it is offered. 
with any of (1) Increases in the choice set, $J_{n}$, (2) Changes in the programming provided on the different choices, $X_{j},(3)$ Changes in prices, $p_{j}$, and (4) Changes in demographic characteristics. Our principal application, the construction of a quality-adjusted price index for cable service, requires this behavioral foundation.

\section{Specification of Consumer Tastes and Aggregation over Individuals}

The model as specified is a model of individual demand for the combinations of cable services offered to households. The data, however, provide market shares for each of the individual services provided by the system. As a consequence, we must aggregate across both individuals and service combinations in order to identify the structure of tastes for cable service from the available data.

This aggregation requires the specification of a functional form of the utility to each combination of services, $\mathrm{U}_{\mathrm{ij}}\left(\mathrm{X}_{\mathrm{j}}, \mathrm{p}_{\mathrm{j}}, \mathrm{D}, \eta_{\mathrm{j}}, \varepsilon_{\mathrm{ij}} \mid \theta^{\mathrm{D}}\right)$, and a distribution among consumers in each market of idiosyncratic tastes, $\varepsilon_{\mathrm{ij}}$, for those service combinations. Following McFadden (1978), I assume that utility to consumer $i$ for the set of choices, $\mathrm{J}_{\mathrm{n}}$, is given by the following linear specification:

$$
\begin{aligned}
& U_{i j}=X_{j}^{\prime} \beta+D^{\prime} \gamma+\alpha\left(1+D^{\prime} \alpha_{D}\right) p_{j}+\eta_{j}+\varepsilon_{i j} \quad j=0,1, \ldots, N_{J_{n}} \\
& =V_{j}\left(X_{j}, D, p_{j}, \eta_{j} \mid \theta^{D}\right)+\varepsilon_{i j} \\
& j=0,1, \ldots, N_{J_{n}}
\end{aligned}
$$

where $V_{j}\left(X_{j}, D, p_{j}, \eta_{j} \mid \theta^{D}\right)$ stands for the mean utility to individuals in market $n$ from the selection of product $\mathrm{j}$, and $\varepsilon_{\mathrm{ij}}$ represents the variation of individual i's idiosyncratic tastes for product $\mathrm{j}$ around that mean. $^{58}$ The vector $\theta^{\mathrm{D}}=\left(\alpha, \beta^{\prime}, \gamma^{\prime}\right)^{\prime}$, parameterizes mean consumer marginal utility for income, marginal utility for programming networks, and differences in aggregate tastes across markets and time arising from different demographic features of the market. Note that in addition to permitting the mean utility of each choice to differ according to the demographic features of the market, we also permit the marginal utility of income to differ as well.

Different individuals have different tastes and thus make different choices. For any given individual, that choice is deterministic. Market demand for each choice is then determined by the set

58 Given the aforementioned structure of $\left(\mathrm{X}_{\mathrm{jn}}, \mathrm{p}_{\mathrm{jn}}, \eta_{\mathrm{jn}}\right)$, the formula for $\mathrm{V}_{\mathrm{jn}}$ can be rewritten as $V_{j n}=\sum_{s \supset j} V_{s n}$ where $V_{s}=X_{s}^{\prime} \beta+D^{\prime} \gamma+\alpha p_{s}+\eta_{s}$. 
of tastes in the population of consumers such that each is preferred to all others. ${ }^{59}$

The decomposition of utility into a component common to all individuals, $\mathrm{V}_{\mathrm{j}}$, and a component specific to each individual, $\varepsilon_{\mathrm{ij}}$, is often used to analyze demand in the presence of heterogeneous preferences among consumers regarding the value of the products of choice. ${ }^{60}$ In our case, these products represent combinations of cable television services, the tastes for which are likely to vary across consumers. ${ }^{61}$ However, while the general form of this decomposition presents an accurate characterization of tastes in cable markets, its implementation requires a specification of a distribution over the unobserved consumer tastes for alternatives in each cable market, $\varepsilon_{\mathrm{i}}=\left(\varepsilon_{\mathrm{i} 1}, \varepsilon_{\mathrm{i} 2}, \ldots\right.$, $\left.\varepsilon_{i N_{J}}\right)$. This specification is central to any empirical implementation, determining both the flexibility of substitution patterns permitted among products as well as the form of market demand. Much of the recent work in implementing product-level models of demand for discrete goods have focused on the specification of these tastes and their implications for characterizing demand. ${ }^{62}$

In the specification implemented in this model, consumers tastes for products are assumed to be continuously distributed within markets according to a Type I Extreme Value distribution, independent across individuals and products. Given this assumption, the market share for choice $\mathrm{j}$, $\mathrm{w}_{\mathrm{j}}$, as a function of the characteristics of all other choices in the market is given by familiar multinomial logit market shares:

$$
\begin{aligned}
& w_{0}(X, D, p, \eta \mid \theta)=\frac{1}{\sum_{k \in J_{n}} e^{V_{k}}} \\
& w_{j}(X, D, p, \eta \mid \theta)=\frac{e^{V_{j}}}{\sum_{k \in J_{n}} e^{V_{k}}} \quad j=1,2, \ldots, N_{J_{n}}
\end{aligned}
$$

where the utility of the outside good has been normalized to zero. ${ }^{63}$

\footnotetext{
59 This process is described in detail in, for example, ...

60 See Anderson, DePalma, and Thisse (1993) for an overview of alternative models of Product Differentiation.

61 The assumption that consumers have heterogeneous tastes for programming underlies all models of programming choice known to the author. See, inter alia, Spence and Owen (1977) or Webster and Wakshlag (1983). Since tastes for programming are likely to be heterogeneous, tastes for programming networks and services consisting of combinations of those networks are also likely to be heterogeneous.

62 See Berry, Levinsohn, and Pakes (1995) and Goldberg (1995) for two alternative specifications for the demand for automobiles.

63 Since $\mathrm{w}_{\mathrm{j}}$ is homogenous of degree 0 in $\left(\mathrm{V}_{0}, \mathrm{~V}_{1}, \mathrm{~V}_{2}, \ldots, V_{N_{J}}\right)$, a normalization of utility to one of the alternatives is
} 


\section{Aggregation over Combinations of Services}

Under normal circumstances, we would transform the above equations and estimate the model. As mentioned earlier, however, while individual choice is defined over all products, $\mathrm{j} \in \mathrm{J}_{\mathrm{n}}$, in market $n$, only the market shares of each service, $s \in S_{n}$, are available in the data. ${ }^{64}$ That is to say, while we may observe the market share of each of Basic Service, HBO, and the Disney channel in a market, we do not observe, for instance, the share of the market that buys all three. ${ }^{65}$ To match the model with the data requires aggregating the market shares for choices predicted by the model to the market shares for services observed in the data.

Measuring the market shares of each of these services, however, is relatively easy. Since the set of choices containing, for instance $\mathrm{HBO}$, is easily enumerated, the market share for $\mathrm{HBO}$ is just given by the sum over that set. ${ }^{66}$ This process is akin to adding across a joint probability distribution to obtain the corresponding marginal probabilities.

With a slight abuse of notation, we define $j \subset s$ to be those choices containing each service, $\{\mathrm{j}$ $\in \mathrm{J}_{\mathrm{n}} \mid \mathrm{j}$ contains service $\left.\mathrm{s}\right\} .{ }^{67}$ Then the market share for each service, $\mathrm{s} \in \mathrm{S}_{\mathrm{n}}$, is given by the sum of all product market shares containing that service: ${ }^{68}$

$$
w_{s}\left(X, D, p, \eta \mid \theta^{D}\right)=\sum_{j \subset s} w_{j}=\sum_{j \subset s} \frac{e^{V_{j}}}{\sum_{k \in J_{n}} e^{V_{k}}} \quad s \in S_{n}
$$

Note that this implies that the number of demand equations in each market is equal to the number of services - Basic, Expanded Basic, or Premium - offered by the system in market n, defined earlier as

required. This is accomplished by setting the mean utility of the outside good, $\mathrm{V}_{0}$, to zero and measuring all remaining utilities relative to that good. As the only observable attributes of the outside good are broadcast signals, this normalization only impacts the measurement of comparative broadcast signals provided by cable. For notational convenience, I will assume that this normalization is implicitly defined in the specification of the $\left(0 X \eta_{\mathrm{j}}\right)$.

${ }_{64}$ Note again the difference between services, $\mathbb{R}$ and combinations of those services, $\mathrm{R}$.

65 Nor any other similar combination.

66 In the example above, it would simply equal the market share of two combinations of services: Basic $+\mathrm{HBO}$ and Basic + HBO + Disney. Naturally, the number of elements in this sum is a bit larger for systems offering more than just three services.

67 Note the distinction here between $s \supset j$, the set of services provided on product $\mathrm{j}$, and $j \subset s$, the set of products offering service $s$.

68 Note that, given the structure of choice in cable markets, all services containing Basic Service, denoted $j \subset b$, is equivalent to all services excluding 'no cable service', denotej $\neq \varnothing \varnothing$. 
$N_{S_{n}}$

\section{Endogeneity and Estimation}

The first step towards estimation is to transform each these shares into a tractable form. Taking the log-ratio of the service shares, $\mathrm{w}_{\mathrm{s}}$, relative to the outside good, $\mathrm{w}_{0}$, yields: ${ }^{69}$

$$
\log \left(\frac{w_{s}}{w_{0}}\right)=\log \left(\sum_{j \subset s} e^{V_{j}}\right)=\log \left(\sum_{j \subset s} e^{X_{j}^{\prime} \beta+D^{\prime} \gamma+\alpha p_{j}+\eta_{j}}\right) \quad s \in S_{n}
$$

where we've exploited the definition of $\mathrm{V}_{\mathrm{j}}$ in the last equality.

Because of the correlation between price, $\mathrm{p}_{\mathrm{j}}$, and the unobserved product quality, $\eta_{\mathrm{j}}$, estimation of the above equations (excluding the unobservable $\eta_{\mathrm{j}}$ ) by Non-Linear Least Squares would yield inconsistent estimates of the parameters $\theta^{\mathrm{D}}=\left(\alpha, \beta^{\prime}, \gamma^{\prime}\right)^{\prime}$. Moreover, the traditional solution to this problem, instrumental variables estimation, is complicated by the non-linearity of the $\log$-share functions in the error, $\eta_{\mathrm{j}}{ }^{70}$

To accommodate the endogeneity of price, we pursue a strategy of instrumental variables estimation first suggested by Berry(1994) and modified to accommodate the aggregation over the combinations of services, $j \subset s$. In particular, after some algebraic manipulation, we invert the market share equation for each service offered in each cable market to equate mean expected consumer utility for each service with a nonlinear function of its market share. The unobservable quality associated with each service remains as a source of econometric error. Since we can solve for this error as a function of observables and taste parameters, conventional instrumental variable techniques obtain. Variables which shift the marginal cost of providing both each services offered by the cable system in each market serve as instruments for price. The intuition of the process is

\footnotetext{
69 Due to the restriction that all shares sum to one, the third ratio, $\log _{3}\left(\mathrm{w}_{\mathrm{Bn}}\right)$, is redundant and therefore omitted.

70 Traditional Instrumental Variable estimation solves a linear system of equations for the parameter vector, $\theta$. This system of equations is constructed from the sample analogs to a set of moment conditions. For an equation of the model specified here, $\log \left(\mathrm{w}_{\mathrm{r}} / \mathrm{w}_{0}\right)=\mathrm{f}(\mathrm{X}, \mathrm{p}, \mathrm{D}, \eta \mid \theta)$, these conditions are of the form

$$
E\left[\left(\log \left(\frac{w_{r}}{w_{0}}\right)-f(X, p, D, \eta \mid \theta)\right) \mid Z\right]=0
$$

where $Z_{n}$ stands for a vector of instruments and the expectation is with respect to the unobservable, $\eta_{n}$. While it is assumed that $E \eta=0$, this does not imply that $E[f(X, p, D, \eta \mid \theta)]=[f(X, p, D, E \eta \mid \theta)]=f(X, p, D, 0 \mid \theta)$ and it is therefore not possible form the moment conditions necessary to estimate the model by Instrumental Variables.
} 
described as follows; a detailed derivation is provided in Appendix B.

Implementing the Berry procedure requires a one-to-one mapping between observed market shares, $w_{\mathrm{s}}$, and unobserved quality, $\eta_{\mathrm{j}}$. Indeed, Berry (1994) presents a convenient solution for the typical case of unobserved individual heterogeneity which is distributed as a Type I Extreme Value, as is the case here. In the case of the aggregation over products required by the limitations in our data, however, this solution is unavailable to us and must be modified slightly.

The core of the problem is that while there are only as many as 8 market shares, $w_{s}$, observable in each market, there are as many as $2^{7}$ unobservable errors, $\eta_{\mathrm{j}}$. To resolve this issue, we make one assumption and one mathematical simplification. First, we assume that the utility of the combination of any set of services simply equals the sum of the utilities of its component services. This assumption unfortunately eliminates complementarities in either cost of production across services, although complementarities within services are still possible. ${ }^{71}$ An immediate benefit, however, is that the unobservable error associated with each combination of services is merely the sum of the unobservable errors associated with each service in the combination, or $\eta_{j}=\sum_{s \supset j} \eta_{s}$. As such, it succeeds in equating the dimensions of the observable and unobservable components of the model.

It remains, however, to solve for each of these unobservable service components, $\eta_{\mathrm{s}}$, as a function of observables and parameters. This is complicated by the severe non-linearity of the market share functions, $w_{s}$, in $\eta$. As described in more detail in the Appendix, the logit structure to each product share, $\mathrm{w}_{\mathrm{j}}$, permits a factorization of service shares which permits a solution. The intuition can be described as follows. Suppose a system elected to offer a new service, e.g. Expanded Basic, to the set of services it was currently offering in the market. Because of the independence of the error structure across alternatives inherent in the logit structure, the incremental utility to any individual from the purchase of the new service would be the same, regardless of the existing combination of services chosen by him. This feature provides a natural method for measuring that incremental utility. Consider the market share of all consumers who choose to subscribe to the new service as well as the

71 In the same way that observed complementarities across services cannot be accommodated, neither can unobserved correlations in tastes across services. 
market share of those who do not. Given the independence structure described above, that these market shares are different can wholly be ascribed to the incremental utility of the new service. In fact, for all Expanded Basic and Premium Services, the difference in the log ratio of the market share for the service and the log ratio of the market share for cable services excluding that service identifies that incremental utility:

$$
\begin{array}{r}
\log \left(\frac{w_{r}}{w_{0}}\right)-\log \left(\frac{w_{r}^{-}}{w_{0}}\right)=X_{r}{ }^{\prime} \beta+D^{\prime} \gamma+\alpha p_{r}+\eta_{r} \\
\text { or } \log \left(\frac{w_{r}}{w_{r}^{-}}\right)=X_{r}{ }^{\prime} \beta+D^{\prime} \gamma+\alpha p_{r}+\eta_{r}
\end{array}
$$

where $\mathrm{r}$ indexes the Expanded Basic and Premium services offered in the market in addition to Basic Service, and $\mathrm{w}_{\mathrm{r}}$ and $w_{\bar{r}}$ are the market shares for all cable services including and excluding, respectively, that service. ${ }^{72}$ This solution then permits a comparable solution for $\eta_{b}$, the unobservable component of utility associated with Basic Service:

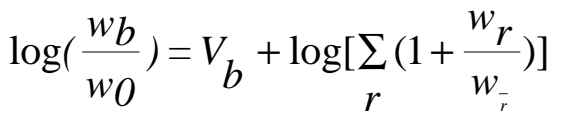

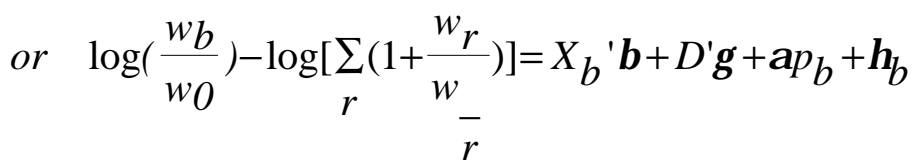

where $b$ indexes Basic Service and the third equality exploits the definition of $\mathrm{V}_{\mathrm{b}}$.

Taken together, these $N_{S_{n}}$ equations defined by (2-6) and (2-7) imply a solution for $\eta_{\mathrm{s}}, \mathrm{s} \in$ $S_{n}$, as a function of the observable variables, $\left(w_{n}, X_{n}, D_{n}, p_{n}\right)$, and the parameters of the model, $\theta^{D}=$ $\left(\alpha, \beta^{\prime}, \gamma^{\prime}\right)^{\prime}$. The specification of the population moment conditions underlying the estimation of this model of demand and alternative econometric specifications are discussed after introducing the model of pricing behavior.

\subsubsection{The Pricing of Cable Television Services}

\footnotetext{
72 That is to say, we partition the market share for basic service into those that do and do not buy each additional service beyond Basic. By construction, the $\mathrm{W}_{\mathrm{b}}=\mathrm{w}_{\mathrm{r}}+w_{\bar{r}}$
} 
While the above system of demand equations could be estimated of its own accord, we pursue modeling the supply side of the market as well. This has the benefit of providing important crossequation restrictions on the system of equations and permitting the measurement of the efficiency as well as welfare gains from changes to the set of services offered by cable systems over time.

Reflecting the institutional features of cable television supply, the structure of the cost of providing each offered service is assumed to consist of a fixed cost and a marginal cost which varies according to the programming provided on that service and demographic features of the cable market: ${ }^{73}$

$$
C_{s n}\left(X_{n}, W_{n}, q_{n}\right)=F_{s n}+c_{s}\left(X_{s n}, W_{n}\right) q_{s n}
$$

where $\mathrm{F}_{\mathrm{sn}}, \mathrm{c}_{\mathrm{sn}}()$, and $\mathrm{C}_{\mathrm{sn}}($ ) measure the fixed, marginal, and total cost of providing each service, $\mathrm{s} \in$ $\mathrm{S}_{\mathrm{n}}$, in market $\mathrm{n}, \mathrm{X}_{\mathrm{sn}}$ are, as for the system of demand equations, the observable attributes of service $\mathrm{s}$ in market $\mathrm{n}$, and $\mathrm{W}_{\mathrm{n}}$ is a vector of attributes shifting marginal costs across markets. As for the system of demand above, for ease of exposition, the index for the market, $n$, will be omitted from this point forward.

The solution of each cable system's profit maximization problem yields equilibrium conditions for the price of each offered service as a function of the marginal cost of that service and of the demand for that service. Given the above structure, firm profits are given by

$$
\begin{aligned}
& \Pi=\left(p_{b}-c_{b}\left(X_{b}, W\right)\right) q_{b}(p)+\sum_{r}\left(p_{r}-c_{r}\left(X_{b}\right)\right) q_{r}(p) \\
& \Rightarrow \Pi^{*}=\left(p_{b}-c_{b}\left(X_{b}, W\right)\right) w_{b}(p)+\sum_{r}\left(p_{r}-c_{r}\left(X_{b}\right)\right) w_{r}(p)
\end{aligned}
$$

where $\Pi^{*}$ stands for per-household profits, defined as $\Pi / \mathrm{HP}, \mathrm{p}$ equals the vector of prices for the $N_{S_{n}}$ services offered in the market, and for the second equality knowledge about the size of the market, measured by the number of homes passed, HP, is exploited. ${ }^{74}$ Firms are assumed to maximize profits by choice of the price of each service, $\mathrm{s} \in \mathrm{S}_{\mathrm{n}}$, they offer in their market. ${ }^{75}$

Given the assumed distribution of tastes within each cable market, the institutional feature that

73 The decomposition of total costs of providing any cable service into a fixed cost and a marginal cost independent of the number of subscribers served by the system has been used by nearly all previous papers analyzing the industry. Examples include Mayo and Otsuka (1991) and Chipty (1995).

74 Tautologically, $\mathrm{w}=\mathrm{q}_{\mathrm{b}} / \mathrm{HP}$.

75 For this reason, we exclude from the dataset those very few markets where multiple cable systems compete for subscribers. 
Basic Service purchases are tied to the purchase of any additional services greatly simplifies the solution to this problem and yields closed form solutions for the optimal price-cost margins for each offered cable service: ${ }^{76}$

$$
x=\left[\begin{array}{c}
-1 \\
\alpha\left(1-w_{b}\right) \\
0 \\
0 \\
\vdots \\
0
\end{array}\right]
$$

where $\mathrm{x}_{\mathrm{s}}$, defined as $\mathrm{p}_{\mathrm{s}}-\mathrm{mc}_{\mathrm{s}}$, are the price-cost margins for each service offered in market $\mathrm{n}$. This solution suggests that systems maximize profits by setting the price of Basic Service equal to its marginal cost plus a markup equal to $1 /|\alpha|\left(1-w_{b}\right)$ and setting the prices of all additional services equal to their marginal costs. As a consequence, any monopoly rents accruing to cable systems can be exploited in the pricing of just the Basic Service tier. This structure then implies pricing equations of the form:

$$
\begin{aligned}
& p_{b}=c_{b}\left(X_{b}, W_{b}\right)-\frac{1}{\alpha\left(1-w_{b}\right)} \\
& p_{r}=c_{r}\left(X_{r}, W_{r}\right)
\end{aligned}
$$

where r, as usual, indexes the Expanded Basic and Premium Services offered in market n.

We take a moment to explain the intuition underlying the optimal prices derived from this framework. It is the requirement tying the purchase of Basic Service to all other services, in conjunction with the assumed distribution of tastes for each of the products containing these services, which is the fundamental cause of this result. ${ }^{77}$ For this assumed distribution, if systems elected to price some or all of their additional services above instead of at cost, this would imply a reduction not only in the demand for that service, but also in the demand for Basic Service. This occurs as those consumers who were just indifferent between purchasing, for example, $\{$ Basic Service, $\mathrm{HBO}\}$ at the

76 This solution was obtained via the Maple mathematics program. The processing capabilities of my personal computer would only permit the solution of the linear system of equations for as many as basic plus 4 additional services. Due to the inherent symmetry in the structure of $\mathrm{A}$, and the uniformity of solution structure for each of the cases of basic $+1,2,3$, and 4 additional services, we confidently assert that the structure given here is correct.

77 For a 'standard' logit model, it is optimal for systems to equate the markup across services. We later use this fact in the counter-factual simulation of untying Basic Service purchases. 
old price, $\mathrm{p}_{\mathrm{b}}+\mathrm{p}_{\mathrm{h}}$, and who would not purchase $\{$ Basic Service $\}$ alone at its given price, $\mathrm{p}_{\mathrm{b}}$, drop out of the market completely when the price of $\mathrm{HBO}, \mathrm{p}_{\mathrm{h}}$, is increased. In this way, profits from the sale of Basic Service to those individuals who would not otherwise have purchased it, extracts the consumers' surplus which would have arisen from untied sales of HBO at price $\mathrm{p}_{\mathrm{h}}{ }^{78}$ As a consequence, the optimal pricing strategy is to not forgo the loss of sales of Basic Service stemming from increases in the price of additional services, relying instead on the increase in demand for basic from consumers who value these additional services highly enough to cause them to purchase Basic Service when they otherwise would not have. ${ }^{79}$

The marginal cost functions, $\mathrm{c}_{\mathrm{s}}(\mathrm{)})$, are parameterized as

$$
c_{s}\left(X_{s}, W\right)=X_{s}{ }^{\prime} \rho+W^{\prime} \delta_{s}+v_{s}
$$

where $v_{\mathrm{s}}$ measures unobservable components of marginal cost for service s. Following the strategy pursued in the demand section, implicit in this specification is the assumption that only that programming provided on each service impacts the marginal cost for that service. ${ }^{80}$

Substituting these into equation (2-10) above yields the estimating equations for the pricing model:

$$
\begin{aligned}
& p_{b}=X_{b}{ }^{\prime} \rho+W^{\prime} \delta_{b}+\frac{1}{\alpha\left(1-w_{b}\right)}+v_{b} \\
& p_{r}=X_{r}{ }^{\prime} \rho+W^{\prime} \delta_{r}+v_{r}
\end{aligned}
$$

Taken together, these $N_{S_{n}}$ equations imply a solution for the $v$, the s-vector of unobserved cost errors, as a function of the observables, $(\mathrm{p}, \mathrm{X}, \mathrm{W}, \mathrm{w})$, and the parameters of the model, $\theta^{\mathrm{S}}=(\alpha$, $\left.\rho^{\prime}, \delta_{\mathrm{b}}{ }^{\prime}, \delta_{\mathrm{R}}{ }^{\prime}\right)^{\prime}$.

78 See, e.g., Bowman (1957), Burstein (1960), or Markovits (1967).

79 That being said, how reasonable is this result for cable services? Going back to Stigler's (1963) findings in the motion picture industry, there is strong theoretical evidence that firms may elect to price discriminate in media industries by bundling entertainment programming. Incentives to tie the purchase of Basic Service to other cable services are much the same. Whenever consumers have heterogeneous tastes, bundling (or tying) can increase profits by reducing buyer heterogeneity, allowing more efficient rent-extraction with linear prices. While other, institutional and technological, reasons for tying may play a role in the case of cable television, these additional benefits may have contributed to tying's adoption and continued presence. A detailed treatment of system incentives to bundle and tie programming and services is beyond the scope of this paper, but remains as an area of future research.

${ }^{80}$ In the interest of parsimony, the impact of cost characteristics, parameterized by $\mathrm{W}$, is assumed to impact each additional service with a common effect measured b $\oint_{R}$ 


\section{Pricing and the 1992 Cable Act}

In September of 1992, Congress passed the Cable Television Consumer Protection and Competition Act, also known as the 1992 Cable Act. As the title suggests, the principal purpose of the Act was to limit the rates charged by systems for most types of cable service. ${ }^{81}$ In 1993 and 1994, the FCC promulgated a set of rules establishing a cap for the prices charged by cable systems for both Basic and Expanded Basic services. Premium services and a-la-carte programming were excluded from the regulations. Regulation was not mandatory, however. Instead, local franchise authorities had the option of certifying with the FCC to regulate. ${ }^{82}$ Many franchise authorities elected not to do so. ${ }^{83}$ Regulated systems were mandated to compare their September 1992 rates for programming to a benchmark rate charged by a subset of systems determined by Congress to face "effective competition," reducing it by as much as $17 \%$ if it exceeded this benchmark. ${ }^{84}$

The pricing equations given in (2-11) assume profit maximizing behavior on the part of the cable system, an assumption not likely to hold in the presence of the price regulation described above. As a consequence, we modify slightly the estimating equation for those observations in the dataset reported after September, 1992, to accommodate these regulations. In particular, we permit the markup in (2-11) to vary, presumably to decline, in those markets where franchise authorities certified with the FCC to regulate Basic service. This practice is in the spirit of the Conjectural Variations literature and has precedent in the analysis of the impact of regulation of cable system pricing. ${ }^{85}$

For systems in the earlier sample which predates the passage of the Cable Act, equations (211) continue to hold. For the systems in the latter sample, however, the following, modified, equations are used:

\footnotetext{
81 The Act imposed a number of additional regulations on cable systems. See Crawford (1997) or Johnson (1994) for a concise summary of the motivation for and implementation of the ' 92 Cable Act.

82 Technically, local franchise authorities were only permitted to regulate Basic service. The FCC was responsible for regulation of Expanded Basic services, but could only implement those regulations if a consumer in the local market area filed a complaint with the Commission.

${ }^{83}$ As of January 1994, approximately $25 \%$ of eligible municipal franchise authorities had certified with the FCC to provide rate regulation. In the data used in this paper, $\mathrm{X} \%$ of systems operated in a market where the franchise authority had certified.

84 The initial reduction was 10\%. In February of 1994, this was increased to 17\%. See Crawford (1997) or Johnson (1994) for more.

85 See the review article by Bresnahan (19??) for a discussion of Conjectural Variations (and the measurement of market power in general) and Rubinovitz (1994) for an example of this practice in the cable literature.
} 


$$
\begin{aligned}
& p_{b}=X_{b}^{\prime} \rho+W^{\prime} \delta_{b}+\frac{1}{\alpha\left(1-w_{b}\right)}(1+\phi \text { Cert })+v_{b} \\
& p_{r}=X_{r}^{\prime} \rho+W^{\prime} \delta_{r}+v_{r}
\end{aligned}
$$

where Cert is a dummy variable indicating those markets where the local franchise authority has elected to regulate. $\phi$ in this context measure the percentage reduction in the markup present in those markets. ${ }^{86}$ Adding these $N_{S_{n}}$ equations to the $N_{S_{n}}$ demand equations given by equations (2-6) and (2-7) yields the $2 * N_{S_{n}}$ system of demand and pricing equations taken to the data.

\subsubsection{Alternative Distributional Assumptions on Tastes}

Having fully described the models of demand and pricing and derived their associated estimating equations, we now discuss the implications of our distributional assumptions on tastes and consider alternative specifications. The weaknesses of the Type I Extreme Value specification for the distribution of consumer tastes for products and the implied Logit product market shares are well known. ${ }^{87}$ Principle among these is the property that fitted market shares have the Independence from Irrelevant Alternatives (IIA) property implying that the ratio of any two market shares is independent of the presence of additional products in the market. IIA is problematical in situations when certain choices are more similar than others, as might likely be the case for cable television services. ${ }^{88,89}$ Furthermore, the validity of this two-part pricing structure depends critically on the validity of the underlying assumption of logit demand for combinations of services. As a consequence of these sorts of counter-intuitive implications of logit specifications, recent advances in the implementing less restrictive specifications in models of demand built from individual discrete-choice models of demand have achieved some acceptance. Because of the importance of this issue, these competing alternatives to the specification outlined above are briefly discussed here.

\footnotetext{
86 This assumes, as turns out to be the case, th申t $<0$.

87 See review articles in f.n. 1 for more.

88 The classic example of a choice context which violates IIA is the choice of transportation mode between a car, a red bus, and a blue bus. IIA implies that the ratio of the market shares of the car to a red bus is independent of the presence of the blue bus option in the choice set.

89 We also note that while IIA holds for the individual products over which choice is considered, it also holds over the choice among the individual premium services which are the focus of the analysis. This can easily be shown by comparing the ratio of the predicted market shares for any two such services, e.g. HBO and Showtime. On the other hand, by virtue of the requirement tying the purchase of Basic Services to premium services, IIA dos hold for basic cable service.
} 
There are two general approaches to implementing more general taste structures. The first approach relaxes the functional form assumption somewhat while still maintaining closed-form estimating equations. Generalized Extreme Value (GEV) distributions, including those yielding nested logit market shares, pursue this approach. ${ }^{90}$ Choices are grouped according to a priori expectations of 'sameness' and the variance-covariance matrix is parameterized to permit correlation in unobserved tastes within these groups. Exploiting the structure of demand in a manner analogous to the methods described in this chapter, closed form market shares for each product, $\mathrm{w}_{\mathrm{j}}$, obtain as a function of the mean utilities for that product, the mean utilities for products in the same group, and the similarity parameters described above. A second approach assumes a much more general distribution of tastes, with the consequence that the computed market shares obtained under the assumed distribution do not have closed form values. As a result, the implied market shares are computed instead via simulation. ${ }^{91}$ As this process must be undertaken for each share for each observation at each step in the econometric estimation, it is very computationally-intensive. It has the benefit, however, of not imposing any structure on the correlation in tastes among products. ${ }^{92}$

Neither of these approaches is feasible, however, in the context of aggregation over the product market shares described in this chapter. ${ }^{93}$ For the closed-form results of the former method to obtain requires observations on each of the product market shares, $w_{j}$, defined over combinations of services available in the market. Since we observe only the aggregate market shares for each service $w_{s}, s \in S_{n}$, and not the market shares for the combinations of these services, $w_{j}, j \in J_{n}$, the straightforward implementation of the GEV procedure is not possible. Moreover, introducing a GEV structure and its associated covariance parameters across cable services and trying to solve for the mean utility to each service as we did for the case of logit demands immediately breaks the solution mechanism which yields the demand-side estimating equations, (2-6) and (2-7). ${ }^{94}$ Similarly, introducing a general error structure and solving numerically for the errors, $\eta_{s}$, as a function of the

\footnotetext{
90 See McFadden (1978)

91 Cites

92 Subject to degrees of freedom constraints.

93 In the absence of this aggregation, the market shares for each cable product, $\mathrm{w}_{\mathrm{j}}$, as a function of the product errors, $\eta_{\mathrm{j}}$, $\mathrm{w}=\left(\mathrm{w}_{1}\left(\eta_{1}\right), \mathrm{w}_{2}\left(\eta_{2}\right), \ldots, \mathrm{w}_{\mathrm{Nj}}\left(\eta_{\mathrm{Nj}}\right)\right)$, from either of these approaches would need to be inverted to solve for the errors as a function of the observable shares within each marke $q_{0}=\mathrm{w}^{-1}(\mathrm{w})$ as detailed in Berry (1994).

94 See Appendix B for more detail. The intuition follows that just as complementarity in programming offered across services breaks the solution mechanism, unobserved correlation in tastes across services does the same.
} 
observed market shares, $\mathrm{w}_{\mathrm{s}}$, is also infeasible. The iterative method and existence proof which forms the core of the Berry (1994) inversion proof critically depends on the presence of a contraction mapping of the market share function $w=\left(w_{1}\left(\eta_{1}\right), w_{2}\left(\eta_{2}\right), \ldots, w_{N j}\left(\eta_{N j}\right)\right)$. In the context of completely general product share aggregation, the contraction mapping assumptions no longer hold and a unique solution to $\eta(w)$ is no longer guaranteed..$^{95}$

As a consequence of these difficulties, we pursue the strategy of specifying the distribution of tastes as a Type I Extreme Value and comment on the results in light of the tenuous implications underlying this assumption. We note, however, that the consumer response to new Expanded Basic Services which are the focus of our study suggest that this is not particularly a problem. IIA is most troublesome in cases where services share common unobserved attributes, implying that they are more similar - and thus more substitutable - than permitted by the model. This is unlikely to be the case for Basic and Expanded Basic Services. The large penetration of Expanded Basic Services among Basic subscribers suggests strong complementarity rather than substitutability. The logit model with tied goods implemented here explicitly permits such complementarity and thus may be an adequate assumption in this context. ${ }^{96}$ The solution to the general problem of implementing aggregate empirical models of discrete-choice demand in the presence of limited product information, however, remains as an area of future research.

\section{Identification, Estimation and Results}

\subsection{Estimating Equations}

Instrumental Variable estimation proceeds as follows. By virtue of their presence in firm's price-setting equations, the variables which shift marginal cost across markets, denoted $\mathrm{W}_{\mathrm{n}}$, provide instruments for price in the $N_{S_{n}}$ demand equations. Similarly, by virtue of their presence in the demand equations, the variables which shift demand across markets, defined by $\mathrm{D}_{\mathrm{n}}$, provide instruments for the inverse market share of Basic Service in its pricing equation. ${ }^{97}$ The programming

\footnotetext{
95 Some experimentation of implementing this procedure despite a sufficient condition for existence validates this theoretical concern.

96 In addition, we test the logit assumption in the empirical estimation.

97 Note that the special structure of the pricing equations imply that there are no endogenous right-hand side variables in the $N_{R_{n}}$ equations defined by (2-8).
} 
provided on each service, denoted $\mathrm{X}_{\mathrm{sn}}$, and demand and cost shifters, $\mathrm{D}_{\mathrm{n}}$ and $\mathrm{W}_{\mathrm{n}}$, serve as their own instruments. As is evident from this description, however, the set of instruments used for each equation is not the same. Because different services provide different types of programming, only those programming networks provided on any service are included as instruments for that equation. We fully describe this procedure for both the system of demand and pricing equations as follows.

The identifying population moment assumption made here is that, for each service, $s \in \mathrm{S}_{\mathrm{n}}, \mathrm{z}_{\mathrm{sn}}{ }^{\prime}$ $=\left[\mathrm{X}_{\mathrm{sn}}{ }^{\prime}, \mathrm{D}_{\mathrm{n}}{ }^{\prime}, \mathrm{W}_{\mathrm{n}}{ }^{\prime}\right]$, defined the $1 \times \mathrm{K}_{\mathrm{s}}$ row vector of instruments for the $\mathrm{s}^{\text {th }}$ equation in the $\mathrm{n}^{\text {th }}$ observation in the sample, is uncorrelated with $\eta_{\mathrm{sn}}$, the unobservable component of demand for that service in market $n$, or $E\left(z_{s n} \eta_{s n}\right)=0 .{ }^{98}$ Similarly, we assume that $z_{s n}{ }^{\prime}$ is uncorrelated with $v_{s n}$, the unobservable component of cost for Basic Service in market $n$, or $E\left(z_{\mathrm{sn}} v_{\mathrm{sn}}\right)=0$. In the interests of parsimony, it is assumed that demographic characteristics which impact demand only do so in the demand for Basic Services and not for the additional services provided in the market, implying that D does not enter into the instrument vector for premium services.

The sample analogs to these population moment restrictions defined above follow. We first solve each of the $N_{S_{n}}$ equations defined by the demand system for $\eta$ as a function of the parameters of interest, $\eta\left(\theta^{\mathrm{D}}\right)$, where $\theta^{\mathrm{D}}=\left(\alpha, \beta^{\prime}, \gamma^{\prime}\right)^{\prime}$ is a $1 \times \mathrm{K}^{\mathrm{D}}$ vector of parameters of interest. ${ }^{99}$ We similarly solve each of the $N_{S_{n}}$ equations defined by the pricing system for $v$ as a function of the parameters of interest, $v\left(\theta^{S}\right)$, where $\theta^{S}=\left(\alpha, \rho^{\prime}, \delta_{b}{ }^{\prime}, \delta_{R}{ }^{\prime}\right)^{\prime}$ is a $1 \times \mathrm{K}^{S}$ vector of parameters of interest. ${ }^{100}$ We then stack the equation-specific vectors of errors and instruments, yielding the two $N * N_{S_{n}} \times 1$ vectors of demand and cost errors, $\eta\left(\theta^{\mathrm{D}}\right)$ and $v\left(\theta^{\mathrm{S}}\right)$, and the $N^{*} N_{S_{n}} \times 2 *\left(\sum_{s} K_{s}\right)$ matrix of instruments, $\mathrm{Z}:{ }^{101}$

\footnotetext{
98 The notation used is consistent across variables -- vectors of the form $Z_{b n}$ are column vectors, $Z_{b n}$ ' are row vectors, and $\mathrm{Z}_{\mathrm{b}}$ are matrices.

${ }^{99}$ For example, for Basic Service, this yield $\eta_{b}(\theta)=D V_{b}-X_{b}{ }^{\prime} \beta+D^{\prime} \gamma+\alpha p_{b}$.

${ }^{100}$ For example, for Basic Service, this yield $\eta_{b}(\theta)=D V_{b}-X_{b}{ }^{\prime} \beta+D^{\prime} \gamma+\alpha p_{b}$.

${ }^{101}$ In the empirical implementation, some elements of $Z_{s}, s \in S_{n}$, overlap -- each of the $Z_{s}$ contain $W_{n}$. With a detailed change in notation, this could be accommodated in the presentation here. For ease of exposition, however, we persist in the description provided here.
} 


$$
\eta(\theta)=\left[\begin{array}{c}
\eta_{1}(\theta) \\
\eta_{2}(\theta) \\
\vdots \\
\eta_{N_{s}}(\theta)
\end{array}\right] \quad v\left(\theta^{S}\right)=\left[\begin{array}{c}
v_{1}\left(\theta^{S}\right) \\
v_{2}\left(\theta^{S}\right) \\
\vdots \\
v_{N_{s}}\left(\theta^{S}\right)
\end{array}\right] \quad Z=\left[\begin{array}{cccc}
Z_{1} & 0 & \cdots & 0 \\
0 & Z_{2} & & \\
\vdots & & \ddots & \\
0 & & & Z_{N_{s}}
\end{array}\right]
$$

To estimate, let $\omega=\left(\eta\left(\theta^{\mathrm{D}}\right)^{\prime}, v\left(\theta^{\mathrm{S}}\right)^{\prime}\right)^{\prime}$ be the $2 * N^{*} N_{S_{n}} \times 1$ vector of errors, $Z^{*}=\left[\begin{array}{cc}Z & 0 \\ 0 & Z\end{array}\right]$ be the $2 * N * N_{S_{n}} \times 2 *\left(\sum_{s} K_{s}\right)$ matrix of instruments, and $\theta=\left(\theta^{\mathrm{D},}, \theta^{\mathrm{S}}\right)$ ' be the $\left(\mathrm{K}^{\mathrm{D}}+\mathrm{K}^{\mathrm{S}}\right) \times 1$ vector of parameters of interest. Further, let $\Sigma=\operatorname{Var}\left(Z^{*}{ }^{\prime} \omega\right)$ be expected variance-covariance matrix of these orthogonality conditions. Then the estimated parameters solve

$$
\theta=\underset{\theta}{\operatorname{argmax}} \omega(\theta)^{\prime} Z \Sigma^{-1} Z^{\prime} \omega(\theta)^{102}
$$

Under the assumption that the instruments are uncorrelated with unobserved product quality, $E\left(Z^{\prime} \eta\right)$ $=0$, and unobserved cost errors, $E\left(Z^{\prime} v\right)=0$, minimizing this objective function with respect to the parameters, $\theta$, yields consistent, asymptotically normal estimates of all the parameters in the model. The specification of each of the matrices used above, $\mathrm{X}, \mathrm{D}$, and $\mathrm{W}$, is discussed in detail in the next section.

As has been mentioned previously, not all services are offered in each market. In particular, while Basic Service is offered in each market, each of the additional services possibly offered by each cable system are not. For some observations, there are as many as 8 services offered, implying 8 equations, while for others there are as few as 2. As a result, market shares (and prices) will not be observed for those services which the system elects not to provide. This is accommodated in the econometric estimation by defining each of the dependent, independent, and instrumental variables for a given service to be identically equal to zero in those markets which do not offer the service. This 'balancing' of the unbalanced dataset has no impact on the parameter estimates of any of the equations, permitting the use of standard econometric statistical packages. ${ }^{103}$

\footnotetext{
${ }^{102}$ Implicit in this definition of the GMM objective function is the assumption of possible heteroscedasticity in the error structure and differences across equations in the set of instruments considered. In the absence of these assumptions, the general GMM objective function simplifies $t \theta=\underset{\theta}{\operatorname{argmax}} \eta(\theta)^{\prime} Z\left(\Sigma \otimes Z\left(Z^{\prime} Z\right)^{-1} Z^{\prime}\right) \eta(\theta)$.

103 The intuition behind this result is straightforward. Since the objective function is a weighted sum of the sample analogs
} 
The invariance of the inclusion of these zeros on the estimation is not true, however, for the resulting standard errors. In particular, the estimation procedure implicitly assumes a rectangular dataset, resulting in the contribution of $\mathrm{N}$ observations to the calculation of the variance-covariance matrix of the resulting parameter vector. The absence of services in some markets, however, implies that fewer than $\mathrm{N}$ observations are contributing to the observed variation in some equations. We accommodate the impact of this assumption by appealing to the large sample characteristics of the GMM estimator upon which we are relying. In particular, we assume that, as the number of systems in the sample goes to infinity, that the ratio of the smallest number of observations in the data divided by the total number of observations goes to one. ${ }^{104}$ This is equivalent to the assumption that if we were to sample an infinite number of cable systems, in the limit, all would offer each of the $\operatorname{Max}_{\mathrm{n}}\left(N_{S_{n}}\right)$ services considered in the model. In small samples, we accommodate the possibility that we may be getting more precise standard errors than would be expected because of this procedure by using both $\mathrm{N}$ and $N_{\text {Smallest }}$ to estimate the approximate, small-sample Variance-Covariance matrix of the parameters.

\subsection{Identification}

This section discusses the theoretical and empirical identification of the parameters of individual utility and marginal costs, $\theta=\left(\alpha, \beta^{\prime}, \gamma^{\prime}, \rho^{\prime}, \delta^{\prime}\right)^{\prime}$, for cable television services There are two associated theoretical identifying assumptions, one corresponding to each of the demand and pricing equations. On the demand side, $\left(\alpha, \beta^{\prime}, \gamma^{\prime}\right)^{\prime}$, are identified if the instrument vector, $Z=[X, D, W]$, is uncorrelated with the vector of unobserved components of service quality, $\eta$. $X$ and $D$ enter the specification for demand. W, however, does not and serves as an instrument for price in the demand equations, by virtue of its correlation with price from the pricing equations. The maintained assumption is that variables which shift marginal costs across markets, W, are uncorrelated with unobserved components of the utility for services parameterized by the $\eta$. Similarly, on the supply side, $\delta$ is identified if the instrument vector, $M=[X, W, D]$, is uncorrelated with the vector of

to the population orthogonality conditions, the addition of 0's to this sum for those observations missing a subset of the equations has no effect on the resulting estimation.

104 i.e. $N_{\text {Smallest }} / N \rightarrow 1$ where $N_{\text {Smallest }}=$ the number of systems providing the service which is least likely to be 
unobserved components of marginal cost, $v$. Analogously, $\mathrm{X}$ and $\mathrm{W}$ now enter into the specification of cost. D, however, does not and serves as an instrument for market share in (2-14) by virtue of its correlation with quantity from the demand equations. The maintained assumption here is that variables which shift demand across markets, D, are uncorrelated with unobserved components of the marginal cost of providing services parameterized by $v$.

Among the set of instruments and assumptions described in this section, the assumption of mean independence seems most suspect for the vector of programming networks carried by each system, $X$, and therefore deserves special comment. Since the portfolio of programming is a choice variable for systems, if this portfolio is chosen on the basis of characteristics of the market that are unobservable to the econometrician but observable to the system, then $\mathrm{X}$ will be correlated with $\eta$ and the parameter estimates of $\theta$ will be inconsistent. Instrumenting for every element of $\mathrm{X}$ is infeasible due to a lack of instruments for the number of networks we consider in the model. Moreover, eliminating or aggregating programming networks could potentially mis-characterize demand for cable television service. Therefore, we reluctantly maintain the assumption that the instruments are uncorrelated with the errors.

While it is important to understand the theoretical assumptions identifying the parameters of interest, it is equally important to understand the economic intuition underlying this identification, particularly for the marginal utility to programming networks parameterized by $\beta$. Because most broadcast and cable programming networks are offered in bundles, the identification of the marginal utility to networks is complicated by the commingling of their individual impacts in each market. In the case of such bundling, identification of $\beta$ comes from two sources. First, systems differ in the portfolio of programming they offer to consumers. As a result, variation in the carriage of individual programming networks offered in any bundle of programming in conjunction with variation in the price of those bundles identifies the marginal utility to the network. For some popular networks, however, especially the most popular of the cable programming networks, few systems elect not to carry them, implying that this source of identification depends on the price charged by only the few systems which make that choice. In the extreme case - that all systems carry a given network - it could not be identified in this way. Fortunately, identification also arises from variation in the 
allocation of programming to different services. ${ }^{105}$ If some systems offer a given network on an expanded Basic Service, while others offer it solely on Basic Service, its absence from the Basic Service in the former markets permits price-portfolio comparisons of the Basic Service across systems which identifies its contribution to individual's utility.

\section{Parameter Estimates and Results}

We begin the description of our results by reporting the results for several possible specifications. We then describe the parameter estimates from the preferred specification and discuss the implications of these estimates for the nature of cable demand and costs. We also describe the changing nature of tastes for cable services over time. In a final section, we construct a qualityadjusted price index for cable television services. Detailed variable definitions and their motivation for inclusion in the empirical specification are given in Appendix A.

\subsection{Alternative Specifications and the Demand and Pricing of Cable TV Services}

Table 2-6 presents several alternative joint demand and pricing specifications considered in the GMM estimation. The base specification, shown in the first column of Table 2-6, is the most restrictive. In this specification, we impose three important restrictions. We require that (1) $\alpha$, the Mean Marginal Utility of Income in each market, is identical across markets; (2) that the certification decisions of local franchise authorities have no impact on the pricing decisions of cable systems, and (3) that the average quality of cable programming networks offered on Basic and Expanded Basic Services are the same. The specifications in the other columns of Table 2-6 relax and test the merits of these restrictions.

Moving from the first to the second column of Table 2-6, we permit the marginal utility of income to vary according to the demographic characteristics of each cable market. Like including demographics in the levels specification, including them in the slope specification is motivated by differences in tastes across markets. ${ }^{106}$ A Wald test of the hypothesis that they are jointly zero can be

\footnotetext{
105 In particular, expanded Basic Services.

106 Tastes within market are still assumed to vary only itself additively separable from prices and income.
} 
rejected at $95 \%$ confidence levels. ${ }^{107}$ The third column introduces into the specification the possibility that firms in those cable markets where the local franchise authority chose to regulate Basic Service may be setting the price for that service below profit-maximizing levels. The point estimate is -0.08 , suggesting that markups are indeed slightly lower in these markets. This is imprecisely estimated, however, and the null hypothesis that there is no discount relative to profit-maximizing prices in regulated markets cannot be rejected. ${ }^{108}$ Despite this finding, we maintain its presence as insurance against possible mis-specification. The final column addresses the differences in average quality in services characterized by the examination of the data in Section 2. There we saw that in those markets where Expanded Basic Services were offered, the networks offered there tended to be disproportionately drawn from the most popular networks available. To reflect this difference, we permit the marginal utility to additional networks beyond those individually parameterized by dummy variables to differ across Basic and Expanded Basic Services. The null hypothesis that the difference in these parameters is zero can also be rejected at conventional confidence levels. ${ }^{109}$ As a consequence, this last column is our preferred specification.

The estimates in Table 2-6 illuminate the importance of individual networks in driving demand and cost. To aid in the presentation of these findings, we refer the reader also to Table 2-7 which computes the implied mean marginal utility of income across markets predicted by the model as well as the mean consumer willingness-to-pay across markets for a subset of service characteristics offered by systems. ${ }^{110}$ The average effects presented in the columns of Table 2-7 correspond to the specifications in the comparable columns of Table $2-6 .{ }^{111}$

We first focus on the interpretation of the measures of the competitive programming provided by local broadcast networks. While not estimated with much precision, the estimates suggest that

\footnotetext{
107 Test Statistic $=30.12, \chi(5)_{0.05}=11.07$.

108 Test Statistic $=0.61 \chi(1)_{0.05}=3.84$.

109 Test Statistic $=8.39 \chi(1)_{0.05}=3.84$.

110 The mean marginal utility associated with any particular service characteristic may be converted to mean willingness-topay for that characteristics by simply dividing its marginal utilipy,by the marginal utility of income.

111 The standard errors in the two columns, however, have different meanings. In Table 2-6, the standard errors represent the predicted dispersion in the parameter estimates as predicted by the estimated variance-covariance matrix of the parameters. In Table 2-7, however, the standard errors represent the actual dispersion across markets in the average effects computed in the data. This dispersion arises in all but the base specification for two reasons: (1) heterogeneity in the predicted marginal utility of income across markets and (2) differences in program carriage decisions by systems in conjunction with a specification which permits complementarity of cable programming within services.
} 
broadcast networks still provide a modicum of competition with cable. The impact to demand for Basic Service from the presence of the first incarnation of each of the six major types of networks offered over-the-air by broadcast television stations is negative in all specifications. ${ }^{12}$ All estimates, however, are very imprecisely estimated and we cannot reject the null hypothesis in any case that the effect is negligible. ${ }^{113}$

While broadcast networks do not seem to drive cable demand, cable and premium networks do. Three groups of parameters measure these effects for the former group. The first group are the parameters estimating the mean marginal utility associated with each of the top-5 cable programming networks offered in the U.S.: ESPN, CNN, WTBS, USA, and The Discovery Channel. ${ }^{114}$ The second estimate the average (per-channel) marginal utility associated with cable programming networks offered on cable beyond these five and the third, parameterized by constants in the Expanded Basic Service equations, measure the average WTP for Expanded Basic Services in general. $^{115}$

In all specifications, there are substantial differences between the WTP by consumers for the top-5 cable networks both relative to each other and to those outside the top-5. ESPN, as befits its popularity, is uniformly the cable programming network consumers would be most willing to pay for, with a mean WTP of over $\$ 6.00$. While not quite as high, similar results obtain for the other networks: mean WTP for CNN, WTBS, USA and The Discovery Channel are \$0.06, \$1.33, \$0.97, and $\$ 0.59$ respectively. ${ }^{116}$ By contrast, WTP, on average, for networks outside these five are $\$ 0.13$ if

\footnotetext{
112 These six types of networks are the 4 major broadcast networks - ABC, CBS, Fox, and NBC - as well as Independent and Public networks. See Appendix A for a detailed discussion and justification for the specification employed here.

113 Test Statistic $=2.42 . \chi(1)_{0.05}=3.84$. Of course, in addition to locally available broadcast programming, systems also provide broadcast programming not otherwise available in local markets. For several decades, this was the principal determinant of the demand for cable. [Noll, Park, and McGowan (1973), Park (1972), Comanor and Mitchell (1971)]. The results here, however, are mixed. A network offered on Basic Service which is not available over-the-air has a small, positive, impact to demand while any duplicates have a small, negative impact. Both of these results are consistent with our expectations given the historical importance to systems of this type of programming and the subsequent exploitation of MustCarry rules by small UHF stations to guarantee carriage on cable systems. [Crawford (1997)] In each case, however, we cannot reject the hypothesis that the true benefit of all such programming is negligible.

114 These were defined in Table 2-1.

115 Because only cable programming networks are offered on Expanded Basic Services, the constants in these two equations can be attributed solely to that programming. The other parameters in these equations then measure the incremental benefit associated with programming provided on that service, controlling for these differences in average quality. Estimating the model without these constants - in essence requiring that all the benefit in Expanded Basic Services accrue only to the programming provided there-yielded qualitatively similar results, but with a dramatic loss of fit.

${ }_{116}$ We cannot reject the hypothesis that average tastes for CNN are zero, however. See Table 2-6.
} 
offered on Basic Services and \$0.06 if offered on Expanded Basic Services. Average WTP for Expanded Basic Services, controlling for the programming offered, was nearly $\$ 5.00 .^{117}$

That the top-5 cable programming networks are so highly valued relative to each other prompted us to further investigate the value of individual networks outside these five. Did this heterogeneity persist? Tables 2-8 and 2-9 present the parameter estimates and average WTP, respectively, for specification which expand the set of networks permitted an individual impact on demand and cost. The first column in these tables duplicates our preferred specification from Tables 2-5 and 2-6 while the neighboring columns expand to ten and twenty the number of individual network effects.

The results, again, are mixed. Estimates of mean WTP for the top-5 networks are generally stable to the addition of the remaining other networks, while the estimates for these additional five and fifteen, respectively, tend to vary. Mean WTP for some, measured, for instance, for MTV at $\$ 0.97$ and \$0.89 and for The Family Channel at \$0.41 and \$0.73, are comparable with those in the top-5. Others, however, yield small or even negative estimates. In no case, however, can we reject the hypothesis of a small, positive average WTP associated with any given cable network. ${ }^{118}$

Average tastes for premium programming networks are also quite high. In our preferred specification [Table 2-7, col. 4], mean WTP for HBO, Showtime, The Disney Channel, Cinemax, and The Movie Channel, vary from a low of $\$ 4.04$ to a high of $\$ 7.09 .^{119}$ Several demographic variables also proved important in the joint estimation. ${ }^{120}$

\footnotetext{
117 That these estimates are high reflects the extraordinary penetration of Expanded Basic Services among Basic Subscribers. See also previous footnote.

118 [Pending Ses for test statistic] Note that a negative mean WTP is not inconsistent with profit-maximizing behavior. While, on average, consumers do not care for the network, there is a distribution about that mean suggesting some might value it quite highly.

119 That prices for these networks are substantially higher than these figures is consistent with the data. Penetration of individual premium services averages only about $20 \%$, implying that the majority of individuals value them at a level below their incremental price, particularly when the purchase of Basic Service is first required.

120 Demographic characteristics measure differences in aggregate tastes for cable across markets. Among the variables considered, measures of population density, as captured by the Designated Market Area ranking, proved quite important. The results indicate that the lesser the population per square kilometer and the smaller the television market ranking, the greater was the demand for cable. Even after conditioning on the broadcast programming provided in these cable markets, this result suggests that more rural areas exhibit greater demand for cable, undoubtedly due to the lesser range of alternative entertainment options available in those markets. Similarly, certain of the demographic features of individuals in cable markets, also impacted demand. In particular, the greater the percentage of the population aged 5-18 and with some college education, the lower, but more inelastic, the demand. Median income had a negligible effect on either level or slope.
} 
For completeness, we compute and report the own- and cross-price elasticities of demand for the Basic, Expanded Basic, and Premium services available in each cable market. Following McFadden (1981), the elasticity of demand for the Basic Service tier with respect to its price for our specification is given by

$$
\varepsilon_{b b}=\frac{\partial \log \left(w_{b}\right)}{\partial \log \left(p_{b}\right)}=\frac{p_{b}}{w_{b}}\left[\frac{\partial w_{b}}{\partial p_{b}}\right]=\alpha p_{b}\left(1-w_{b}\right)
$$

where $e_{b b}$ is the elasticity of demand for the Basic Service tier with respect to its price, $p_{b}, w_{b}$ is the market share of Basic Service, and $\alpha$ is the mean marginal utility of income. The remaining own- and cross-price elasticities are computed in an analogous manner. ${ }^{121}$

Table 2-10 provides these computed own- and cross-price elasticities of demand for each of the services provided in the 1992-1995 sample period. ${ }^{122}$ Own-price elasticities of demand are generally elastic, although not extremely so. The average own-price elasticity of demand for Basic Service, $\varepsilon_{\mathrm{bb}}$, of -4.83 , and the range of own-price elasticities of demand for individual premium service, $\varepsilon_{\mathrm{rr}}$, are comparable if a bit higher than results found in previous studies. ${ }^{123}$ We note, however, while the logit assumption normally predicts substitutability among services, the nature of tied demand in cable markets instead predicts complementarity. ${ }^{124}$

\section{Changing Tastes for Cable Television Services}

The results described so far estimate tastes and costs for contemporary cable service; tables 211 and 2-12, however, present similar estimates of tastes and costs for cable services offered in the

\footnotetext{
121 Note that the requirement tying the purchase of Basic Service to all other services does not impact the form of the ownprice elasticity for Basic Service. This is not true, however, for the remaining own- and cross-price elasticity calculations. Indeed, because the specification requires that Basic Service be included in the purchase of any other cable service, increasing the price of Basic Service in this model increases the price of all cable services. This has the effect of making Basic Service and all remaining services complements, despite the fact that the structure of the discrete-choice problem facing individuals implies that all combinations of services are substitutes.

${ }_{122}$ Since not all markets provide all services, the number of observations for each of the own- and cross-price elasticities depends on the number of markets in the data which offered both of the services considered. This number is given in the upper-right-hand corner of the corresponding cell in Table 3-7.

${ }_{123}$ In particular, Rubinovitz (1993) found average own-price elasticity of demand for Basic Service of -1.51, as did Mayo and Otsuka (1991). The latter study, in addition, found average elasticities of demand for pay subscribers (and not the individual pay services) of approximately -1.77 .

124 The degree of flexibility in modeling this complementarity, however, is as limited as is the ability of the standard logit to model substitutability.
} 
late 1980s and early 1990s. ${ }^{125}$ The predictions of the model exhibit considerable variance for the programming offered by systems across these two sample periods. It appears that the competitive impact of broadcast networks on cable demand is roughly comparable, in both sign and magnitude, across sample periods. Average tastes for premium networks also appear stable. Average tastes for cable networks, however, show considerable change in both absolute and relative magnitude. While mean WTP for ESPN was over $\$ 5.00$ in the latter sample, in was $\$ 0.67$ in the earlier period. Similarly, average tastes for The Discovery Channel has grown considerably over time. By contrast, mean WTP for WTBS is roughly constant, and for CNN and USA has fallen slightly over time. ${ }^{126}$

Average tastes for the programming provided on Expanded Basic Services - as measured by the Expanded Basic Service constants - has grown substantially over time, while average tastes for programming beyond the five individually parameterized, controlling for the former increase, have fallen. $^{127}$

\section{Implications}

Taken together, these findings present a comprehensive picture of the nature of demand and cost for cable television services, both now and in the recent past. While historically important, the contemporary importance of broadcast programming has waned significantly. In contrast, the importance of cable programming, at least in certain cases, has appeared only to have increased. Mean tastes for individual cable networks exceed that of broadcast networks and have generally increased over time, in some cases substantially. ${ }^{128}$ This phenomenon is consistent with the increased expenditures undertaken by the networks for the programming provided there. ${ }^{129}$ There appears also,

\footnotetext{
125 We focus on the fourth column - our preferred specification - in the analysis to follow.

126 Each of these effects is broadly consistent with the differential experiences of these networks over time. ESPN is now among the most valuable cable networks and now offers programming (in the sports domain) comparable with that historically provided only by the major broadcast networks. CNN has fallen on harder times, no doubt in part to increased competition from other news programming. The USA network, once among the most valuable program networks has also lost ground over time. \$hapiro, 1997]

127 The inclusion of constants in the Expanded Basic demand equations complicates the exposition of the change in tastes for cable programming over time, but is necessary as excluding them induces a dramatic loss of fit.

128 In drawing this conclusion, we rely on the stronger relative growth in mean tastes for programming provided on Expanded Basic Services as compared to the relative decline in tastes for additional program networks provided on Expanded Basic Services.

129 As the most prominent example, ESPN now broadcasts both Major League Baseball and National Football League games, at considerable expense. These additional offerings no doubt have contributed to its growth in value.
} 
however, to be a concentration of tastes among the most popular cable networks. In particular, while average tastes for some of the top-5 networks has grown, it has fallen for programming networks outside these five.

The heterogeneity evident in tastes for individual networks and the concentration of those tastes in the most popular programming networks has important implications for measuring consumer benefits to the programming changes undertaken by systems. Since systems tend to add the more popular networks when expanding capacity and tastes for these networks have grown over time, measures of the benefits of program additions by systems that consider only the number of networks are likely to understate the aggregate benefits. Similarly, since new services also draw disproportionately from the top networks, the added value to these services is potentially large. We explore these issues in more detail in the next section.

\subsection{A Price Index for Cable Television Services}

In this section, we draw on recent results in the economic theory of group index numbers in differentiated products markets to construct index for the price of cable television services that controls for changes in the quality and variety of those services over time. We then compare its predictions to those obtained by the Bureau of Labor Statistics as part of the Consumer Price Index.

\section{Aggregate Price Indices in Differentiated Products Markets}

In the economic theory of index numbers, a cost-of-living, or Konüs, index (CLI) is given by the ratio of the expenditure required to reach a given indifference surface for an individual household at two different price levels. ${ }^{130}$ As such, these have a strong grounding in economic theory, but depend on having correctly identified the structure of household preferences in order to be

constructed. ${ }^{131}$ Conventional indices, on the other hand, like the well-known and commonly applied Laspeyres and Paasche indices, only provide bounds on this true index, but require only observations on reference and comparison prices and quantities. ${ }^{132}$

\footnotetext{
130 See Diewert (1987).

131 See Jorgenson and Slesnick (1990) and Brown and Greenstein (1994) for examples.

132 In particular, the Laspeyres index provides an upper bound on the CLI evaluated at comparison period utility levels while the Paasche index provides a lower bound on the CLI evaluated at reference period utility levels.
} 
For policy purposes, however, we often wish to characterize the impact of prices on an aggregate of households. Constructing aggregate, or group, price indices, however, is more complicated. As described by Pollak(1980), this complication is not one of implementation, but of conception: to adequately describe the welfare impact of price changes on groups of households requires, "interpersonal [welfare] comparisons and distributional judgments."133 Except under special circumstances, the specification of a Social Welfare Function is required to express these judgments. ${ }^{134}$ In the special case that market demands may be assumed to be independent of the distribution of income across the group, these market demands can be derived from the preferences of a representative consumer. In this case, these preferences correspond exactly to the group Social Welfare Function. As was the case for an individual household, exact group indices may then be defined as the ratio of expenditure required to attain the indifference surface of the representative consumer at two different price levels.

Recent work in the analysis of differentiated products markets by Anderson, DePalma, and Thisse (1993) and Feenstra (1995) outline the conditions under which the behavior of a heterogeneous collection of agents may be described by a representative consumer in this same sense. This is extremely useful as the data requirements in the analysis of household behavior in differentiated product markets often exceed available resources, while market-level data is relatively abundant. ${ }^{135}$ The conditions naturally turn on the specification of individual tastes and the distribution of those tastes in the population of individuals. ${ }^{136}$ For the linear random utility model with tastes distributed as Type I Extreme Value as in this paper, the conditions are satisfied, and the representative consumers indirect utility function (equivalently the population social welfare function) is given by

$$
U_{n}\left(p_{n}, Y_{n}\right)=Y_{n}+N_{b} \log \left(\sum_{j}^{N_{j_{n}}} \exp \left[V_{j}\left(p_{j n}, Z_{j n}, D_{b}\right)\right]\right)
$$

where $\mathrm{Y}$ indexes mean income, $\mathrm{N}$ indexes the number of homes, and $\mathrm{V}(\mathrm{)}$ parameterizes the

\footnotetext{
133 P.273.

134 In particular, Pollak introduces two basic group Cost-of-Living Indices (CLIs): A social CLI and a democratic CLI. Both require knowledge of household preferences, but only the former requires specification of a Social Welfare Function. The latter is obtained by simply averaging each households CLI, hence the name democratic.

135 As mentioned earlier, this is certainly the case in cable television markets.

136 The intuition underlying the conditions and the likelihood that they are satisfied in the case of the cable television industry is discussed below.
} 
conditional indirect utility for each offered combination of services in market $n$. As usual, $V()$ is a function of the prices, $\mathrm{p}$, and programming, $\mathrm{Z}$, of each of the $N_{J_{n}}$ combination of services, as well as of demographic features, D, of the market. The representative consumers expenditure function is then, as usual, just the inverse:

$$
e_{n}\left(p_{n}, U_{n}\right)=U_{n}-N_{b} \log \left(\sum_{j}^{N_{j_{n}}} \exp \left[V_{j}\left(p_{j n}, Z_{j n}, D_{b}\right)\right]\right)
$$

This formulation is particularly useful when constructing indices in the presence of quality change or new service introductions, areas of difficulty for conventional indices. ${ }^{137}$ When changes in quality arise from changes in characteristics and new goods are new varieties of existing goods, as is often the case in differentiated products markets, the above form naturally quantifies aggregate benefits. In essence, the knowledge of household preferences required to quantify the value of changes in quality and diversity at the individual level are extended to quantify the value of aggregate quality and diversity. ${ }^{138}$

The legitimacy of this practice, of course, rests with the robustness of the underlying assumptions. In the case above, it is the assumption of the linear random utility framework with linear additive unobserved heterogeneity that permits the characterization of aggregate tastes with the behavior of a representative consumer. ${ }^{139}$ How reasonable is this practice? That remains an empirical question. ${ }^{140}$ One alternatives would be the calculation of a democratic aggregate indices constructed by an unweighted average of individual household CLIs using 'average' reservation prices inferred from a hedonic regression. ${ }^{141,142}$ Or the straightforward calculation of a 'dummy-variable' hedonic regression. ${ }^{143}$ These, too, have their defects, however, notably an underestimation of the benefits of new product introductions. ${ }^{144}$ As such, we pursue the formulation described above.

\footnotetext{
137 See the early work by Fisher and Shell (1972) as well as more recent research by Fisher and Griliches (1995) and applications by Griliches and Cockburn (1995) and Berndt and Griliches (1994).

138 As does the CES social welfare function in the seminal work of Dixit and Stiglitz (1977).

139 See Feenstra (1995).

140 We note that in general, it is not intra-household, but inter-household substitutability that forms the core problem to be considered. Feenstra (1995) presents a social welfare function based on McFadden's (1978) Generalized Extreme Value distribution that permits robust intra-household, inter-service substitutability within this framework.

141 The CLI proposed here is a plutocratic CLI and is equivalent to a weighted average of individual household CLIs with reference-period expenditure shares providing the weights. (Diewert, 1987).

142 As in Fisher and Griliches (1995) and Griliches and Cockburn (1995).

143 As in Berndt and Griliches (1994).

144 See Trajtenberg (1990) and Brown and Greenstein (1994).
} 
The index constructed here is similar in spirit to a cost-of-living index but focuses instead of on expenditure, on the particular prices charged for cable service. It was first suggested by Trajtenberg (1990) for the measurement of the benefits associated with innovation in medical scanning technology. The principal is very much the same: we measure the hypothetical price change that would be required to reach a given indifference surface for the representative consumer at two different price-programming-service combinations. Letting 0 and 1 index the initial and final vectors, $\left(p_{j n}, Z_{j n}, N_{j_{n}}, D_{b}\right)$, this price change is implicitly defined by $\delta$ in the following equation:

$$
U_{n}^{R}\left[\left(p_{n}^{0}(1+\delta), Z_{j n}^{0}, N_{j_{n}}^{0}, D_{n}^{0}\right), Y_{n}\right]=U_{n}^{R}\left[\left(p_{n}^{1}, Z_{j n}^{1}, N_{j_{n}}^{1}, D_{n}^{1}\right), Y_{n}\right]
$$

where each of these variables was defined above and we note that $U$ is indexed by $R$, representing the tastes of the representative consumer. ${ }^{145}$ We note that in the former case, the definition above is very similar to that of the Equivalent Variation corresponding to changes in $\left(p_{j n}, Z_{j n}, N_{j_{n}}, D_{b}\right)$ except in quantifying it as a price rather than an income change. ${ }^{146}$ In the applications here, we describe both income and price calculations. ${ }^{147}$

In addition to permitting the quantification of the total change in consumer welfare associated with changes in cable programming, services, prices, and demographics, this methodology permits us to break down these changes into their component parts. That is to say, we can compute the hypothetical price change that would be required to reach a given indifference surface for the representative consumer for observed changes in services alone, programming alone, or prices alone.

To implement this procedure, we make two assumptions. First, we choose to calculate the index on the basis of period 1 (1992-1995) tastes. Following Fisher in Shell (1995), we choose the latter as that is most relevant for policy decisions in the industry. While it may be instructive to know how consumers in 1991 might value the subsequent changes in the set of choices available to them, it is more relevant to know how consumers today value these same changes. Second, we modify the index slightly to calculate not the percentage change in all prices, as indicated in the formula above,

\footnotetext{
145 This dependence on tastes is often omitted in the definition of price indices, but in the presence of changing tastes over time is critically important and amounts to selecting a metric for valuing changes in the choice set facing consumers. As is the case for selecting a reference utility level, these tastes are typically chosen to correspond to those held in either period 0 or period 1 .

${ }^{146}$ In particular, the Equivalent Variation, EV, is implicitly defined by:

$$
U_{n}^{R}\left[\left(p_{n}^{0}, Z_{j n}^{0}, N_{j_{n}}^{0}, D_{n}^{0}\right), Y_{n}+E V\right]=U_{n}^{R}\left[\left(p_{n}^{1}, Z_{j n}^{1}, N_{j_{n}}^{1}, D_{n}^{1}\right), Y_{n}\right]
$$
}


but instead the percentage change in the price of Basic Service that would be required to reach a given indifference surface for the representative consumer. We do so for two reasons. First, not all services are offered in each market. As such, the interpretation of the 'percentage increase in all cable service prices' would differ according to the set of services offered in that market. Moreover, even if all services were offered in each market, not all cable subscribers purchase each service. Since, however, all markets offer Basic Service and it must be purchased in order to purchase any other service, it is a natural candidate for indexing.

Table 2-13 presents the Equivalent Variation and equivalent price changes associated with changes in each of four characteristics of cable services and markets across our sample periods. These are: (1) Changes in demographic characteristics, D, (2) Changes in the services provided (and thus the choice set), $N_{J_{n}}$, (3) Changes in programming offered on all services, Z, and (4) Changes in prices of all services, p. Furthermore, changes in programming are decomposed into two parts: (a) Additions to the programming offered on any service and (b) Reallocation of existing programming among services. The sum of these effects yields the total effect given in the final row of each section of Table $2-13 .{ }^{148}$

The results of this exercise are quite illuminating. Focusing first on the total effects of changes in services, prices, programming, and demographic characteristics, we see that, on average across markets, consumer welfare gains between our sample periods are small, but nonetheless positive. Average Equivalent Variation (EV) across markets were $\$ 0.04$ per consumer per month. In addition, consumers would be indifferent between the many changes to their choice sets and an equivalent reduction in the price of 1988-1991 Basic Service of $0.08 \%$, or about $\$ 0.01$. Decomposing this result further yields some interesting results as well. Increases in the price(s) of various cable services had a fairly substantial negative impact on consumer welfare. Average welfare losses were $\$ 0.86$ per household per month and equivalent to an $8.47 \%$ increase in the price of Basic Service. The introduction of new services and addition of new programming to all services more than offset these losses, however. Welfare gains for new Expanded Basic Services were equivalent to average Basic Service price reductions of $8.00 \%$ and similar gains from the addition of new 
programming yielded equivalent price reductions of 4.54\%. The reallocation of programming across services had a small, negative welfare effect.

To interpret these figures, we compare their predictions with those obtained by the Bureau of Labor Statistics Consumer Price Index for cable television services. The Cable CPI, like all but a very few elements of the CPI, is a 'matched-model' index. Using probability sampling, CPI field representatives select to price some combination of cable services offered in each of their sampling areas. ${ }^{149}$ Each successive time the system is sampled, this same combination of services is priced. At that time, the characteristics of the service (i.e. the programming offered) is compared to that available in the previous period. If there are changes, and the BLS determines that they constitute a quality change, "the value of that quality change is removed prior to calculation of the index." ${ }^{\text {"150 }}$ If a new service is introduced, this represents an entirely new 'level of service' and is not included in the index.

As constructed, the cable CPI has difficulty accommodating the problems of new goods and quality change in cable services. Due to the 'matched-model' nature of the index, the benefits associated with new services do not appear in the index. ${ }^{151}$ Furthermore, quality change in the form of new programming is accommodated in an ambiguous manner while increases in the value of existing programming is not at all addressed. ${ }^{152}$

Figure 2-2 presents a series of price indices for cable television service over the period January, 1989 to July, 1995. Principal among these, described by the solid line, it the Cable CPI index. The remaining indices are those developed using the equivalent price changes described in Table 2-13. For each index presented - both that for the total change as well as for each of its components - we decompose for each market the total percentage change between the sampled months into an equivalent, monthly index. ${ }^{153}$ Setting all indexes equal to 1 in January, 1989, we then

\footnotetext{
consequence, this will be associated with a negative equivalent price change.

149 Technically, field representatives first select among either (1) installation charges plus minimum (Basic Service) charges and (2) period monthly charges for some 'level of service' (i.e. combinations of cable services). [BLS (1994)]

150 BLS (1994). It is not clear how exactly this is done.

151 This is more of a problem in industries where new products are very substitutable with existing products, as in the introduction of generic drugs after pioneer drug patent expiration. [Griliches and Cockburn (1994)]

152 These issues, in principal, could be addressed, albeit imperfectly, with the adoption of hedonic methods as has been done in the construction of BLS price indices for computers. See Triplett (1990) or Griliches (1990).

153 For example, an estimated total price reduction of $6.18 \%$ for a cable market sampled in November, 1991 and again in May, 1995 would yield an equivalent reduction of $0.15 \%$ for each of the 42 months between observations.
} 
average the monthly effects across markets to construct our comparable monthly index. Due to the need to construct monthly figures by averaging over two observations for each market, however, our indices are significantly smoother than the comparable BLS index.

Despite this difference in construction method, the predictions of the model shed considerable light on measuring consumer benefits to quality change and new product introduction in cable television markets. Focusing solely on price changes and ignoring the benefits associated with changes in the programming and services offered on cable, we see that our index largely duplicates the increases in prices predicted by the CPI. ${ }^{154}$ In particular, while the CPI predicts an increase of $14.6 \%$ in cable prices over this period, our 'price-only' index predicts a 16.8\% increase. [Table 2-13] When we measure the benefits associated with increases in cable programming and services, however, this conclusion is substantially altered. ${ }^{155}$ Aggregate benefits from the introduction of new services would have yielded price decline of $14.9 \%$ while the addition of new programming would have yielded an additional decline of $6.2 \%$. As would be expected given these findings, incorporating the benefits of new product introduction and quality change yield a substantially lower aggregate index. Indeed, while the CPI predicts price increases of $14.6 \%$ over this period, we predict an aggregate price decrease of $2.2 \%$. In light of these results, we conclude that existing BLS methods substantially understate the benefits associated with changes in cable television services over the period 19891995.

\section{Extensions and Conclusions}

The goal of this paper has been to quantify the benefit to consumers from changes in the services, programming, and prices offered by cable systems over the period 1989-1995. To do so, we introduced a discrete-choice, differentiated products model of demand and pricing designed to accommodate the arbitrary program selection and bundling decisions of systems, as well as changes in those decisions over time. Our principal finding is that while prices for cable services indeed have risen - at rates comparable to those predicted by the Cable Consumer Price Index - that accounting

\footnotetext{
154 Note our data cannot possibly predict the early decline and later increase in the CPI index as we only have two observations per market with the latter occurring some time after September, 1992.

155 In the graph here, the programming index measures the combined effects of the addition of new programming as well as the reallocation of existing programming among services reported in Table 2-11.
} 
for the benefits associated with new services, new programming on those services, and changing tastes in cable markets yield effective price decreases.

Despite the flexibility of the modeling framework at the individual level, the compromises required to estimate the model at the aggregate level suggest several possible extensions. Most promising among these would be to generalize the nature of inter-service substitutability within cable markets. Recent advances in the development of computation algorithms as in Berry, Levinsohn, and Pakes (1995) and Bresnahan, Stern, and Trajtenberg (1997) for unobserved tastes distributed under Normal and Generalized Extreme Value distributions suggest this as an avenue of research. The principal benefit of such a generalization, in addition to addressing concerns about the importance of such substitutability for the results presented here, would be the ability to address the cable bundling decisions themselves. While demand complementarities, cost complementarities, or price discrimination could each motivate cable bundling as emphasized in the theoretical literature, no empirical tests of these alternatives have been undertaken. To address this issue requires the flexible inter-service patterns of substitutability described above and is a lucrative topic of future research. Additional extensions include analysis of alternative indices to the ones compared here.

The implications of our results for industry regulatory policy are significant. The principal motivating factor in recent policy debates has been the extent to which consumers have borne the cost of freely exercised market power by monopoly cable television systems. While the model does predict a degree of monopoly power, it also predicts that consumer benefits to increases in the quality and diversity of cable services have largely outweighed the losses associated with the price increases with the exercise of that power. While it is in principle possible that price regulation like that imposed by the 1992 Cable Act could further benefit consumers, the disincentive for systems to further increase the quality of their offered services (and indeed the incentive to decrease that quality) deter us from such a recommendation. ${ }^{156}$ The sunsetting of cable regulations included in the 1996 Telecommunications Act and associated reliance on pro-competition, rather than pro-regulation, policies suggest the rather welcome view federal regulators share our view. ${ }^{157}$

156 In addition, in Crawford (1997), we find that the actual regulations imposed by the Act have had little effect.

157 The recent discussion of further re-regulation notwithstanding. (Wilke, 1997) 


\section{Appendix A - The Data and Empirical Specification}

This appendix describes the collection of the data used in this paper and motivates the selection of the variables used to estimate the models of demand and pricing. It is divided into two sections. First, the sources of data used in the empirical analysis are described. Most of the data comes from the 1992 and 1996 editions of the Television and Cable Factbook, but additional information is also provided by the Bureau of Labor Statistics, the City and County Data Book, and FCC sources. Because many observations are lost in the process of checking the validity of the reported data, we discuss the comparability of our sample to the population of cable systems as a whole. We find that while the systems in our sample are significantly smaller than those in the population, they charge comparable prices and exhibit comparable market shares. Second, we describe the empirical counterparts to the variables described in the modeling section

\section{A.1 The Data}

This paper compiles a market-level dataset on the population of United States cable systems to implement the models of demand and pricing introduced here. The primary source of data for these systems is Warren Publishing's Television and Cable Factbook Directory of Cable Systems. The Factbook conducts detailed annual surveys of the population of United States Cable systems. As completed surveys are returned, the information provided is entered into a database whose contents are published in annual editions. Systems are asked about characteristics of their market (e.g. communities served, population of system area, and county of service), characteristics of their system (e.g. channel capacity, miles of plant, and homes passed), and characteristics of the services they provide. In particular, systems are asked to report, for each service offered, the number of subscribers to that service, the monthly fee for that service, and the identities of the broadcast, cable, and premium programming networks provided on that service. ${ }^{158}$ Table A-1 provides a detailed account of the definitions and sources of the variables used in the model.

Nearly all previous studies of the cable industry have relied on the Factbook data and its

158 See Chapter 1 for a definition of these terms. 
weaknesses are well-known. ${ }^{159}$ Systems are neither required nor are compensated for responding to surveys from Warren Publishing. As a consequence, response rates for individual annual surveys are relatively low, and have been estimated by the publisher at approximately $33 \% .{ }^{160}$ Since not all systems respond in a given year, the resulting databank provides data of widely varying vintages some from the very recent and others from the very distant past. ${ }^{161}$ In some instances, data for a given cable system itself will have information of differing vintages. ${ }^{162}$ Moreover, what data is reported is neither cross-validated with follow-up surveys nor checked for internal consistency. As a consequence of these problems, in order to be included in the empirical implementation, the data provided by the Factbook were required to satisfy a fairly large number of conditions. The interested reader can find these conditions and their impact on the sample in the Table A-2.

This reduced Factbook dataset was then supplemented with information from three additional sources. First, to account for the different vintages of the reported observations, we deflated all reported Factbook prices by the Consumer Price Index for Non-Durable Consumption for the month corresponding to the reporting date. This index was chosen to reflect that cable television service constitutes a discretionary purchase whose real price should reflect the growth in prices of similar goods. The reference date chosen for the normalization of the prices was December, 1986, the month the 1984 Cable Act took effect. ${ }^{163,164}$ As a consequence, all reported magnitudes in all tables are in units of December, 1986 dollars.

Second, because the demand for cable television service in a cable market depends on the availability of alternatives sources of video programming, a measure of the availability of conventional over-the-air broadcast signals was constructed. ${ }^{165}$ The source of this information was the American Research Bureau's listing of "Significantly Viewed" television stations from December, $1986 .{ }^{166}$ This

\footnotetext{
159 See Mayo and Otsuka (1991) and Rubinovitz (1993) for recent comments.

160 Conversation with Lynn Levine, Director of Marketing and Data Sales, Warren Publishing.

161 The oldest reported observation in the data was from 1977.

162 I.e. If returned surveys updated only a subset of the information requested.

163 See Chapter 1 for a discussion of the 1984 Cable Act and its impact on cable prices during the sample period.

164 Note that this implies that all reported prices are properly interpreted in 'December, 1986, Dollars'.

165 The importance of accommodating the comparative broadcast services provided by cable television systems was first emphasized in Comanor and Mitchell (1971), Park (1972), and Noll, Peck, and McGowan (1973).

166 The "Significantly Viewed" criterion was one condition that broadcast television stations could satisfy in order to guarantee carriage on local cable systems until 1987 under existing 'Must-Carry' rules. It is a market measure, defined for network stations as, "a share of weekly viewing hours of non-cable households of 3 percent and a net weekly circulation of 25 percent." See Television Digest (1987) for more.
} 
listing provides, at the level of each county in the United States, the identities of those broadcast signals considered generally available and able to be satisfactorily viewed by all households in that county. While somewhat dated, the use of the 'Significantly Viewed' criteria is superior to the alternative of omitting the impact of over-the-air broadcast signals on the demand for cable. ${ }^{167}$

Finally, to avoid confounding heterogeneity in tastes and costs across markets, system characteristics reported in the Factbook were supplemented with demographic features of the county in which the system provided service. These were obtained from the County and City Compendium, a CD-ROM database which contains an array of United States statistical data compiled by the Census Bureau, Department of Commerce, and Bureau of Labor Statistics. Selected for inclusion were variables thought to impact the demand and cost of providing cable service and which have been used in previous studies of the industry. ${ }^{168}$ A brief description of the variables used in the analysis is provided in the next section.

The information from these four sources of data were then merged. The information was linked by the county served by the cable system. While necessarily imperfect, in that systems rarely serve every household in the county in which they reside, it was the most detailed level of geographic aggregation available for all the systems in the sample. ${ }^{169}$

After merging these sources of data, the conditions listed in the Table A-2 were imposed. The vast majority of these conditions reflected missing or erroneous reporting on the part of systems. Among these, for example, the conditions which eliminated the most observations were those excluding systems for missing price or quantity information and for missing or internally inconsistent reported dates. ${ }^{170}$ Upon satisfaction of all restrictions, 1,460 observations remained from the pre-Act sample and 1,015 remained from the post-Act sample. Of these, 344 systems were present in both samples and formed the basis of our analysis. ${ }^{171}$

\footnotetext{
167 A frequently-used alternative measure of broadcast signal availability is the presence of any part of the system's franchise area within the Grade B contour of the station. (A television station's Grade B contour is the set of locations within which $50 \%$ of the households can adequately receive the television signal $90 \%$ of the time). See, inter alia, op.cit. 24, Pacey (1985), and Mayo and Otsuka (1991). The size of my sample precluded the use of this measure.

168 See, inter alia, sources ().

169 Precluding the use of more detailed information such as zip codes was the reporting procedure used by systems. Often, a Multiple System Operator (MSO) at the level of a state would report on all its systems in that state. In these cases, the operator address was that belonging to the state operator and not that of the system itself.

170 Over 20 conditions were required, however. See the Data Appendix.

171 The panel data is used in Chapter 4.
} 
Since so many systems were eliminated from this sample, we are concerned about the comparability of the systems in the sample to the population of cable systems as a whole. To address this point, Table A-3 compares the summary statistics for a set of core characteristics of cable television systems obtained both for our sample and for the population of United States cable systems. This latter data is provided by the National Cable Television Association from separate and independent sampling mechanisms. ${ }^{172}$ As can be seen, the systems used in this analysis are quite a bit smaller than are the average cable system and are more likely to offer premium services. ${ }^{173}$ Market shares for basic service tend to be higher than the national average in the sample, but premium subscriptions, despite the higher incidence of carriage, tend to be lower. Prices for basic and premium services are fairly comparable, with the price of basic service somewhat lower in the sample than in the nation as a whole. Moreover, we tend to overestimate the share of revenue earned by basic services, largely, we suspect, due to the absence of equipment and pay-per-view information for the systems in our sample. Taken together, these results suggest that the exclusion criteria described by Table A-2 have eliminated large, urban, cable systems from the sample. ${ }^{174,175}$ We are encouraged, however, that prices do not appear to be differ in a large way between the sample and the population. We offer no conclusions, except to state that the results obtained in this paper should not necessarily be interpreted as representative of the population of United States cable systems.

\section{A-2. Empirical Specification}

This section briefly describes and motivates the selection of the variables used to estimate the models of demand and pricing. Detailed definitions and sources for the information presented here are available in the Data Appendix Table A-1.

The demand equations estimated in this paper are given by equations (2-6) and (2-7) and the pricing equations are given by equations (2-12). We begin by noting that the identities of the Basic, Expanded Basic, and Premium programming services offered by the cable system in each market in

\footnotetext{
172 In practice, most of the other data came from various published reports from Paul Kagan Associates, Inc.

173 We cannot test for the difference in means across our sample and the population characteristics as we do not have information about the distribution of the latter variables.

174 To the extent that such systems provide more services, urban are more likely to fail one of the criteria imposed in Table 3-2.

175 The justification for the conclusion that urban systems have been excluded stems from the finding that consumers in
} 
the data are given by the Factbook. The price and number of subscribers to each of these services are also reported in the Factbook, as are the number of homes passed, permitting the transformation of these quantities into the market shares, $\mathrm{w}_{\mathrm{s}}, \mathrm{s} \in \mathrm{S}_{\mathrm{n}}$, required by the equations above. ${ }^{176}$.

The resulting prices are denoted by $\mathrm{p}_{\mathrm{x}}$, where $\mathrm{x}$ stands for one of the services, $\mathrm{s} \in \mathrm{S}_{\mathrm{n}}$, offered by the cable system in market $n{ }^{177}$ The observable characteristics of each service, parameterized by $\mathrm{X}_{\mathrm{s}}, \mathrm{s} \in \mathrm{S}_{\mathrm{n}}$, consist, in part, of individual dummy variables indicating the presence of the individual broadcast, cable, and premium programming networks provided on that service.

Because of the sheer number of broadcast, cable, and premium programming networks offered by cable systems, ${ }^{178}$ however, the following general strategy is pursued to parsimoniously measure the utility to consumers of that programming. For each of these types of programming, the networks provided by systems are separated into two classes. The first class contains those networks thought to provide an individual impact on the demand for cable. They are parameterized by dummy variables and enter the specification of $\mathrm{X}_{\mathrm{j}}$ as separate regressors. The second class contain those networks thought to provide a common impact on demand for cable. They are counted and enter the specification of $\mathrm{X}_{\mathrm{j}}$ as a single regressor. This unequal treatment of some networks relative to others reflects the belief that there is significant heterogeneity in value to an individual consumer of different networks. To the extent that the demand for any product, $\mathrm{j}$, is driven by the carriage of the particular individual cable programming networks it provides and not by the sheer number of such networks, this specification captures this distinction. ${ }^{179}$ The choice of the networks to enter the specification of $\mathrm{X}_{\mathrm{s}}$ with separate or common impact depends on the type of programming considered.

urban markets are more likely to subscribe to premium services. [Cite]

176 The market share for any service, $w_{s}$, is defined as the number of subscribers to that service divided by the number of homes passed by the cable system. See the Data Appendix for a justification for the assumption that the number of homes passed in each cable market measures market size.

177 In the empirical implementation, there are as many as 8 prices. 3 for tiers of Basic service $(b=b a s i c, e=$ expanded basic, and $\mathrm{f}=$ second tier of expanded basic) and 5 for tiers of Premium service $(\mathrm{h}=\mathrm{HBO}, \mathrm{s}=$ Showtime, $\mathrm{d}=$ Disney, $\mathrm{c}=$ Cinemax, and $t=$ The Movie Channel). In addition, we define $p=p_{b}+p_{e}+p_{f}$ to denote the price paid by consumers for the purchase of all tiers of basic service offered in their market.

${ }_{178}$ In the Pre-Act sample, for example, there are 143 cable and 25 premium programming networks provided by at least one system in the sample. For the Post-Act sample, there are 197 and 115 such networks.

179 The dichotomy of individual versus common impact is chosen to reflect the inherent tradeoff between theoretical detail (which would ideally permit all networks an individual impact) and parsimony (which restricts us to permitting only some networks an individual impact). Where to draw the line is, of course, an empirical question - in the following chapter we consider in detail the dividing line between individual and common impact for each of the three types of programming network provided by systems -- broadcast, cable, and premium programming networks. 
Broadcast programming networks available in each cable market are given by the Factbook for cable systems and by the American Research Bureau's 'Significantly Viewed' listing for over-theair television. ${ }^{180}$ As broadcast programming is available both over-the-air as well as on cable, we consider the value to consumers of the programming on each medium.

In most television markets, there are up to 6 principal types of networks available. First, and most important as measured by ratings and revenues, are stations affiliated with one of the four major broadcast television networks, ABC, CBS, NBC, and Fox. ${ }^{181}$ Next in importance are independent stations, broadcast television networks which provide for all of their programming throughout the viewing day, typically with syndicated television programs. ${ }^{182}$ Finally are Public (Educational) Television Stations, not-for-profit broadcast television stations providing educational and cultural programming. In the empirical specification considered here, we follow the lead of previous studies to distinguish, within each of these categories, between the first broadcast network of a given type provided and additional (or duplicate) networks of the same type. The reason for this distinction stems from the widespread duplication of programming provided by stations of the same type. When this occurs, we suspect that consumers will value on its merits the first available program network of a given type, but will not value as highly (or will simply value differently) each additional network of the same type. ${ }^{183}$

For each of six types of networks available in any cable market, both over-the-air and on cable, we distinguish between the 'first' such network available and 'additional' such networks. ${ }^{184}$ Given this structure, SMFIR0 and SMFIRB measure the number of first networks available over-theair and on cable, respectively, in the market and OFIR0 and OFIRB measures the number of

\footnotetext{
180 See the Data section for a description of the Significantly Viewed Criterion.

181 Some may disagree with the inclusion of Fox with the other, 'Big Three', television networks. My point here is to just suggest that each has value corresponding to the programming provided on the network and not to finely differentiate between these values.

182 More recently, some of these independent stations have affiliated with one of the two new broadcast networks - Warner Brothers and Paramount. Regardless, it is tacitly assumed that neither of these new networks provided sufficient programming or brand identity to warrant individual recognition.

183 Networks often provide multiple networks of a given type due to Must-Carry requirements of existing cable regulations. In such situations, if a system is within the broadcast area (as measured by the Grade B contour) of two networks of the same type, the station must provide carriage for both networks. As a consequence, systems midway between two large metropolitan areas (like Stanford) tend to carry greater numbers of broadcast networks than systems of comparable size in the suburbs of a single such areas. These rules are currently being challenged in Federal Court.

184 The six types of networks are stations affiliated with ABC, CBS, NBC, and FOX, independent stations, and
} 
'additional' (or 'O'ther than 'FIR'st) networks available over-the-air and on cable. In the estimation, we define the incremental service provided by cable by subtracting each of the over-the-air magnitudes from their cable counterparts, creating SMFIRI and OFIRI, the number of incremental 'first' and 'additional' networks provided by cable. ${ }^{185}$

The cable and premium programming networks provided on each service offered by cable systems were also given in the Factbook. Unlike for broadcast programming, however, each of these represents a comparative service advantage relative to no cable service and we need only concern ourselves with measuring their presence on cable. To accommodate differences in the value to consumers of different networks, we distinguish between the benefit accruing to consumers from 'most preferred' and 'additional' cable and premium programming networks. 'Most preferred' networks are permitted to impact the demand for cable on an individual basis, while 'additional' networks are aggregated and permitted to impact demand on a common basis. For each of cable and premium programming networks, the 'Most Preferred' networks were those networks available to the greatest number of subscribers as of December, 1992. These lists were given earlier in Tables 2-1(a) and 2-1(b). The empirical specification presented in this chapter limits the set of 'Most Preferred' networks to the top five networks on each of these lists. ${ }^{186,187}$ The remaining networks not specifically so accommodated were then counted and their number permitted to enter the specification in levels. ${ }^{188}$

The final category of programming provided by cable systems, implicitly given by the

public/educational stations.

185 While we have elected to aggregate measures of broadcast programming desirability into the four variables described above, several other aggregated and disaggregated specifications were considered. Among these included specifications which (1) aggregated all stations into a single measure, (2) permitted impacts for network stations to differ from independent and public stations, and (3) completely disaggregated the six classes of stations into measures which permitted an individual (first) and common (other) impact within each class. There appeared to be significant explanatory gains to disaggregating stations into a first and an other category relative to a single measure. Beyond that, the results for the network vs. Nonnetwork disaggregation were quite similar and the results for the complete disaggregation were quite noisy.

186 For cable programming networks, these are ESPN, CNN, WTBS, USA, and The Discover Channel. For premium programming networks, these are HBO, Showtime, Disney, Cinemax, and The Movie Channel. To connoisseurs of cable, this list represents a Who's Who of cable and premium programming networks.

187 For cable programming networks, we also consider permitting individual impacts to the next five and next fifteen most popular channels. These are given in Table 2-1.

${ }_{188}$ As was the case for broadcast programming networks, other specifications were also considered. Among these were specifications which (1) aggregated the total number of satellite networks provided on any cable service, (2) aggregated the total number of top-5, top-10, top-20, and total cable programming networks provided on any cable service, and (3) disaggregated networks to each of the top-10, top-20, and top-40 networks. 
Factbook, are Public, Educational, and Government (PEG) channels. The number of such channels is inferred from the observed channel capacity less the total broadcast, cable, and premium programming networks provided by the system and is given by OTHCHB. ${ }^{189}$

Because tastes and costs of providing cable television services may differ across markets, we also include demographic characteristics in the specifications of demand, denoted D, and cost, denoted W. Unlike all of the variables considered to this point, some of these variables may impact only one of demand or cost, but not the other. Variables which are modeled to impact both tastes and cost are those variables which measure the strength of the local television market, DMARNK and DMADUM. The Designated Market Area (DMA) is a variable defined by Arbitron to measure the strength of local television markets. It broadly provides a ranking of the number of television households within each Metropolitan Statistical Area in the U.S. DMARNK is this ranking and DMADUM is a dummy variable indicating if the local market was outside the top-100 markets for which Arbitron collects data. Each of these variables could impact demand (or willingness-to-pay for cable service) by proxying for alternative sources of entertainment in the local system area. Each could also impact cost by measuring heterogeneity in costs associated with providing service in densely populated areas.

We also have available several variables which are thought to impact only the demand for cable television service(s). Most obvious among these is the median income in each cable market, YMED. Other demographic variables measure the percentage of the population within each market that shares certain characteristics likely to impact demand. First among these is the percentage of the population between ages 5 and 18, defined as A518. To the extent that households with children are more likely to subscribe to cable, this should positively impact the demand for all such services. The percentage of the population with any college experience (COL) is the other such variables, included as we expect that there might be structural differences in tastes for cable between those with college experience.

We finally have available several variables which are thought to impact only the marginal cost of providing cable television service(s). Three variables are used. The first, Homes Passed (HP), capture differences in marginal cost arising from potential scale economies in the provision of cable

189 OTHCHB stands for 'Oth'er 'Ch' annels on 'B' asic. 
service. Noam (1985) found evidence of economies of scale in the number of homes passed by a cable system, channel capacity, and also in the density of homes per mile. Another measure, the number of subscribers served by a Multiple System Operator (MSO) captures differences in Marginal cost arising from heterogeneity in bargaining power in the input (programming) market. Chipty (1995), in an analysis of the impact of horizontal integration in the cable television industry, found evidence of such bargaining power. ${ }^{190}$ Along similar lines, we include a dummy variable if a system has vertical ties to programming networks. Both Chipty (199X) and Waterman (1996) have found that systems tend to favor affiliated networks, at least in part because they can purchase programming from their affiliates at its true (and very low) marginal cost.

One final variable is used in the analysis. Because of the structure of the 1992 Cable Act, franchise authorities were required to certify prior to regulating the cable system in their franchise area. $^{191}$ To reflect that only some systems elected to certify, we include a dummy variable, CERT, indicating whether or not a system provided cable service in a market where the franchise authority elected to certify, into the pricing equation defined by (2-12). ${ }^{192}$

\footnotetext{
190 In California, the author has seen price lists with input price ranges of greater than $\$ 0.10$ per subscriber for individual channels.

191 See Crawford (1997) for more details.

192 Because tastes for and costs of providing cable service may differ across regions and over time, we also include several control variables into some specifications of demand and cost. To control for heterogeneity in tastes across regions, we define four region dummies according to the four U.S. Census Regions, each defined with the prefix REG. Similarly, to control for changes in the cost of and tastes for cable service over time, we include a set of year dummies matching the years used in the Post-Act analysis.
} 


\section{Appendix B - Model Derivation}

This appendix describes the inversion of the market share functions to solve for unobserved quality, $\delta_{\mathrm{s}}$, as a function of the observables and parameters of the demand model. The log share ratio for each service offered in the market can be described by the following double sum where $j \subset s$ describes those combinations of services containing service $\mathrm{s}$ and, for each such combination, $\mathrm{j}$, $s \subset j$ enumerates their component services. ${ }^{193}$

$$
\begin{aligned}
\log \left(\frac{W_{s}}{w_{0}}\right) & =\log \left(\sum_{j \subset s} e^{\left.X_{j}^{\prime} \beta+D^{\prime} \gamma+\alpha p_{j}+\eta_{j}\right)}\right)=\log \left(\sum_{j \subset s} e^{\left(\sum_{s \supset j} X_{s} \beta+D^{\prime} \gamma+\alpha p_{s}+\eta_{s}\right)}\right) \quad s \in S_{n} \\
& =\log \left(\sum_{j \subset s} e^{\left(\sum_{s \supset j} V_{s}\right)}\right) \quad s \in S_{n}
\end{aligned}
$$

where we've exploited the definition of $\mathrm{V}_{\mathrm{s}}$ in the last equality above.

While the power in the exponent term has been simplified, we still remain with a function nonlinear in the unobserved quality for each service, $\eta_{\mathrm{s}} \cdot{ }^{194}$ Further simplifications, however, are available. To adequately explain the process, however, requires some additional notation.

Recall $w_{s}=\sum_{j s s} w_{j}$ equals the market share of all products containing service s. The comparable market share for all cable products excluding s, denoted $w_{-}$, can also be defined and is given by $w_{\bar{s}}=\sum_{j \in s, j \neq \varnothing} w_{j} \quad$ It is easy to see that all the combinations of cable service either include or exclude $\mathrm{s}$, and therefore belong to either $\mathrm{w}_{\mathrm{s}}$ or $w_{s}$, regardless of the service being considered. This property proves very useful in deriving the estimating equations.

Focusing first on the Expanded Basic and Premium Services offered in the market, indexed by $\mathrm{r}, \log \left(\mathrm{w}_{\mathrm{r}} / \mathrm{w}_{0}\right)$ can be written to exploit the fact that all combinations of services in $\mathrm{w}_{\mathrm{r}}$ provide both Basic Service, b, as well as, by definition, service r: ${ }^{195}$

193 For example, $j \subset H B O$ would contain all the combinations of services that contain $\mathrm{HBO}$, including $\{\mathrm{Basic}, \mathrm{HBO}\}$, $\{$ Basic, HBO, Disney\}, \{Basic, HBO, Showtime\}, etc. For each of these combinations, $s \subset j$ enumerates their component services. Thus for $\{$ Basic, $\mathrm{HBO}$, Showtime $\}, s \subset\{$ Basic, $H B O$, Showtime $\}=$ each individual service: $\{$ Basic $\},\{\mathrm{HBO}\}$, and $\{$ Showtime $\}$.

194 Recall $\mathrm{V}_{\mathrm{s}}=\mathrm{V}_{\mathrm{s}}\left(\mathrm{X}_{\mathrm{s}}, \mathrm{D}, \mathrm{p}_{\mathrm{s}}, \eta_{\mathrm{s}}\right)$.

195 Since the market share for the HBO is given by the sum of all service combinations which include it, they would be of the form $\{$ Basic Service, HBO, Showtime $\}$, \{Basic Service, HBO, Disney $\}$, and $\{$ Basic Service, HBO, Showtime, Disney $\}$. By 


$$
\begin{aligned}
\log \left(\frac{w_{r}}{w_{0}}\right) & =\log \left(\sum_{j \subset r} e\left(\sum_{r \supset j} V_{r}\right)\right)=\log \left(\sum_{j \subset r^{\prime}} e^{\left[V_{b}+V_{r}+\left(\sum_{r^{\prime} \supset j, r^{\prime} \neq b, r^{\prime}} V_{r^{\prime}}\right)\right]}\right) \\
& =V_{b}+V_{r}+\log \left(\sum_{j \subset r^{\prime}} e^{\left(\sum_{r^{\prime} \supset j, r^{\prime} \neq b, r^{\prime}} V_{r^{\prime}}\right)}\right)
\end{aligned}
$$

where we were able to factor $\mathrm{V}_{\mathrm{b}}+\mathrm{V}_{\mathrm{r}}$ out of each term due to its presence on all products, $r \supset j$, included in $\mathrm{w}_{\mathrm{r}}$.

The above equation is critical to the understanding of the decomposition of market shares to mean utilities required in the estimation. It states that the log ratio of market shares for service $r$ equals the mean utility to Basic Services + Service $r$ (each of which is offered on all products containing r) plus a term capturing the impact to mean utility of the combination of incremental services offered beyond $\mathrm{b}$ and $\mathrm{r}$ alone and indexed by $\mathrm{r}$ '.

A similar decomposition may be made for the log market share for all cable products excluding r, $w_{-}$:

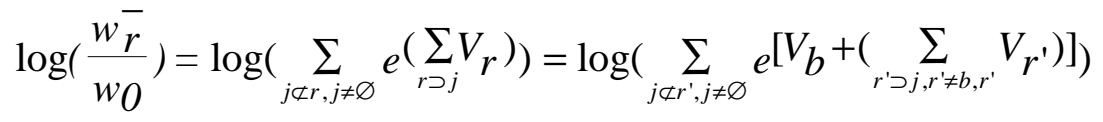

$$
\begin{aligned}
& =V_{b}+\log \left(\sum_{j \not \subset r^{\prime}} e^{(} \sum_{r^{\prime} \supset j, r^{\prime} \neq b, r^{\prime}} V_{r^{\prime}}\right)
\end{aligned}
$$

Notice the similarity to (B-1). Terms common to both sets of equations include the mean utility of basic service, $\mathrm{V}_{\mathrm{b}}$, as well as that of incremental services beyond $\mathrm{b}$ and $\left.\mathrm{r}, \log \left(\sum_{j \notin r^{\prime}} e_{r^{\prime} \supset j, r^{\prime} \neq b, r^{\prime}} V_{r^{\prime}}\right)\right)$.

Taking the difference in these two equations yields the estimating equation for each of the Expanded Basic and Premium Services offered in market n. This was given in the text as equations (2-6).

$$
\begin{aligned}
\log \left(\frac{w_{r}}{w_{0}}\right)-\log \left(\frac{w_{r}}{w_{0}}\right) & =\left[V_{b}+V_{r}+\log \left(\sum_{j \subset r} e^{\left(\sum_{r^{\prime} \supset j, r^{\prime} \neq b, r} V_{r^{\prime}}\right)}\right)\right]-\left[V_{b}+\log \left(\sum_{j \subset r} e^{\left(\sum_{r^{\prime} \supset j, r^{\prime} \neq b, r} V_{r^{\prime}}\right)}\right)\right] \\
\text { or } \log \left(\frac{w_{r}}{w_{r}^{-}}\right) & =X_{r}^{\prime} \beta+D^{\prime} \gamma+\alpha p_{r}+\eta_{r}
\end{aligned}
$$

where the last transformation exploits the both the presence of $\mathrm{w}_{0}$ in the denominator of both dependent variables and the definition of $\mathrm{V}_{\mathrm{r}}$. As can be seen, the log ratio of market share of service

construction, Basic Service and HBO are included in each of these products. 
$\mathrm{r}, \mathrm{w}_{\mathrm{r}}$, to the market share of service not-r, $w_{\bar{r}}$, equals the attributes of just that service. Since equation (2-9) is linear in $\eta_{\mathrm{r}}$, estimation by instrumental variables is now possible.

Solving for the market share of Basic service is somewhat more complicated. From the log share equation for basic service, we have

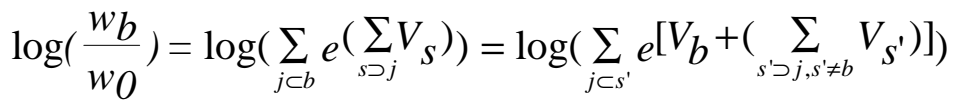

$$
\begin{aligned}
& =V_{b}+\log \left(\sum_{j \subset s^{\prime}} e^{\left(\sum_{s^{\prime} \supset j, s^{\prime} \neq b} V_{s^{\prime}}\right)}\right)
\end{aligned}
$$

If we were to follow the method developed above for each service, $r \in R_{n}$, we would continue by defining the $\log$ market share for service not-b, $\log \left(w_{\bar{b}} / w_{0}\right)$, and subtract this from $\log \left(w_{b} / w_{0}\right)$ to identify $\mathrm{V}_{\mathrm{b}}$. The market share for not-b, $w_{\bar{b}}$, however, is just not-cable, or the outside good, $\mathrm{w}_{0}$, which does not share the incremental utility term above, $\left.\log \left(\sum_{j \in s^{\prime}} e_{s^{\prime} \supset j, s^{\prime} \neq b} V_{s^{\prime}}\right)\right)$. As a consequence, instead we must exploit further the structure of choices to simplify this term.

To demonstrate this simplification, we consider a market where the system offers Basic Service and two additional services, HBO and Disney, denoted by the indices $\mathrm{h}$ and $\mathrm{d}$. In this case, the set of services, $S_{n}$, is given by $\{b, h, d\}$ implying the possible combinations of those services, and the consumer choice set, $J_{n}$, is given by $\{\{\varnothing\},\{b\},\{b, h\},\{b, d\},\{b, h, d\}\}$. Given this structure, the incremental utility term describing the utility to all Expanded Basic and Premium Services, given by $\left.\log \left(\sum_{j \in s^{\prime}} e_{s^{\prime} \supset, s^{\prime} \neq b} V_{s^{\prime}}\right)\right)$ above, simplifies to

$$
\log \left(\sum_{j \propto s^{\prime}} e^{\left(\sum_{s^{\prime} \supset j, s^{\prime} \neq b} V_{s^{\prime}}\right)}\right)=\log \left(1+e^{V_{h}}+e^{V_{d}}+e^{V_{h}+V_{d}}\right) .
$$

The term in the parentheses can then be factored to yield $\log \left[\left(1+e^{V_{h}}\right)\left(1+e^{V_{d}}\right)\right]$.

For the case of a general number of services, it can easily be shown that this example above generalizes naturally to the form:

$$
\log \left(\sum_{j \not s^{\prime}} e^{\left(\sum_{s^{\prime} \supset j, s^{\prime} \neq b} V_{s^{\prime}}\right)}\right)=\log \left[\left(1+e^{V_{r_{1}}}\right)\left(1+e^{V_{r_{2}}}\right) \cdots\left(1+e^{V_{N_{R}}}\right)\right]
$$

Equation (B-1) implied that each of the $e^{V_{r}}=\log \left(w_{r} / w_{-}\right)$. Substituting this into (B-2), this yields the corresponding estimating equation for Basic service: 


$$
\begin{aligned}
& \log \left(\frac{w_{b}}{w_{0}}\right)=\log \left(\sum_{j \subset b} e^{\left.\left(\sum_{s \supset j} V_{s}\right)\right)}\right. \\
& =\log \left(\sum_{j \subset s^{\prime}} e^{\left.\left[V_{b}+\left(\sum_{s^{\prime} \supset j, s^{\prime} \neq b} V_{s^{\prime}}\right)\right]\right)}\right.
\end{aligned}
$$

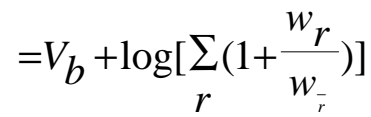

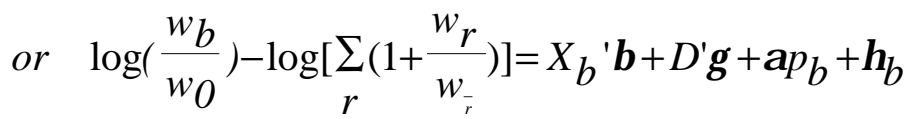

where third equality exploits the definition of $\mathrm{V}_{\mathrm{b}}$. This is equation (2-7) given in the text. 


\section{Bibliography}

Beil, Richard O., P.T.Dazzio, R.B.Ekelund, Jr., and J.D.Jackson, "Competition and the Price of Municipal Cable Television Services: An Empirical Study," Journal or Regulatory Economics, v6 (1993): 401-415.

Besen, S. M. and R. Crandall, "The Deregulation of Cable Television," Law and Contemporary Problems, (1981): 79-124.

Berry, S.T., "Estimating Discrete-Choice Models of Product Differentiation," Rand Journal of Economics, v25n2 (Summer 1994): 242-262.

Berry, S., J. Levinsohn, and A. Pakes, "Automobile Prices in Market Equilibrium," NBER Working Paper No. 4264, (1992).

Bloch, H. and M. Wirth, The Demand for Pay Services on Cable Television," Information Economics and Policy, v1 (1984): 311-332.

Burstein, M. L., "The Economics of Tie-In Sales," Review of Economics and Statistics, v42 (February 1960): 68-73.

The Cable Television Consumer Protection and Competition Act of 1992, Pub. L. No. 102-385, 106 Stat. 1460. (codified as amended at 47 U.S.C. $§ 533$ ).

Carnevale, M. L. and M. Robichaux, “The Deal Collapses: Will the FCC's Cable Rate Cuts Slow Traffic on Information Superhighway?," The Wall Street Journal, 25 February 1994, p. B-1.

Carroll, K. A. and D. J. Lamdin, "Measuring Market Response to Regulation of the Cable TV Industry," Journal of Regulatory Economics, v5 (1993): 385-399.

Chipty, T. "Vertical Integration and its Effects on Unintegrated Rivals: Evidence form the Cable Television Industry," mimeo, Ohio State University (1993).

Chipty, T. "Horizontal Integration for Bargaining Power: Evidence from the Cable Television Industry," Journal of Economics \& Management Strategy, v4n2 (Summer 1995): 375-397.

Code of Federal Regulations, Section 47, Part 75.

Comanor, W. S. and B. M. Mitchell, " Cable Television and the Impact of Regulation," The Bell Journal of Economics and Management Science, v2n1 (Spring 1971): 154-212.

Crandall, R.W. and H. Furchtgott-Roth, Cable TV: Regulation or Competition, (Washington, D.C.: 
The Brookings Institution, 1996).

Demsetz, H., "Why Regulate Utilities?", Journal of Law and Economics, Vol. 11 (1968), pp. 55-65.

Ellickson, B. "Hedonic Theory and the Demand for Cable Television," American Economic Review, v69n1 (March 1979): 183-189.

Federal Communications Commission, Competition, Rate Deregulation and the Commission's Policies Relating to the Provision of Cable Television Service, FCC Mass Media Docket No. 89-600 (July 31, 1990), Washington, D.C.

Federal Communications Commission, Report and Order, FCC Mass Media Docket No. 92-259, 8 FCC Rcd. 2965 (March 29, 1993), Washington, D.C.

Federal Communications Commission, Report and Order and Further Notice of Proposed Rulemaking, FCC Mass Media Docket No. 92-266, 58 Federal Register 29736 (May 21, 1993), Washington, D.C.

Federal Communications Commission, Second Order on Reconsideration, Fourth Report and Order, and Fifth Notice of Proposed Rulemaking, FCC Mass Media Docket No. 92-266, 59 Federal Register 17943 (April 15, 1994), Washington, D.C.

Ferguson, Tim W., "Business World: Viewers Hurt as Cable Gets a Double Dose," The Wall Street Journal, 14 June 1994, p. A-15.

Fisher, F. "Community Antenna Television Systems and the Regulation of Television Broadcasting," American Economic Review, v56 (May, 1966): 320-29.

Fisher, F. and V. E. Ferrall, Jr., "Community Antenna Television Systems and Local Television Station Audience," Quarterly Journal of Economics, v80 (May 1966): 227-51.

Foster, Eugene S., Understanding Broadcasting, 2nd ed., (Reading, MA: Addison-Wesley Publishing Group, 1982).

General Accounting Office, National Survey of Cable Television Rates and Services (August 1989).

General Accounting Office, Follow-Up National Survey of Cable Television Rates and Services (June 1990).

General Accounting Office, 1991 Survey of Cable Television Rates and Services (July 1991) GAO RCED 91-195.

Green, James Harry, ed., Dow-Jones Irwin Handbook of Telecommunications. (Homewood, IL: Dow-Jones Irwin, 1986). 
Hazlett, Thomas W., "Competition vs. Franchise Monopoly in Cable Television," Contemporary Policy Issues, v4n2 (1986): 80-97.

Hazlett, Thomas W., "Duopolistic Competition in Cable Television: Implications for Public Policy," Yale Journal on Regulation, v7n65 (1990), pp.65-148.

Hazlett, Thomas W., "The Demand to Regulate Franchise Monopoly: Evidence from CATV Rate Regulation in California," Economic Inquiry, v29 (April, 1991): 275-296.

Hazlett, Thomas W., "Regulatory Chokehold: Why Your Cable Bill is So High," The Wall Street Journal, 24 September 1993, p. A-10.

Hazlett, Thomas W., "Free Markets for Telecom: How Home-Shopping Became King of Cable," The Wall Street Journal, 14 July 1994, p. A-10.

Hazlett, Thomas W., "How Washington 'Saved' Us from Cable," The Wall Street Journal, 23 March 1995 , p. A-14.

Jaffe, Adam B. and D. M. Kanter, "Market Power of Local Cable Television Franchises: Evidence From the Effects of Deregulation," RAND Journal of Economics, v21n2 (Summer, 1990): 226-234.

Johnson, Leland L., Toward Competition in Cable Television, (Cambridge, MA: MIT Press, 1994)

Kahn, Alfred E., The Economics of Regulation: Principles and Institutions, (Cambridge, MA: MIT Press, 1991)

Levin, Sanford L., and John B. Meisel, "Cable Television and Competition: Theory, Evidence, and Policy," Telecommunications Policy, (December, 1991).

Levy, Melissa, "Marketing and Media: FCC Will Toughen Rules If Necessary on Cable-TV Rates," The Wall Street Journal, 29 September 1993, p. A-13.

MacAvoy, Paul W., "Tobin's q and the Cable Industry's Market Power," Appendix 5 to the United States Telephone Association Comments to the FCC in CC Docket 89-600 (1990).

Markovits, R. S., "Tie-ins, Reciprocity, and the Leverage Theory," The Yale Law Journal, v76 (1960): 1397-1472.

Mayo, J.W. and Y. Otsuka, "Demand, Pricing and Regulation: Evidence from the Cable TV Industry," Rand Journal of Economics, v22n3 (Autumn, 1991): 396-410.

Noam, Eli M., "Economics of Scale in Cable Television: A Multiproduct Analysis," in Noam, Eli M., 
ed., Video Media Competition: Regulation, Economics, and Technology. (New York: Columbia University Press, 1985).

Noll, R.G., M.J. Peck, and J.J. McGowan, Economic Aspects of Television Regulation. (Washington, D.C.: The Brookings Institution, 1973).

Owen, B.M. and P.R. Greenhalgh, "Competitive Considerations in Cable Television Franchising," Contemporary Policy Issues, v4 (April, 1986): 69-79.

Owen, B.M. and S. S. Wildman, Video Economics, (Cambridge, MA: Harvard University Press, 1992).

Pacey, P. L., "Cable Television in a Less Regulated Market," Journal of Industrial Economics, v34n1 (September, 1985): 81-91.

Park, R. E., "Prospects for Cable in the 100 Largest Television Markets," Bell Journal of Economics and Management Science, (Spring, 1972): 130-150.

Prager, R. A., "The Effects of Deregulating Cable Television: Evidence from the Financial Markets," Journal of Regulatory Economics, v4 (1992): 347-363.

Prager, R.A., "Firm Behavior in Franchise Monopoly Markets: The Case of Cable Television," Unpublished Ph.D. Dissertation, Massachusetts Institute of Technology, (1986).

Robichaux, M., "Scrambled Picture: How Cable-TV Firms Raised Rates in Wake of Law to Curb Them; The 1992 Act was Drawn Up Without Industry Help, and FCC Was Hobbled but Some Consumers Benefit," The Wall Street Journal, 28 September 1993, p. A-1.

Rubinovitz, R., "Market Power and Price Increases for Basic Cable Service Since Deregulation," Rand Journal of Economics, v24n1 (Spring 1993): 1-18.

Small, K. and H. Rosen, "Applied Welfare Economics with Discrete Choice Models," Econometrica, v49n1 (January, 1981): 105-130.

Spence, M. and B. Owen, "Television Programming, Monopolistic Competition, and Welfare," Quarterly Journal of Economics, v91 (1975): 103-126.

Silverman, B. Density Estimation for Statistics and Data Analysis, (London: Chapman and Hall, 1986)

Stern, S., "Product Demand in Pharmaceutical Markets," mimeo., Stanford University, (1994).

Television Digest, Inc., Cable and Station Coverage Atlas 1987, (Washington, D.C.: Television Digest, Inc., 1987) 
Trajtenberg, M., "The Welfare Analysis of Product Innovations, with an Application to Computed Tomography Scanners." Journal of Political Economy, v97 (1989): 444-479.

Waterman, D. H., "Local Monopsony and 'Free Riders' in Information Industries," mimeo, University of Southern California, March, 1992.

Waterman, D. H. and A. A. Weiss, "The Effects of Vertical Integration between Cable Television Systems and Pay Cable Networks," Journal of Econometrics, v72 (1996): 357-395.

Webster, J.G. and J.J. Wakshlag, "A Theory of Television Program Choice," Communication Research, v10n4 (October, 1983): 430-446.

Williamson, O., "Franchise Bidding for Natural Monopolies -- in General and with Respect to CATV," Bell Journal of Economics, v7 (Spring, 1976): 73-104.

Zupan, M. A., "The Efficacy of Franchise Bidding Schemes in the Case of Cable Television : Some Systematic Evidence," Journal of Law and Economics, v32 (October, 1989a): 401-456.

Zupan, M. A., "Cable Franchise Renewals : Do Incumbent Firms Behave Opportunistically," Rand Journal of Economics, v20n4 (Winter, 1989b): 473-482.

Zupan, M. A., "A Test for Regulatory Lag and the Role Played by Periodic Contract Renewals in Mitigating Such Lag in Local Cable Franchise Relationships" Journal of Regulatory Economics, v1 (1989c): 1-20. 
Table 2-2(a). Sample Statistics, Panel Data

Programming and Services

\begin{tabular}{|c|c|c|c|c|c|c|c|c|c|c|}
\hline & \multicolumn{5}{|c|}{ 1988-1991 } & \multicolumn{5}{|c|}{ 1993-1995 } \\
\hline Variable & Obs & Mean & Std Dev & Min & Max & Obs & Mean & Std Dev & Min & Max \\
\hline Channel Capacity & 344 & 32.66 & 8.44 & 12 & 62 & 344 & 35.66 & 10.91 & 12 & 110 \\
\hline Total Cable Programming Nets. & 344 & 11.82 & 5.06 & 1 & 25 & 344 & 13.95 & 5.65 & 3 & 30 \\
\hline Top-5 Cable Programming Nets. & 344 & 4.30 & 0.94 & 0 & 5 & 344 & 4.46 & 0.76 & 1 & 5 \\
\hline Top-10 Cable Programming Nets. & 344 & 6.50 & 2.02 & 0 & 10 & 344 & 7.30 & 1.85 & 1 & 10 \\
\hline Top-20 Cable Programming Nets. & 344 & 9.76 & 4.04 & 1 & 20 & 344 & 11.22 & 4.10 & 2 & 20 \\
\hline Top-40 Cable Programming Nets. & 344 & 10.49 & 4.76 & 1 & 24 & 344 & 12.31 & 5.15 & 2 & 26 \\
\hline Services Offered & & & & & & & & & & \\
\hline Any Expanded Basic Services & 344 & $1.7 \%$ & $13.1 \%$ & 0 & 1 & 344 & $17.4 \%$ & $38.0 \%$ & 0 & 1 \\
\hline One Expanded Basic Service & 344 & $1.5 \%$ & $12.0 \%$ & 0 & 1 & 344 & $9.6 \%$ & $29.5 \%$ & 0 & 1 \\
\hline Two Expanded Basic Services & 344 & $0.3 \%$ & $5.4 \%$ & 0 & 1 & 344 & $7.8 \%$ & $26.9 \%$ & 0 & 1 \\
\hline Total Basic Services & 344 & 1.02 & 0.16 & 1 & 3 & 344 & 1.25 & 0.59 & 1 & 3 \\
\hline Total Services & 344 & 3.19 & 1.42 & $\underline{2}$ & 10 & 344 & 3.42 & 1.78 & $\underline{2}$ & 9 \\
\hline $\begin{array}{l}\text { Programming by Service Category } \\
\text { Basic Service }\end{array}$ & & & & & & & & & & \\
\hline Top-5 Cable Prog. Nets. & 344 & 4.26 & 1.01 & 0 & 5 & 344 & 3.99 & 1.27 & 0 & 5 \\
\hline Top-10 Cable Prog. Nets. & 344 & 6.42 & 2.07 & 0 & 10 & 344 & 6.51 & 2.11 & 0 & 10 \\
\hline Top-20 Cable Prog. Nets. & 344 & 9.59 & 4.06 & 1 & 20 & 344 & 9.89 & 3.76 & 0 & 20 \\
\hline Total Cable Prog. Nets. & 344 & 11.62 & 5.05 & 1 & 25 & 344 & 12.30 & 5.10 & 0 & 30 \\
\hline Expanded Basic Service 1 & & & & & & & & & & \\
\hline Top-5 Cable Prog. Nets. & 5 & 2.80 & 0.36 & 0 & 4 & 60 & 2.15 & 1.31 & 0 & 5 \\
\hline Top-10 Cable Prog. Nets. & 5 & 5.00 & 0.62 & 0 & 7 & 60 & 3.73 & 2.69 & 0 & 10 \\
\hline Top-20 Cable Prog. Nets. & 5 & 10.60 & 1.26 & 0 & 13 & 60 & 6.43 & 4.81 & 0 & 20 \\
\hline Total Cable Prog. Nets. & 5 & 13.00 & 1.57 & 0 & 17 & 60 & 7.87 & 6.63 & 0 & 29 \\
\hline Expanded Basic Service 2 & & & & & & & & & & \\
\hline Top-5 Cable Prog. Nets. & 1 & 1.00 & 0.05 & 0 & 1 & 27 & 1.15 & 0.95 & 0 & 3 \\
\hline Top-10 Cable Prog. Nets. & 1 & 3.00 & 0.16 & 0 & 3 & 27 & 1.70 & 1.35 & 0 & 5 \\
\hline Top-20 Cable Prog. Nets. & 1 & 4.00 & 0.22 & 0 & 4 & 27 & 2.67 & 2.06 & 0 & 6 \\
\hline Total Cable Prog. Nets. & 1 & 4.00 & 0.22 & 0 & 4 & 27 & 3.56 & 2.61 & 0 & 7 \\
\hline
\end{tabular}




\begin{tabular}{|c|c|c|c|c|c|c|c|c|}
\hline \multicolumn{9}{|c|}{$\begin{array}{l}\text { Table 2-2(b). Sample Statistics, Panel Data } \\
\text { Top } 20 \text { Cable Programming Networks - By Service }\end{array}$} \\
\hline & \multicolumn{4}{|c|}{ 1988-1991 } & \multicolumn{4}{|c|}{ 1993-1995 } \\
\hline Network & Basic & ExpBas1 & ExpBas2 & Offered & Basic & ExpBas1 & ExpBas2 & Offered \\
\hline ESPN & $97.1 \%$ & $0.6 \%$ & $0.0 \%$ & $97.7 \%$ & $93.9 \%$ & $5.2 \%$ & $0.0 \%$ & $99.1 \%$ \\
\hline $\mathrm{CNN}$ & $91.6 \%$ & $0.9 \%$ & $0.0 \%$ & $92.4 \%$ & $80.5 \%$ & $10.5 \%$ & $2.0 \%$ & $93.0 \%$ \\
\hline WTBS & $97.4 \%$ & $0.6 \%$ & $0.0 \%$ & $98.0 \%$ & $86.6 \%$ & $4.4 \%$ & $4.1 \%$ & $95.1 \%$ \\
\hline USA & $78.5 \%$ & $1.5 \%$ & $0.0 \%$ & $79.9 \%$ & $75.9 \%$ & $9.9 \%$ & $0.3 \%$ & $86.0 \%$ \\
\hline DISC & $61.3 \%$ & $0.6 \%$ & $0.3 \%$ & $62.2 \%$ & $62.5 \%$ & $7.6 \%$ & $2.6 \%$ & $72.7 \%$ \\
\hline Top-5 & 4.26 & 0.04 & 0.00 & 4.30 & 3.99 & 0.38 & 0.09 & 4.46 \\
\hline NICK & $51.5 \%$ & $0.9 \%$ & $0.3 \%$ & $52.6 \%$ & $53.2 \%$ & $5.2 \%$ & $0.0 \%$ & $58.4 \%$ \\
\hline NASH & $88.1 \%$ & $1.2 \%$ & $0.0 \%$ & $89.2 \%$ & $80.2 \%$ & $9.6 \%$ & $1.2 \%$ & $91.0 \%$ \\
\hline TNT & $27.0 \%$ & $0.0 \%$ & $0.0 \%$ & $27.0 \%$ & $62.2 \%$ & $8.7 \%$ & $2.0 \%$ & $73.0 \%$ \\
\hline MTV & $32.3 \%$ & $1.5 \%$ & $0.0 \%$ & $62.2 \%$ & $30.8 \%$ & $3.8 \%$ & $0.3 \%$ & $34.9 \%$ \\
\hline FAMILY & $89.8 \%$ & $0.6 \%$ & $0.3 \%$ & $90.7 \%$ & $83.1 \%$ & $7.8 \%$ & $2.0 \%$ & $93.0 \%$ \\
\hline Top-10 & 6.42 & 0.07 & 0.01 & 6.50 & 6.51 & 0.65 & 0.13 & 7.30 \\
\hline CSPAN & $15.1 \%$ & $0.3 \%$ & $0.0 \%$ & $15.7 \%$ & $22.7 \%$ & $2.0 \%$ & $0.0 \%$ & $24.7 \%$ \\
\hline LIFE & $28.2 \%$ & $0.9 \%$ & $0.0 \%$ & $29.1 \%$ & $29.9 \%$ & $6.4 \%$ & $0.3 \%$ & $36.6 \%$ \\
\hline A_E & $24.7 \%$ & $1.5 \%$ & $0.3 \%$ & $26.5 \%$ & $34.6 \%$ & $4.4 \%$ & $0.0 \%$ & $39.0 \%$ \\
\hline WEATHR & $25.3 \%$ & $0.6 \%$ & $0.0 \%$ & $25.9 \%$ & $26.7 \%$ & $5.8 \%$ & $1.5 \%$ & $34.0 \%$ \\
\hline HEAD & $20.1 \%$ & $0.9 \%$ & $0.0 \%$ & $20.9 \%$ & $18.6 \%$ & $8.7 \%$ & $0.6 \%$ & $27.9 \%$ \\
\hline CNBC & $9.6 \%$ & $1.2 \%$ & $0.0 \%$ & $10.8 \%$ & $9.9 \%$ & $2.0 \%$ & $0.0 \%$ & $11.9 \%$ \\
\hline VH1 & $17.7 \%$ & $1.2 \%$ & $0.0 \%$ & $18.9 \%$ & $19.2 \%$ & $2.3 \%$ & $0.0 \%$ & $21.5 \%$ \\
\hline QVC & $16.0 \%$ & $0.0 \%$ & $0.0 \%$ & $16.0 \%$ & $30.5 \%$ & $0.9 \%$ & $0.0 \%$ & $31.4 \%$ \\
\hline AMC & $8.1 \%$ & $0.3 \%$ & $0.0 \%$ & $8.4 \%$ & $15.1 \%$ & $2.9 \%$ & $0.6 \%$ & $18.6 \%$ \\
\hline WGN & $79.7 \%$ & $0.6 \%$ & $0.0 \%$ & $80.2 \%$ & $73.0 \%$ & $4.1 \%$ & $3.5 \%$ & $80.5 \%$ \\
\hline Top-20 & 9.59 & 0.15 & 0.01 & 9.76 & $\begin{array}{r}9.89 \\
\end{array}$ & 1.12 & 0.21 & 11.22 \\
\hline Obs & 344 & 60 & 27 & 344 & 1 & 1 & 1 & 1 \\
\hline
\end{tabular}




\begin{tabular}{|c|c|c|c|c|c|c|c|c|c|c|}
\hline \multicolumn{11}{|c|}{$\begin{array}{l}\text { Table 2-3(a). Sample Statistics, Panel Data, Systems that Did Not Introduce New Services } \\
\text { Programming and Services }\end{array}$} \\
\hline & \multicolumn{5}{|c|}{$1988-1991$} & \multicolumn{5}{|c|}{$1993-1995$} \\
\hline Variable & Obs & Mean & Std Dev & Min & Max & Obs & Mean & Std Dev 1 & Min & Max \\
\hline Channel Capacity & 281 & 31.71 & 8.60 & 12 & 62 & 281 & 34.04 & 8.12 & 12 & 62 \\
\hline Total Cable Programming Nets. & 281 & 10.74 & 4.31 & 1 & 25 & 281 & 12.61 & 4.95 & 3 & 28 \\
\hline Top-5 Cable Programming Nets. & 281 & 4.26 & 0.96 & 0 & 5 & 281 & 4.44 & 0.75 & 1 & 5 \\
\hline Top-10 Cable Programming Nets. & 281 & 6.16 & 1.89 & 0 & 10 & 281 & 6.98 & 1.77 & 1 & 10 \\
\hline Top-20 Cable Programming Nets. & 281 & 8.87 & 3.41 & 1 & 19 & 281 & 10.22 & 3.55 & 2 & 19 \\
\hline Top-40 Cable Programming Nets. & 281 & 9.44 & 3.98 & 1 & 24 & 281 & 11.01 & 4.43 & 2 & 25 \\
\hline $\begin{array}{l}\text { Programming by Service Category } \\
\text { Basic Service }\end{array}$ & & & & & & & & & & \\
\hline Top-5 Cable Prog. Nets. & 281 & 4.26 & 0.96 & 0 & $5 \|$ & 281 & 4.44 & 0.75 & 1 & 5 \\
\hline Top-10 Cable Prog. Nets. & 281 & 6.16 & 1.89 & 0 & 10 & 281 & 6.98 & 1.77 & 1 & 10 \\
\hline Top-20 Cable Prog. Nets. & 281 & 8.87 & 3.41 & 1 & 19 & 281 & 10.22 & 3.55 & 2 & 19 \\
\hline Total Cable Prog. Nets. & 281 & 10.74 & 4.31 & 1 & 25 & 281 & 12.61 & 4.95 & 3 & 28 \\
\hline
\end{tabular}

Cable/Data/Analyze/Means/panel.xls

Source : Factbook $(1992,1995)$ 


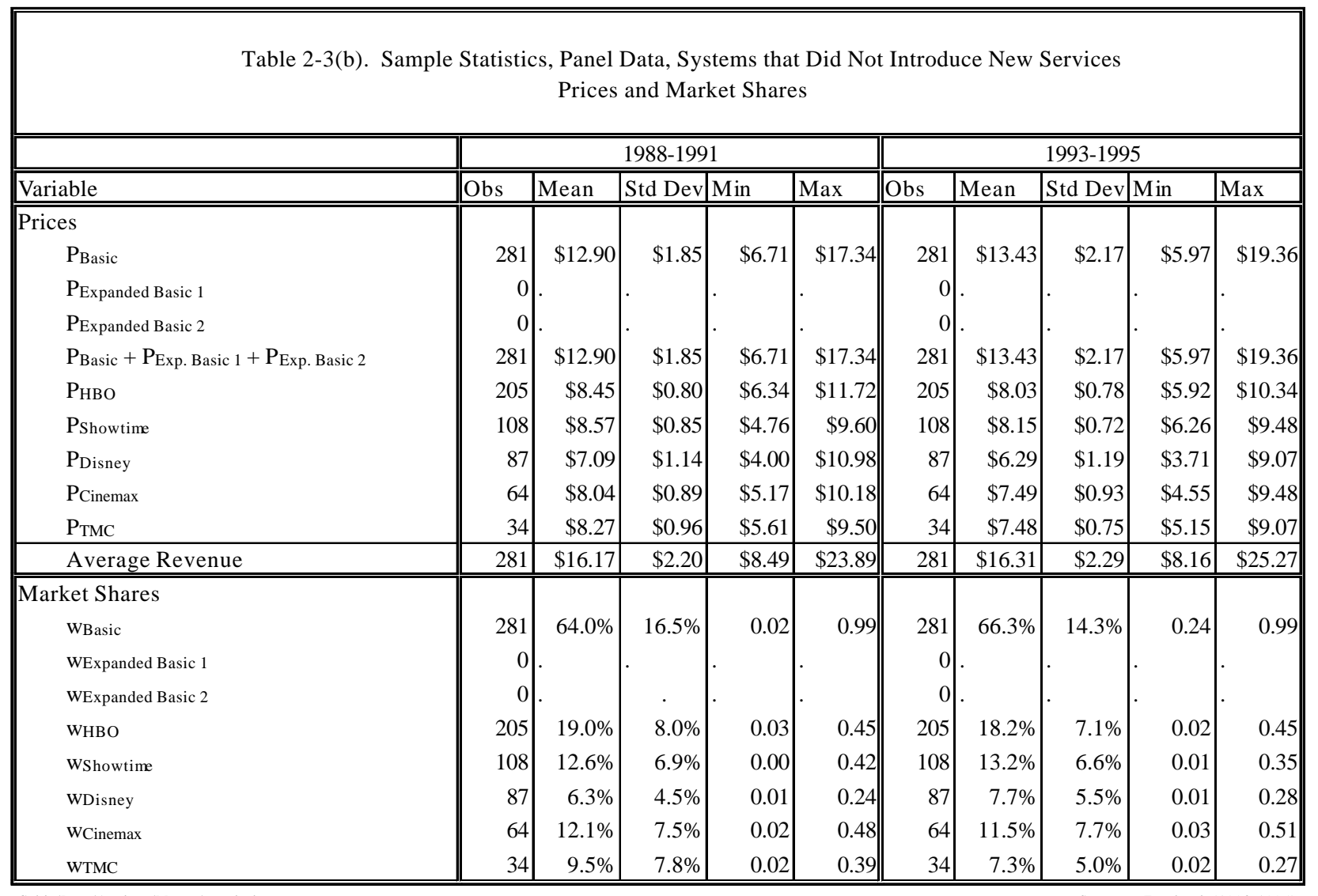

Cable/Data/Analyze/Means/panel.xls 


\begin{tabular}{|c|c|c|c|c|c|c|c|c|c|c|}
\hline \multirow[b]{2}{*}{\begin{tabular}{|r|} 
Variable \\
\end{tabular}} & \multicolumn{5}{|c|}{ 1988-1991 } & \multicolumn{5}{|c|}{$1993-1995$} \\
\hline & Obs & Mean & Std Dev & Min & Max & Obs & Mean & Std Dev & Min & Max \\
\hline Channel Capacity & 31 & \begin{tabular}{l|l}
1 & 37.45
\end{tabular} & 6.53 & 21 & 62 & 31 & 46.39 & 22.89 & 35 & 110 \\
\hline Total Cable Programming Nets. & 31 & 17.03 & 6.80 & 3 & $25 \|$ & 31 & 19.06 & 4.44 & 13 & 30 \\
\hline Top-5 Cable Programming Nets. & 31 & 4.32 & 1.01 & 2 & 5 & 31 & 4.58 & 0.76 & 3 & 5 \\
\hline Top-10 Cable Programming Nets. & 31 & 8.10 & 2.48 & 2 & 10 & 31 & 8.74 & 1.50 & 6 & 10 \\
\hline Top-20 Cable Programming Nets. & 31 & 13.77 & 5.61 & 2 & 20 & 31 & 15.23 & 3.07 & 10 & 20 \\
\hline Top-40 Cable Programming Nets. & 31 & 15.65 & 6.64 & 2 & 23 & 31 & 17.45 & 3.76 & 11 & 26 \\
\hline \multicolumn{11}{|l|}{ Services Offered } \\
\hline Any Expanded Basic Services & 31 & $0.0 \%$ & $0.0 \%$ & 0 & 0 & 31 & $100.0 \%$ & $0.0 \%$ & 1 & 1 \\
\hline One Expanded Basic Service & 31 & $0.0 \%$ & $0.0 \%$ & 0 & 0 & 31 & $100.0 \%$ & $0.0 \%$ & 1 & 1 \\
\hline Two Expanded Basic Services & 31 & $0.0 \%$ & $0.0 \%$ & 0 & 0 & 31 & $0.0 \%$ & $0.0 \%$ & 0 & 0 \\
\hline Total Basic Services & 31 & 1.00 & 0.00 & 1 & $1 \|$ & 31 & 2.00 & 0.00 & 2 & 2 \\
\hline Total Services & 31 & 4.35 & 1.23 & 2 & 6 & 31 & 5.35 & 1.23 & 3 & 7 \\
\hline \multicolumn{11}{|l|}{$\begin{array}{l}\text { Programming by Service Category } \\
\text { Basic Service }\end{array}$} \\
\hline Top-5 Cable Prog. Nets. & 31 & 4.32 & 1.01 & 2 & $5 \|$ & 31 & 2.03 & 1.22 & 0 & 3 \\
\hline Top-10 Cable Prog. Nets. & 31 & 8.10 & 2.48 & 2 & 10 & 31 & 3.94 & 2.49 & 0 & 7 \\
\hline Top-20 Cable Prog. Nets. & 31 & 13.77 & 5.61 & 2 & 20 & 31 & 7.29 & 4.44 & 0 & 13 \\
\hline Total Cable Prog. Nets. & 31 & 17.03 & 6.80 & 3 & 25 & 31 & 9.19 & 5.29 & 0 & 16 \\
\hline \multicolumn{11}{|l|}{ Expanded Basic Service 1} \\
\hline Top-5 Cable Prog. Nets. & 0 & 0.00 & 0.00 & 0 & 0 & 31 & 2.55 & 1.55 & 0 & 5 \\
\hline Top-10 Cable Prog. Nets. & 0 & 0.00 & 0.00 & 0 & 0 & 31 & 4.81 & 3.03 & 0 & 10 \\
\hline Top-20 Cable Prog. Nets. & 0 & 0.00 & 0.00 & 0 & 0 & 31 & 7.94 & 5.32 & 0 & 20 \\
\hline Total Cable Prog. Nets. & 0 & 0.00 & 0.00 & 0 & 0 & 31 & 9.87 & 7.50 & 0 & 29 \\
\hline
\end{tabular}




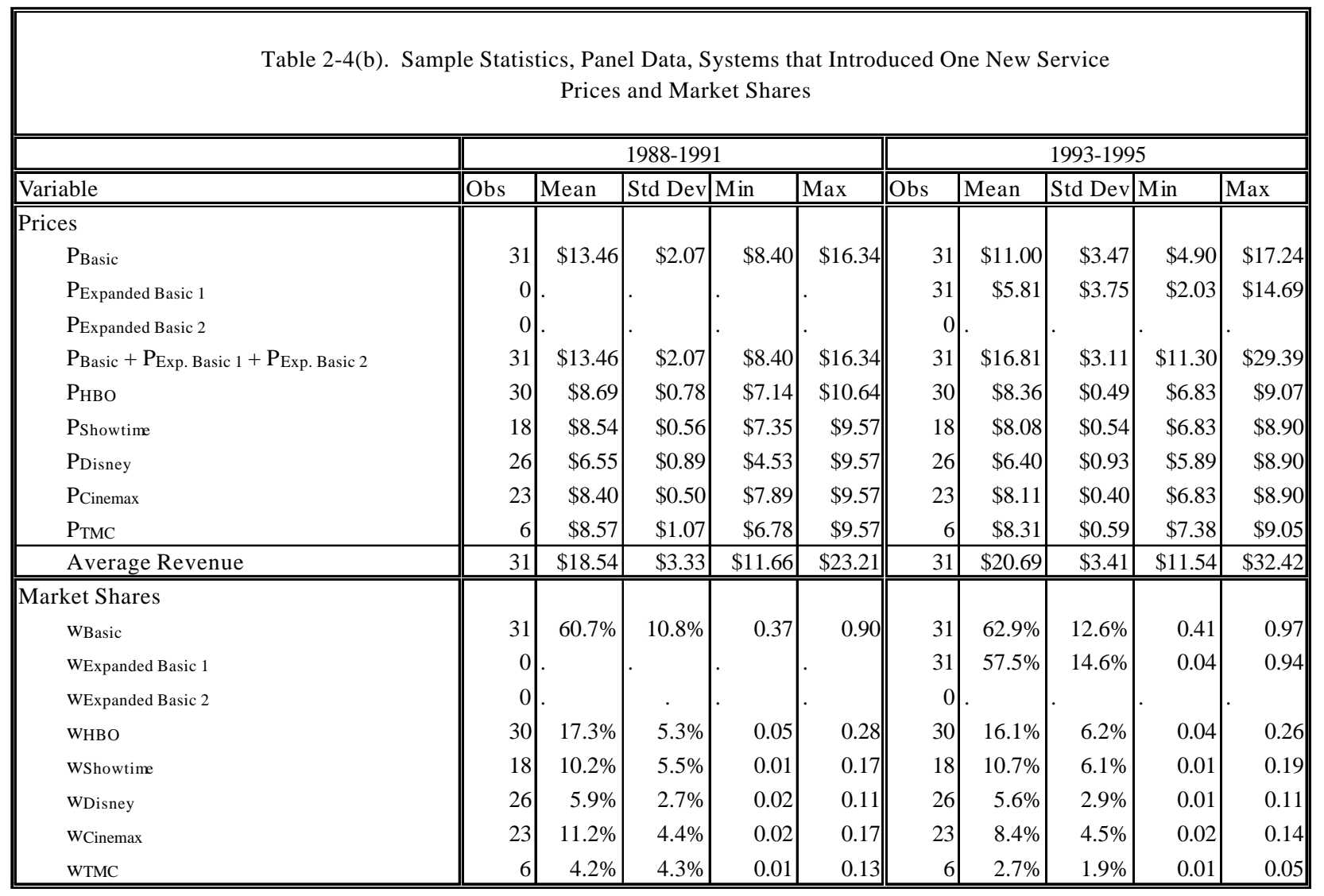

Cable/Data/Analyze/Means/panel.xls 


\begin{tabular}{|c|c|c|c|c|c|c|c|c|c|c|}
\hline \multicolumn{11}{|c|}{$\begin{array}{c}\text { Table 2-5(a). Sample Statistics, Panel Data, Systems that Introduced Two New Services } \\
\text { Programming and Services }\end{array}$} \\
\hline & \multicolumn{5}{|c|}{$1988-1991$} & \multicolumn{5}{|c|}{ 1993-1995 } \\
\hline Variable & Obs & Mean & Std Dev & Min & Max & Obs & Mean & Std Dev & Min & Max \\
\hline Channel Capacity & 26 & 34.92 & 2.61 & 27 & 40 & 26 & 39.00 & 7.18 & 22 & 60 \\
\hline Total Cable Programming Nets. & 26 & 15.92 & 3.57 & 7 & $23 \|$ & 26 & 20.54 & 4.60 & 10 & 26 \\
\hline Top-5 Cable Programming Nets. & 26 & 4.69 & 0.62 & 3 & 5 & 26 & 4.42 & 0.90 & 2 & 5 \\
\hline Top-10 Cable Programming Nets. & 26 & 7.85 & 1.19 & 4 & 10 & 26 & 8.54 & 1.73 & 5 & 10 \\
\hline Top-20 Cable Programming Nets. & 26 & 13.46 & 2.72 & 6 & 18 & 26 & 16.04 & 3.68 & 9 & 20 \\
\hline Top-40 Cable Programming Nets. & 26 & 14.58 & 3.20 & 6 & 20 & 26 & 18.58 & 4.22 & 9 & 24 \\
\hline \multicolumn{11}{|l|}{ Services Offered } \\
\hline Any Expanded Basic Services & 26 & $0.0 \%$ & $0.0 \%$ & 0 & 0 & 26 & $100.0 \%$ & $0.0 \%$ & 1 & 1 \\
\hline One Expanded Basic Service & 26 & $0.0 \%$ & $0.0 \%$ & 0 & 0 & 26 & $0.0 \%$ & $0.0 \%$ & 0 & 0 \\
\hline Two Expanded Basic Services & 26 & $0.0 \%$ & $0.0 \%$ & 0 & 0 & 26 & $100.0 \%$ & $0.0 \%$ & 1 & 1 \\
\hline Total Basic Services & 26 & 1.00 & 0.00 & 1 & $1 \|$ & 26 & 3.00 & 0.00 & 3 & 3 \\
\hline Total Services & 26 & 5.38 & 0.75 & 4 & 6 & 26 & 7.38 & 0.75 & 6 & 8 \\
\hline \multicolumn{11}{|l|}{$\begin{array}{l}\text { Programming by Service Category } \\
\text { Basic Service }\end{array}$} \\
\hline Top-5 Cable Prog. Nets. & 26 & 4.69 & 0.62 & 3 & 5 & 26 & 1.58 & 0.70 & 0 & 3 \\
\hline Top-10 Cable Prog. Nets. & 26 & 7.85 & 1.19 & 4 & 10 & 26 & 4.50 & 1.53 & 1 & 7 \\
\hline Top-20 Cable Prog. Nets. & 26 & 13.46 & 2.72 & 6 & 18 & 26 & 8.92 & 3.19 & 2 & 13 \\
\hline Total Cable Prog. Nets. & 26 & 15.92 & 3.57 & 7 & 23 & 26 & 11.81 & 3.96 & 2 & 17 \\
\hline \multicolumn{11}{|l|}{ Expanded Basic Service 1} \\
\hline Top-5 Cable Prog. Nets. & 0 & 0.00 & 0.00 & 0 & 0 & 26 & 1.77 & 0.86 & 1 & 4 \\
\hline Top-10 Cable Prog. Nets. & 0 & 0.00 & 0.00 & 0 & $0 \|$ & 26 & 2.46 & 1.68 & 1 & 7 \\
\hline Top-20 Cable Prog. Nets. & 0 & 0.00 & 0.00 & 0 & $0 \|$ & 26 & 4.54 & 3.65 & 2 & 16 \\
\hline Total Cable Prog. Nets. & 0 & 0.00 & 0.00 & 0 & 0 & 26 & 5.23 & 4.78 & 3 & 20 \\
\hline \multicolumn{11}{|l|}{ Expanded Basic Service 2} \\
\hline Top-5 Cable Prog. Nets. & 0 & 0.00 & 0.00 & 0 & 0 & 26 & 1.08 & 0.89 & 0 & 2 \\
\hline Top-10 Cable Prog. Nets. & 0 & 0.00 & 0.00 & 0 & 0 & 26 & 1.58 & 1.21 & 0 & 3 \\
\hline Top-20 Cable Prog. Nets. & 0 & 0.00 & 0.00 & 0 & 0 & 26 & 2.58 & 2.04 & 0 & 6 \\
\hline Total Cable Prog. Nets. & 0 & 0.00 & 0.00 & 0 & 0 & 26 & 3.50 & 2.64 & 0 & 7 \\
\hline
\end{tabular}




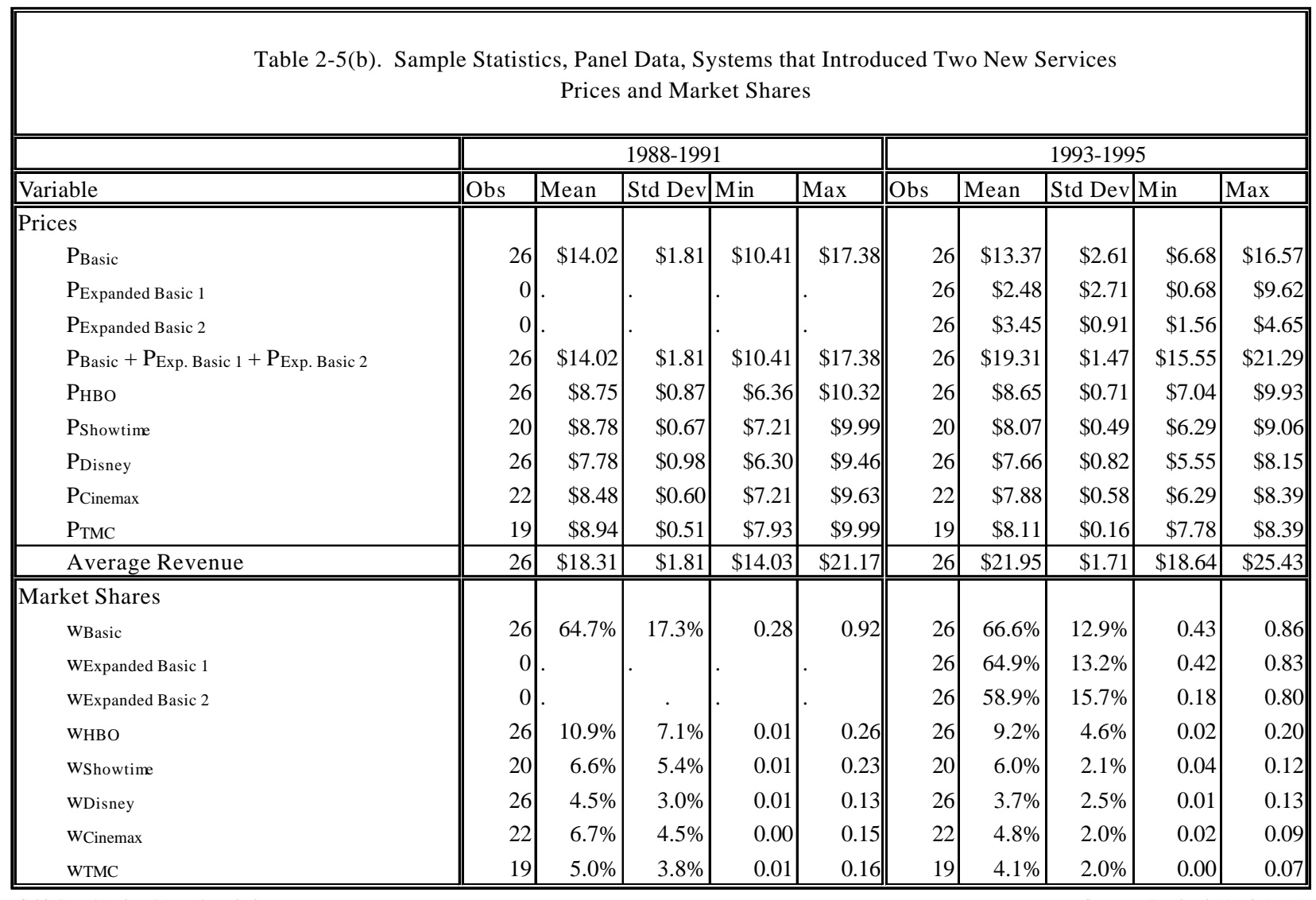

Cable/Data/Analyze/Means/panel.xls 


\begin{tabular}{|c|c|c|c|c|c|c|c|c|c|}
\hline & $\begin{array}{l}\text { Base } \\
\text { Spec. }\end{array}$ & $\begin{array}{l}\text { Spec. } \\
2\end{array}$ & $\begin{array}{l}\text { Spec. } \\
11\end{array}$ & $\begin{array}{l}\text { Spec. } \\
13\end{array}$ & & $\begin{array}{l}\text { Base } \\
\text { Spec. }\end{array}$ & $\begin{array}{c}\text { Spec. } \\
2\end{array}$ & $\begin{array}{l}\text { Spec. } \\
11\end{array}$ & $\begin{array}{l}\text { Spec. } \\
13\end{array}$ \\
\hline \multirow[t]{2}{*}{ Parameter } & $\begin{array}{l}\text { Estimate } \\
\text { (Std. Err) }\end{array}$ & $\begin{array}{l}\text { Estimate } \\
\text { (Std. Err) }\end{array}$ & $\begin{array}{l}\text { Estimate } \\
\text { (Std. Err) }\end{array}$ & $\begin{array}{l}\text { Estimate } \\
\text { (Std. Err) }\end{array}$ & Parameter & \begin{tabular}{|l|} 
Estimate \\
(Std. Err)
\end{tabular} & $\begin{array}{l}\text { Estimate } \\
\text { (Std. Err) }\end{array}$ & $\begin{array}{l}\text { Estimate } \\
\text { (Std. Err) }\end{array}$ & $\begin{array}{l}\text { Estimate } \\
\text { (Std. Err) }\end{array}$ \\
\hline & \multicolumn{4}{|c|}{ Demand } & & \multicolumn{4}{|c|}{ Pricing } \\
\hline $\begin{array}{l}\text { Price } \\
\quad \alpha=\exp (\text { parameter })\end{array}$ & $\begin{array}{c}0.20 \\
(0.03)\end{array}$ & $\begin{array}{c}0.12 \\
(0.06)\end{array}$ & $\begin{array}{c}0.09 \\
(0.00)\end{array}$ & $\begin{array}{l}0.01 \\
(0.13)\end{array}$ & 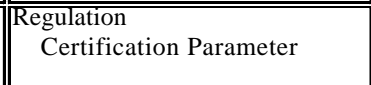 & $-\cdots--$ & ---- & $\begin{array}{r}0.00 \\
(0.00)\end{array}$ & $\begin{array}{l}-0.08 \\
(0.10)\end{array}$ \\
\hline Constant Terms & & & & & Constant Terms & & & & \\
\hline Basic & $\begin{array}{l}6.76 \\
(1.21)\end{array}$ & $\begin{array}{l}8.06 \\
(1.12)\end{array}$ & $\begin{array}{l}7.85 \\
\text { (u.vo) }\end{array}$ & $\begin{array}{l}6.20 \\
(1.80)\end{array}$ & Basic & $\begin{array}{l}1.65 \\
(0.02)\end{array}$ & $\begin{array}{l}-0.03 \\
(1.11)\end{array}$ & $\begin{array}{l}-0.26 \\
(0.00)\end{array}$ & $\begin{array}{c}0.42 \\
(0 . \supset 3)\end{array}$ \\
\hline Exp. Basic I & $\begin{array}{l}4.64 \\
\text { (u.uช) }\end{array}$ & $\begin{array}{l}3.78 \\
(0.14)\end{array}$ & $\begin{array}{l}3.76 \\
\text { (u.vo) }\end{array}$ & $\begin{array}{l}4.43 \\
(u . v \prime)\end{array}$ & Exp. Basic I & ---- & ---- & $-\cdots$ & --- \\
\hline Exp. Basic II & $\begin{array}{c}5.49 \\
\text { (u.vy) }\end{array}$ & $\begin{array}{l}3.70 \\
(0.1,1\end{array}$ & $\begin{array}{l}3.65 \\
\text { (v.vou }\end{array}$ & $\begin{array}{l}4.62 \\
(v .11)\end{array}$ & Exp. Basic II & ----- & ---- & ---- & ----- \\
\hline $\begin{array}{l}\text { Broadcast Prog. } \\
\text { First Over-the-Air }\end{array}$ & -0.13 & -0.31 & -0.31 & -0.18 & $\begin{array}{l}\text { Broadcast Prog. } \\
\text { First Over-the-Air }\end{array}$ & ---- & $-\cdots--$ & ---- & ---- \\
\hline Dup. Over-the-Air & $\begin{array}{l}-0.69 \\
(0.20)\end{array}$ & $\begin{array}{l}-0.17 \\
(0.28)\end{array}$ & $\begin{array}{l}-0.16 \\
\text { (u.vo) }\end{array}$ & $\begin{array}{c}0.12 \\
(0.23)\end{array}$ & Dup. Over-the-Air & ---- & ---- & ---- & ----- \\
\hline $\begin{array}{l}\text { First on Basic } \\
\text { not available Over-the-Air }\end{array}$ & $\begin{array}{l}-0.04 \\
(0.16)\end{array}$ & $\begin{array}{l}-0.29 \\
(0.16)\end{array}$ & $\begin{array}{l}-0.29 \\
(0.00)\end{array}$ & $\begin{array}{l}0.02 \\
(0.12)\end{array}$ & $\begin{array}{l}\text { First on Basic } \\
\text { not available Over-the-Air }\end{array}$ & $\begin{array}{l}-0.07 \\
(0.20)\end{array}$ & $\begin{array}{l}0.33 \\
(0.41)\end{array}$ & $\begin{array}{l}0.35 \\
(0.00)\end{array}$ & $\begin{array}{l}0.24 \\
(0.17)\end{array}$ \\
\hline $\begin{array}{l}\text { Duplicate on Basic } \\
\text { not available Over-the-Air }\end{array}$ & $\begin{array}{l}-0.08 \\
(0.11)\end{array}$ & $\begin{array}{l}0.06 \\
(0.10)\end{array}$ & $\begin{array}{l}0.07 \\
(0.00)\end{array}$ & $\begin{array}{c}-0.04 \\
(0.07)\end{array}$ & $\begin{array}{l}\text { Duplicate on Basic } \\
\text { not available Over-the-Air }\end{array}$ & $\begin{array}{l}-0.41 \\
(0.14)\end{array}$ & $\begin{array}{r}-0.39 \\
(0.28)\end{array}$ & $\begin{array}{l}-0.39 \\
(0.00)\end{array}$ & $\begin{array}{l}-0.29 \\
(0.09)\end{array}$ \\
\hline Cable Programming & & & & & Cable Programming & & & & \\
\hline ESPN & $\begin{array}{l}7.02 \\
(0.2 y)\end{array}$ & $\begin{array}{l}4.93 \\
(\text { (ט.ग0) }\end{array}$ & $\begin{array}{l}4.77 \\
\text { (u.vo) }\end{array}$ & $\begin{array}{l}5.92 \\
(0.21)\end{array}$ & ESPN & $\begin{array}{l}5.50 \\
(0.21)\end{array}$ & $\begin{array}{l}4.22 \\
(0.20)\end{array}$ & $\begin{array}{c}4.22 \\
\text { (v.uv) }\end{array}$ & $\begin{array}{c}5.89 \\
(0.24)\end{array}$ \\
\hline $\mathrm{CNN}$ & $\begin{array}{c}0.19 \\
\text { (u.uy) }\end{array}$ & $\begin{array}{l}0.34 \\
(\cup .10)\end{array}$ & $\begin{array}{l}0.32 \\
\text { (v.vo) }\end{array}$ & $\begin{array}{l}0.06 \\
(0.10)\end{array}$ & $\mathrm{CNN}$ & $\begin{array}{l}0.78 \\
\text { (บ.vo) }\end{array}$ & $\begin{array}{l}0.56 \\
(u .14)\end{array}$ & $\begin{array}{l}0.56 \\
\text { (u.vo) }\end{array}$ & $\begin{array}{l}0.94 \\
\text { (u.uy) }\end{array}$ \\
\hline WTBS & $\begin{array}{l}0.98 \\
(0.15)\end{array}$ & $\underset{1.26}{1.26)}$ & $\begin{array}{c}1.23 \\
(0.00)\end{array}$ & $\begin{array}{l}1.28 \\
(0.12)\end{array}$ & WTBS & $\begin{array}{l}1.19 \\
\text { (v.10) }\end{array}$ & $\begin{array}{l}1.34 \\
(0.10)\end{array}$ & $\begin{array}{l}1.33 \\
\text { (u.vo) }\end{array}$ & $\begin{array}{l}1.24 \\
(0.11)\end{array}$ \\
\hline USA & $\begin{array}{l}1.06 \\
\text { (v.uy) }\end{array}$ & $\begin{array}{l}0.91 \\
\text { (v.<v) }\end{array}$ & $\begin{array}{l}0.89 \\
\text { (u.vu) }\end{array}$ & $\begin{array}{l}0.94 \\
\text { (u.uy) }\end{array}$ & USA & $\begin{array}{l}0.32 \\
\text { (v.10) }\end{array}$ & $\begin{array}{l}0.47 \\
(0.12)\end{array}$ & $\begin{array}{l}0.46 \\
\text { (u.vo) }\end{array}$ & $\begin{array}{l}-0.02 \\
(0.1<)\end{array}$ \\
\hline The Discovery Channel & 0.82 & 0.82 & $\begin{array}{l}0.79 \\
\text { (v.vu, }\end{array}$ & $\begin{array}{l}0.57 \\
\text { (u.vy, }\end{array}$ & The Discovery Channel & 0.52 & 1.18 & $\underset{\text { covo, }}{1.18}$ & $\begin{array}{r}0.54 \\
(0.1<)\end{array}$ \\
\hline $\begin{array}{l}\text { Other Cable Networks } \\
\text { on Basic Service }\end{array}$ & $\begin{array}{l}0.12 \\
(0.02)\end{array}$ & $\begin{array}{l}0.13 \\
(0.02)\end{array}$ & $\begin{array}{l}0.12 \\
(0.00)\end{array}$ & $\begin{array}{l}0.13 \\
(0.02)\end{array}$ & $\begin{array}{l}\text { Other Cable Networks } \\
\text { on Basic Service }\end{array}$ & $\begin{array}{l}0.18 \\
(0.01)\end{array}$ & $\begin{array}{l}0.24 \\
(0.02)\end{array}$ & $\begin{array}{l}0.24 \\
(0.00)\end{array}$ & $\begin{array}{l}0.17 \\
(0.01)\end{array}$ \\
\hline $\begin{array}{c}\text { Other Cable Networks } \\
\text { on Expanded Basic Svcs. }\end{array}$ & ----- & ----- & ----- & $\begin{array}{l}0.05 \\
(0.02)\end{array}$ & \begin{tabular}{|c} 
Other Cable Networks \\
on Expanded Basic Svcs.
\end{tabular} & ----- & ---- & ----- & ---- \\
\hline $\begin{array}{l}\text { Premium Programming } \\
\text { HBO }\end{array}$ & $\begin{array}{l}8.91 \\
(0.93)\end{array}$ & $\begin{array}{l}6.66 \\
(0.2 y)\end{array}$ & $\begin{array}{l}6.34 \\
\text { (u.vo) }\end{array}$ & $\begin{array}{l}6.82 \\
(0.22)\end{array}$ & $\begin{array}{l}\text { Premium Programming } \\
\text { HBO }\end{array}$ & $\begin{array}{l}8.15 \\
\text { (ט.0y) }\end{array}$ & $\begin{array}{l}8.10 \\
(0.04)\end{array}$ & $\begin{array}{l}8.10 \\
(0.00)\end{array}$ & $\begin{array}{l}8.18 \\
(0.03)\end{array}$ \\
\hline Showtime & $\begin{array}{l}8.45 \\
(\text { (u. })<)\end{array}$ & $\begin{array}{l}6.10 \\
(u .2 y)\end{array}$ & $\begin{array}{l}5.78 \\
\text { (v.uv) }\end{array}$ & $\begin{array}{l}6.24 \\
(0.2<)\end{array}$ & Showtime & $\begin{array}{l}8.17 \\
\text { (บ.us) }\end{array}$ & $\begin{array}{l}8.12 \\
(u . v 4)\end{array}$ & $\begin{array}{l}8.12 \\
\text { (u.vo) }\end{array}$ & $\begin{array}{l}8.10 \\
\text { (บ.uว) }\end{array}$ \\
\hline The Disney Channel & $\begin{array}{l}5.61 \\
(\cup . \angle 8)\end{array}$ & $\begin{array}{l}3.81 \\
(u .24)\end{array}$ & $\begin{array}{l}3.56 \\
\text { (u. vou }\end{array}$ & $\begin{array}{l}3.89 \\
(\text { (u.1y) }\end{array}$ & The Disney Channel & $\begin{array}{l}6.41 \\
(0.04)\end{array}$ & $\begin{array}{l}6.39 \\
\text { (u.vo }\end{array}$ & $\begin{array}{l}6.39 \\
\text { (u.vo) }\end{array}$ & $\begin{array}{l}6.38 \\
(v .04)\end{array}$ \\
\hline Cinemax & $\begin{array}{l}7.68 \\
(0.92)\end{array}$ & $\begin{array}{l}5.46 \\
(0.21)\end{array}$ & $\underset{\substack{5.00 u \\
\text { (v.vo) }}}{5.16}$ & $\begin{array}{l}5.62 \\
(0.2<)\end{array}$ & Cinemax & $\begin{array}{l}7.75 \\
\text { (v. vos) }\end{array}$ & $\begin{array}{l}7.69 \\
(0.04)\end{array}$ & $\begin{array}{l}7.69 \\
\text { (v.vu) }\end{array}$ & $\begin{array}{l}7.74 \\
\text { (v.vo) }\end{array}$ \\
\hline The Movie Channel & $\begin{array}{l}7.05 \\
(0.32)\end{array}$ & $\begin{array}{l}4.93 \\
\text { (u. } 28)\end{array}$ & $\begin{array}{l}4.63 \\
\text { (u.vo) }\end{array}$ & $\begin{array}{l}5.13 \\
(0.22)\end{array}$ & The Movie Channel & $\begin{array}{l}7.69 \\
(0.04)\end{array}$ & $\begin{array}{l}7.71 \\
\text { (u.vo) }\end{array}$ & $\begin{array}{l}7.71 \\
\text { (u.vo) }\end{array}$ & $\begin{array}{l}7.69 \\
(\text { (u.v3) }\end{array}$ \\
\hline $\begin{array}{l}\text { Other Programming } \\
\text { Other Programming }\end{array}$ & $\begin{array}{l}-0.01 \\
(0.01)\end{array}$ & $\begin{array}{l}-0.01 \\
(0.01)\end{array}$ & 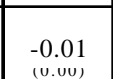 & $\begin{array}{l}0.00 \\
1(0.011\end{array}$ & $\begin{array}{c}\text { Other Programming } \\
\text { Other Programming }\end{array}$ & $\begin{array}{l}0.03 \\
\text { (1.vi) }\end{array}$ & $\begin{array}{l}0.04 \\
(0.04)\end{array}$ & $\begin{array}{l}0.04 \\
\text { (v.vu) }\end{array}$ & $\begin{array}{l}0.08 \\
\text { (v.v1) }\end{array}$ \\
\hline $\begin{array}{c}\text { Demographics } \\
\text { DMA Rank }\end{array}$ & 0.07 & 0.06 & 0.06 & 0.06 & $\begin{array}{c}\text { Demographics } \\
\text { DMA Rank }\end{array}$ & 0.00 & 0.00 & $\begin{array}{l}-0.01 \\
-0.001\end{array}$ & -0.02 \\
\hline DMA Dummy & $\underset{(0.31)}{2.82}$ & $\begin{array}{l}2.77 \\
(0.40)\end{array}$ & $\begin{array}{c}2.78 \\
(\text { (v.vo) }\end{array}$ & $\underset{(0.21)}{2.56}$ & DMA Dummy & $\begin{array}{l}-2.88 \\
(0.2 y)\end{array}$ & $\begin{array}{l}-3.68 \\
(1.22)\end{array}$ & $\begin{array}{l}-3.74 \\
\text { (u.vo) }\end{array}$ & $\begin{array}{l}-4.27 \\
(0.38)\end{array}$ \\
\hline$\%$ Population Aged 5-18 & -5.73 & -18.21 & -18.24 & -20.47 & Number of Subs. controlle & 0.00 & 0.00 & 0.00 & 0.00 \\
\hline$\%$ Population With Collegd & $\begin{array}{l}(4.2 y) \\
2.65\end{array}$ & $\begin{array}{l}(0.121 \\
-3.75\end{array}$ & $\begin{array}{l}\text { (u.vo) } \\
-3.84\end{array}$ & $\begin{array}{l}(0.10) \\
1.64\end{array}$ & MSO Affiliated with Progr & $\begin{array}{l}\text { (u.vo) } \\
-1.46\end{array}$ & $\begin{array}{l}(\text { u.vu } \\
0.13\end{array}$ & $\begin{array}{l}(\text { u.vu) } \\
0.29\end{array}$ & 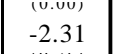 \\
\hline Median Income (thousand & $\begin{array}{l}(2.1) \\
-0.10 \\
(0.00)\end{array}$ & $\begin{array}{l}(2.12) \\
-0.01 \\
(0.0+4)\end{array}$ & $\begin{array}{l}(0.00) \\
-0.01 \\
\text { (u.vo) }\end{array}$ & $\begin{array}{l}-0.01) \\
-0.02 \\
(0.001\end{array}$ & Homes Passed & $\begin{array}{l}\text { (u. } \\
0.00 \\
\text { (u.vou }\end{array}$ & $\begin{array}{l}\text { (c.vo) } \\
0.00 \\
\text { iv.uve }\end{array}$ & $\begin{array}{l}\text { (u.vo) } \\
0.00 \\
\text { (u.vou }\end{array}$ & 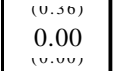 \\
\hline Price*Demographics & & & & & Log Likelihood Function & 0.70 & 0.00 & 0.00 & 0.50 \\
\hline$\alpha^{*}$ DMA Rank & ---- & 0.00 & 0.00 & 0.00 & Test of Overidentifying Restricti & 239.40 & 0.00 & 0.00 & 173.02 \\
\hline$\alpha^{*}$ DMA Dummy & ----- & 0.04 & 0.04 & 0.04 & Number of Observations & 344 & 344 & 344 & $\overline{544}$ \\
\hline$\alpha^{*} \%$ Population Aged 5-1 & ----- & $\begin{array}{l}(0.01) \\
-1.05 \\
(1.05,1\end{array}$ & $\begin{array}{l}\text { (u.vo) } \\
-1.09\end{array}$ & $\begin{array}{l}(0.02) \\
-0.65 \\
-(1.030)\end{array}$ & & & & & \\
\hline$\alpha^{*} \%$ Population With Coll & ---- & -0.22 & -0.23 & $\begin{array}{l}0.11 \\
(0 .<y)\end{array}$ & & & & & \\
\hline$\alpha^{*}$ Median Income (thousa & ---- & 0.00 & 0.00 & 0.00 & & & & & \\
\hline
\end{tabular}




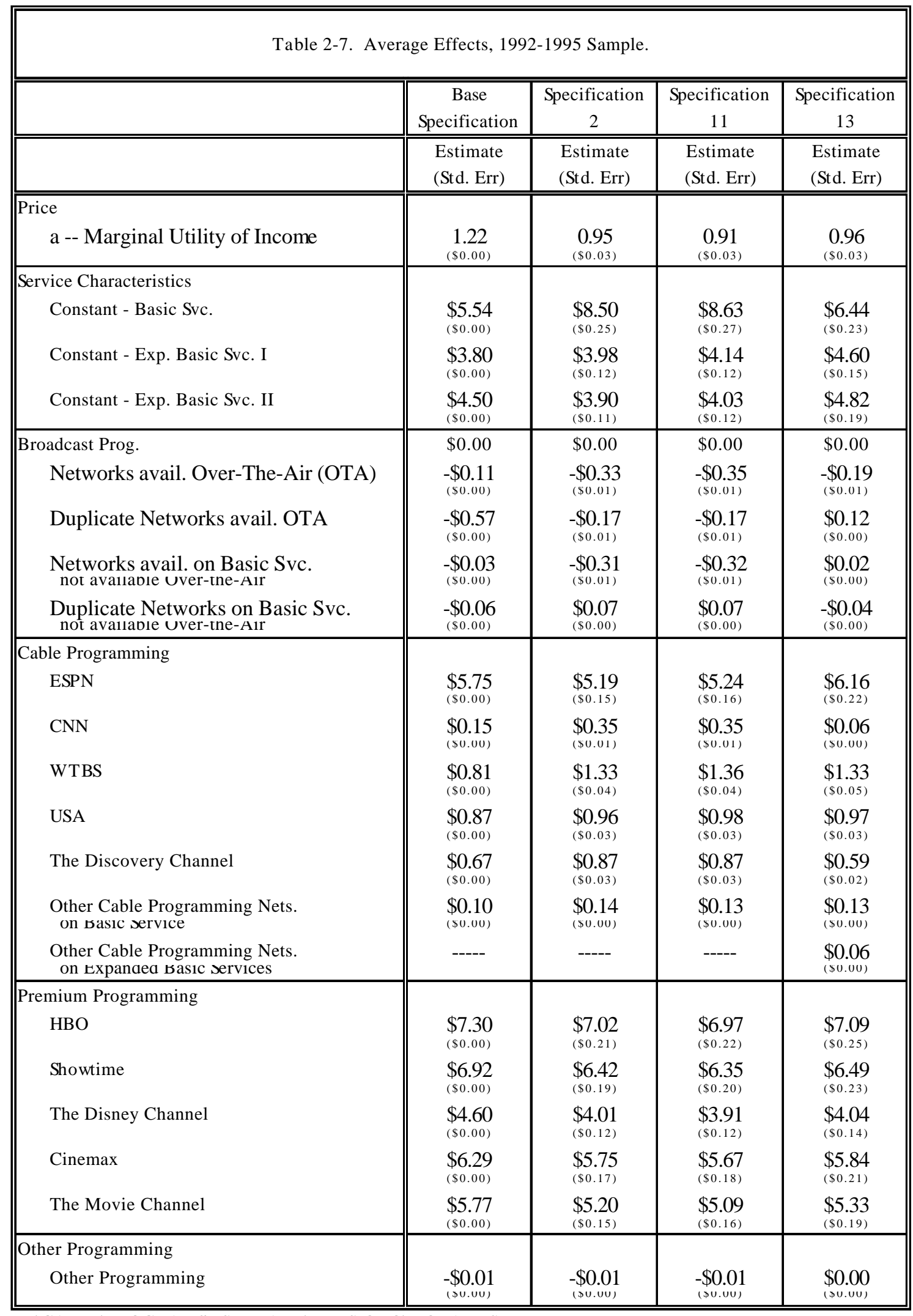

D:ICABLE\PROGRAMSIESTIMATEIVERSIONQIMOD1.XLS 


\begin{tabular}{|c|c|c|c|c|c|c|c|}
\hline & $\begin{array}{c}5 \\
\text { Networks }\end{array}$ & $\begin{array}{c}10 \\
\text { Networks }\end{array}$ & $\begin{array}{c}20 \\
\text { Networks }\end{array}$ & 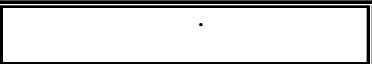 & $\begin{array}{c}5 \\
\text { Networks }\end{array}$ & $\begin{array}{c}10 \\
\text { Networks }\end{array}$ & $\begin{array}{c}20 \\
\text { Networks }\end{array}$ \\
\hline & $\begin{array}{l}\text { Estimate } \\
\text { (Std. Err) }\end{array}$ & $\begin{array}{l}\text { Estimate } \\
\text { (Std. Err) }\end{array}$ & $\begin{array}{l}\text { Estimate } \\
\text { (Std. Err) }\end{array}$ & & $\begin{array}{l}\text { Estimate } \\
\text { (Std. Err) }\end{array}$ & $\begin{array}{l}\text { Estimate } \\
\text { (Std. Err) }\end{array}$ & $\begin{array}{l}\text { Estimate } \\
\text { (Std. Err) }\end{array}$ \\
\hline & \multicolumn{3}{|c|}{ Demand } & & \multicolumn{3}{|c|}{ Pricing } \\
\hline $\begin{array}{l}\text { Price } \\
\quad \alpha=\exp (\text { parameter })\end{array}$ & $\begin{array}{l}0.01 \\
(0.15)\end{array}$ & $\begin{array}{l}0.03 \\
\text { (v.vo) }\end{array}$ & $\begin{array}{l}0.00 \\
\text { (u.vo) }\end{array}$ & $\begin{array}{l}\text { Regulation } \\
\text { Certification Parameter }\end{array}$ & $\begin{array}{l}-0.08 \\
(0.10)\end{array}$ & $\begin{array}{l}-0.05 \\
\text { (u.vo) }\end{array}$ & $\begin{array}{l}-0.09 \\
\text { (u.vu) }\end{array}$ \\
\hline $\begin{array}{l}\text { Constant Terms } \\
\text { Basic }\end{array}$ & $\begin{array}{r}6.20 \\
(1.80)\end{array}$ & $\begin{array}{r}8.16 \\
(\text { v.vo) }\end{array}$ & $\begin{array}{c}6.64 \\
\text { (u.vo) }\end{array}$ & $\begin{array}{l}\text { Constant Terms } \\
\text { Basic }\end{array}$ & $\begin{array}{c}0.42 \\
(\text { (u. }\end{array}$ & $\begin{array}{l}-0.86 \\
\text { (u.vo) }\end{array}$ & $\begin{array}{l}-0.97 \\
\text { (u.vu) }\end{array}$ \\
\hline Exp. Basic I & $\begin{array}{c}4.43 \\
\text { (v.vi) }\end{array}$ & $\begin{array}{c}3.70 \\
\text { (v.vu) }\end{array}$ & $\begin{array}{l}3.29 \\
\text { (u.vo) }\end{array}$ & Exp. Basic I & ---- & ---- & ---- \\
\hline Exp. Basic II & $\begin{array}{l}4.62 \\
(0.11)\end{array}$ & $\begin{array}{l}3.39 \\
\text { (u.vo) }\end{array}$ & $\begin{array}{l}3.43 \\
(0.00)\end{array}$ & Exp. Basic II & ----- & ----- & ----- \\
\hline $\begin{array}{l}\text { Broadcast Prog. } \\
\text { First Over-the-Air }\end{array}$ & $\begin{array}{l}-0.18 \\
(0.11)\end{array}$ & $\begin{array}{l}-0.39 \\
\text { (v.vo) }\end{array}$ & $\begin{array}{l}-0.38 \\
\text { (u.vo) }\end{array}$ & $\begin{array}{l}\text { Broadcast Prog. } \\
\text { First Over-the-Air }\end{array}$ & ----- & ----- & ----- \\
\hline Dup. Over-the-Air & $\begin{array}{c}0.12 \\
(0.25)\end{array}$ & $\begin{array}{l}-0.25 \\
\text { (u.vu) }\end{array}$ & $\begin{array}{l}-0.21 \\
\text { (u.vo) }\end{array}$ & Dup. Over-the-Air & ----- & ----- & ----- \\
\hline First on Basic & 0.02 & -0.35 & -0.27 & First on Basic & 0.24 & 0.42 & 0.44 \\
\hline not available Over-the-Air & $(0.12)$ & $(0.00)$ & $(0.00)$ & not available Over-the-Air & $(0.17)$ & $(0.00)$ & $(0.00)$ \\
\hline Duplicate on Basic & -0.04 & 0.12 & 0.07 & Duplicate on Basic & -0.29 & -0.40 & -0.42 \\
\hline not available Over-the-Air & $(0.07)$ & $(0.00)$ & $(0.00)$ & not available Over-the-Air & $(0.09)$ & $(0.00)$ & $(0.00)$ \\
\hline $\begin{array}{l}\text { Cable Programming } \\
\text { ESPN }\end{array}$ & $\begin{array}{l}5.92 \\
(0.21)\end{array}$ & $\begin{array}{l}4.22 \\
(0.00)\end{array}$ & $\begin{array}{l}3.58 \\
(0.00)\end{array}$ & $\begin{array}{l}\text { Cable Programming } \\
\text { ESPN }\end{array}$ & $\begin{array}{l}5.89 \\
(0.24)\end{array}$ & $\begin{array}{l}4.09 \\
(0.00)\end{array}$ & $\begin{array}{l}3.89 \\
(0.00)\end{array}$ \\
\hline $\mathrm{CNN}$ & $\begin{array}{l}0.06 \\
(u .10)\end{array}$ & $\begin{array}{c}0.26 \\
(0.00)\end{array}$ & $\begin{array}{c}0.06 \\
\text { (u.vo) }\end{array}$ & CNN & $\begin{array}{c}0.94 \\
\text { (u.vy) }\end{array}$ & $\begin{array}{l}0.36 \\
\text { (u.vo) }\end{array}$ & $\begin{array}{l}0.71 \\
(0 . v 0)\end{array}$ \\
\hline WTBS & $\begin{array}{l}1.28 \\
(0.12)\end{array}$ & $\begin{array}{c}1.32 \\
\text { (v.vo) }\end{array}$ & $\begin{array}{c}1.63 \\
\text { (v.vo) }\end{array}$ & WTBS & $\begin{array}{c}1.24 \\
(0.11)\end{array}$ & $\begin{array}{c}1.14 \\
\text { (v.vo) }\end{array}$ & $\begin{array}{c}1.51 \\
\text { (v.vo) }\end{array}$ \\
\hline USA & $\begin{array}{c}0.94 \\
\text { (u.vy) }\end{array}$ & $\begin{array}{c}0.84 \\
(0.00)\end{array}$ & $\begin{array}{c}1.26 \\
\text { (u.vo) }\end{array}$ & USA & $\begin{array}{l}-0.02 \\
(0.1<)\end{array}$ & $\begin{array}{c}0.11 \\
\text { (u.vo) }\end{array}$ & $\begin{array}{l}0.13 \\
\text { (v.vu) }\end{array}$ \\
\hline The Discovery Channel & $\begin{array}{c}0.57 \\
\text { (u.vy) }\end{array}$ & $\begin{array}{c}0.70 \\
(0.00)\end{array}$ & $\begin{array}{l}0.83 \\
\text { (u.vo) }\end{array}$ & The Discovery Channel & $\begin{array}{l}0.54 \\
(0.12)\end{array}$ & $\begin{array}{c}1.02 \\
\text { (v.vo) }\end{array}$ & $\begin{array}{l}0.85 \\
\text { (u.vo) }\end{array}$ \\
\hline Nickelodeon & ---- & $\begin{array}{c}0.19 \\
(0 . v 0)\end{array}$ & $\begin{array}{l}0.43 \\
\text { (u.vu) }\end{array}$ & Nickelodeon & -...- & $\begin{array}{l}0.61 \\
\text { (u.vu) }\end{array}$ & $\begin{array}{l}0.61 \\
(0 . v 0)\end{array}$ \\
\hline Nashville & $-\cdots-\cdot$ & $\begin{array}{l}-0.04 \\
\text { (v.vo) }\end{array}$ & $\begin{array}{l}-0.05 \\
\text { (u.vo) }\end{array}$ & Nashville & -..-. & $\begin{array}{l}0.02 \\
\text { (u.vo) }\end{array}$ & $\begin{array}{l}0.08 \\
(0.00)\end{array}$ \\
\hline TNT & -..-. & $\begin{array}{l}-0.01 \\
(0.00)\end{array}$ & $\begin{array}{l}-0.16 \\
\text { (v.vo) }\end{array}$ & TNT & -...- & $\begin{array}{c}0.57 \\
\text { (u.vo) }\end{array}$ & $\begin{array}{l}0.28 \\
(v . v 0)\end{array}$ \\
\hline MTV & -..- & $\begin{array}{c}0.82 \\
(0 . v 0)\end{array}$ & $\begin{array}{l}0.72 \\
(\text { (u.vu) }\end{array}$ & MTV & -..-. & $\begin{array}{l}1.55 \\
\text { (u.vo) }\end{array}$ & $\begin{array}{l}0.88 \\
\text { (u.vo) }\end{array}$ \\
\hline The Family Channel & $\cdots-$. & $\begin{array}{c}0.34 \\
\text { (v.vo) }\end{array}$ & $\begin{array}{l}0.59 \\
\text { (u.vo) }\end{array}$ & The Family Channel & -...- & $\begin{array}{l}1.20 \\
\text { (v.vo) }\end{array}$ & $\begin{array}{l}1.42 \\
\text { (v.vo) }\end{array}$ \\
\hline C-SPAN-I & $\cdots+-$. & 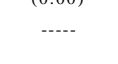 & $\begin{array}{l}-0.46 \\
(0.00)\end{array}$ & C-SPAN-I & -...- & (c.00) & $\begin{array}{l}0.80 \\
(0.00)\end{array}$ \\
\hline Lifetime Television & -..- & $\cdots-\cdot$ & $\begin{array}{l}-0.64 \\
(v . v 0)\end{array}$ & Lifetime Television & 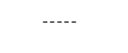 & -..-. & $\begin{array}{l}-1.79 \\
\text { (v.vu) }\end{array}$ \\
\hline Arts \& Entertainment & $\cdots-\cdot$ & $\cdots-$. & $\begin{array}{l}1.10 \\
(v . v 0)\end{array}$ & Arts \& Entertainment & -..-. & -..- & $\begin{array}{l}0.17 \\
\text { (u.vo) }\end{array}$ \\
\hline The Weather Channel & -..-. & $\cdots-$. & $\begin{array}{c}0.42 \\
\text { (v.vo) }\end{array}$ & The Weather Channel & -..-. & -..- & $\begin{array}{l}0.10 \\
\text { (v.vo) }\end{array}$ \\
\hline Headline News (HNN) & $\cdots+$. & $\cdots+$. & $\begin{array}{l}0.76 \\
\text { (u.vo) }\end{array}$ & Headline News (HNN) & -.... & -...- & $\begin{array}{l}-0.78 \\
\text { (v.vu) }\end{array}$ \\
\hline $\mathrm{CNBC}$ & -..-. & $\cdots-$. & $\begin{array}{l}-1.43 \\
\text { (v.vu) }\end{array}$ & $\mathrm{CNBC}$ & -.-.- & -..-. & $\begin{array}{l}-0.44 \\
\text { (v.vu) }\end{array}$ \\
\hline Video Hits One (VH-1) & 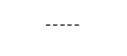 & $\cdots-$. & $\begin{array}{l}-0.26 \\
\text { (u.vo) }\end{array}$ & Video Hits One (VH-1) & -.... & -.... & $\begin{array}{l}0.00 \\
\text { (u.vo) }\end{array}$ \\
\hline QVC Network & $\cdots+$. & -.... & $\begin{array}{c}1.49 \\
(\text { (u.vu) }\end{array}$ & QVC Network & 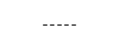 & -..- & $\begin{array}{l}0.74 \\
(0.00)\end{array}$ \\
\hline AMC & -.... & -... & $\begin{array}{l}0.17 \\
\text { (u.vo) }\end{array}$ & $\mathrm{AMC}$ & -... & -... & $\begin{array}{l}0.69 \\
(0.00)\end{array}$ \\
\hline WGN & $\cdots-$. & 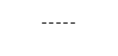 & $\begin{array}{l}-0.21 \\
\text { (v.vu) }\end{array}$ & WGN & $\cdots-$. & -..-. & $\begin{array}{l}-0.48 \\
\text { (v.vu) }\end{array}$ \\
\hline $\begin{array}{l}\text { Other Cable Networks } \\
\text { on basic service }\end{array}$ & $\begin{array}{c}0.13 \\
(0.02)\end{array}$ & $\begin{array}{c}0.03 \\
(0.00)\end{array}$ & $\begin{array}{c}0.08 \\
(0.00)\end{array}$ & $\begin{array}{l}\text { Other Cable Networks } \\
\text { on basic service }\end{array}$ & $\begin{array}{c}0.17 \\
(0.01)\end{array}$ & $\begin{array}{c}0.10 \\
(0.00)\end{array}$ & $\begin{array}{l}0.22 \\
(0.00)\end{array}$ \\
\hline $\begin{array}{l}\text { Other Cable Networks } \\
\text { on Expanaed basic svcs. }\end{array}$ & $\begin{array}{l}-0.07 \\
(0.02)\end{array}$ & $\begin{array}{r}0.06 \\
(0.00)\end{array}$ & $\begin{array}{l}0.07 \\
(0.00)\end{array}$ & $\begin{array}{l}\text { Other Cable Networks } \\
\text { on Expandea Basic svcs. }\end{array}$ & ----- & ----- & ----- \\
\hline $\begin{array}{l}\text { Other Programming } \\
\text { Other Programming }\end{array}$ & $\begin{array}{l}0.00 \\
(\text { (u.vi) }\end{array}$ & $\begin{array}{l}-0.01 \\
\text { (v.vo) }\end{array}$ & $\begin{array}{l}-0.01 \\
\text { (v.vu) }\end{array}$ & $\begin{array}{l}\text { Other Programming } \\
\text { Other Programming }\end{array}$ & $\begin{array}{c}0.08 \\
\left(\begin{array}{c}0 \\
\left(v_{1}\right)\end{array}\right.\end{array}$ & $\begin{array}{c}0.04 \\
\text { (v.uv) }\end{array}$ & $\begin{array}{l}0.04 \\
\text { (u.ve) }\end{array}$ \\
\hline Log Likelinood Function & 0.00 & 0.00 & 0.00 & Log Likelinood Function & 0.00 & 0.00 & 0.00 \\
\hline $\begin{array}{l}\text { Test of Overidentifying Restricti } \\
\text { Degrees of Freedom }\end{array}$ & $\begin{array}{l}20.20 \\
25.5993\end{array}$ & $\begin{array}{c}0.00 \\
0\end{array}$ & $\begin{array}{c}0.00 \\
0\end{array}$ & $\begin{array}{l}\text { Test of Overidentifying Restricti } \\
\text { Degrees of Freedom }\end{array}$ & $\begin{array}{c}0.00 \\
0\end{array}$ & $\begin{array}{c}0.00 \\
0\end{array}$ & $\begin{array}{c}0.00 \\
0\end{array}$ \\
\hline Number of Ubservations & 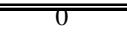 & 0 & $\overline{0}$ & Number of Ubservations & $\overline{0}$ & $\overline{0}$ & $\overline{0}$ \\
\hline
\end{tabular}




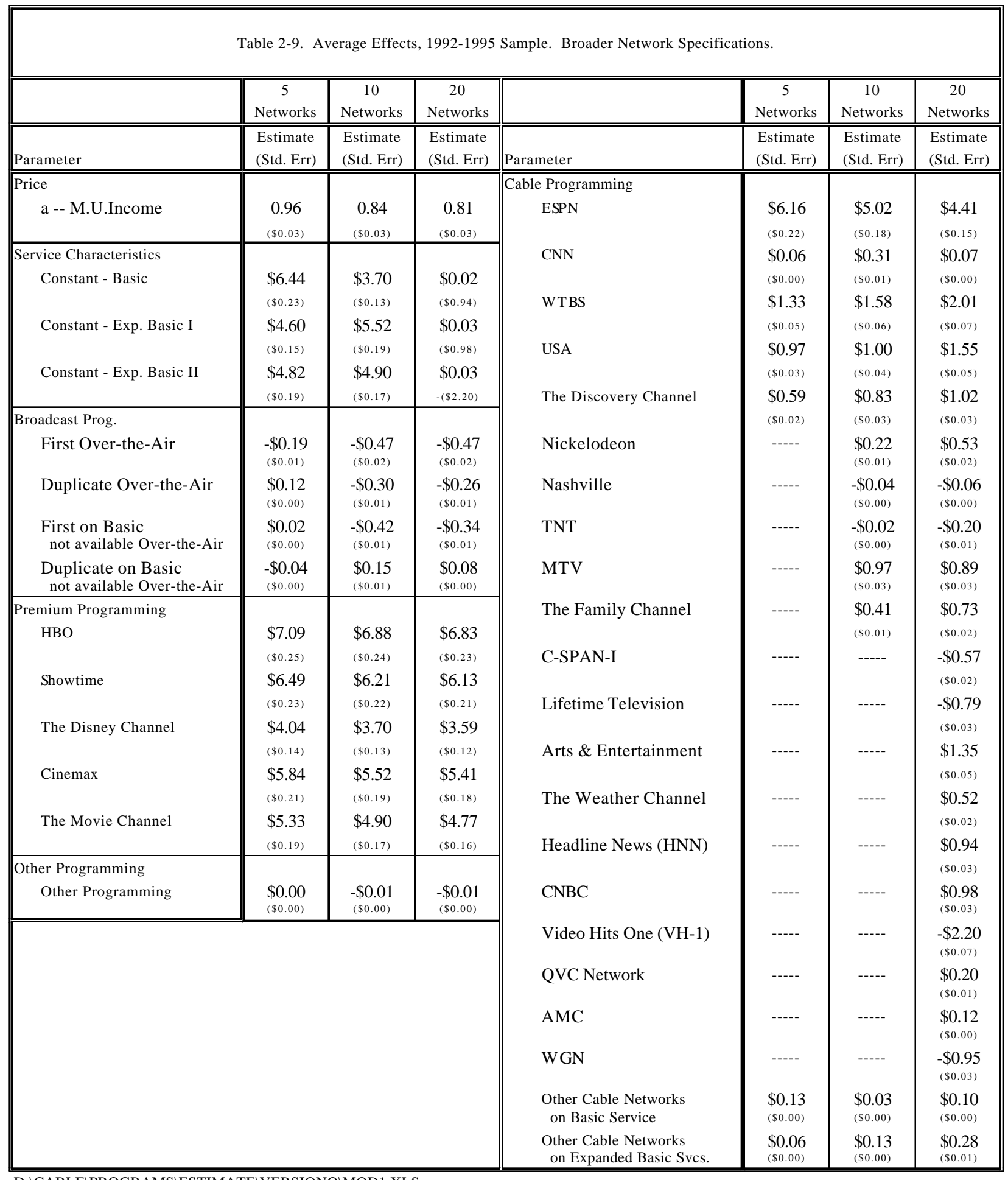


Table 2-10. Elasticities, 1992-1995 Sample

\begin{tabular}{|c|c|c|c|c|c|c|c|c|c|c|c|c|c|c|c|c|}
\hline & $\varepsilon_{. b}$ & & $\varepsilon_{. e}$ & & $\varepsilon_{. f}$ & & $\varepsilon_{. h}$ & & $\varepsilon_{. s}$ & & $\varepsilon_{. d}$ & & $\varepsilon_{\text {.c }}$ & & $\varepsilon_{\text {.t }}$ & \\
\hline$\varepsilon_{\mathrm{b}}$. & & 344 & & 60 & & & & 267 & & 145 & & 150 & & 114 & & \\
\hline$\varepsilon_{\mathrm{e}}$ & -4.83 & 60 & -0.75 & 60 & -0.24 & 27 & -0.66 & 59 & -0.18 & 55 & -0.51 & 41 & -0.25 & 47 & -0.23 & 27 \\
\hline$\varepsilon_{f .}$ & -2.08 & 27 & -1.38 & 27 & -0.24 & 27 & -0.26 & 27 & -0.06 & 27 & -0.19 & 21 & -0.12 & 23 & -0.08 & 20 \\
\hline & -1.13 & & -0.23 & & -0.70 & & -0.12 & & -0.02 & & -0.14 & & -0.05 & & -0.05 & \\
\hline$\overline{\varepsilon h}$. & & 267 & & 59 & & 27 & & 267 & & 133 & & 80 & & 111 & & 4 \\
\hline$\varepsilon_{\mathrm{s}}$ & -4.59 & 145 & -0.76 & 55 & -0.24 & 27 & -6.42 & 133 & -0.16 & 145 & -0.39 & 80 & -0.26 & 88 & -0.15 & 51 \\
\hline$\varepsilon_{\mathrm{d} .}$ & -4.42 & 150 & -0.56 & 41 & -0.24 & 21 & -0.53 & 80 & -5.97 & 80 & -0.41 & 150 & -0.23 & 54 & -0.20 & 48 \\
\hline$\varepsilon_{\mathrm{c} .}$ & -5.07 & 114 & -0.51 & 47 & -0.29 & 23 & -0.51 & 111 & -0.19 & 88 & -6.82 & 54 & -0.17 & 114 & -0.19 & 35 \\
\hline$\varepsilon_{\mathrm{t} .}$ & -3.49 & 63 & -0.61 & 27 & -0.18 & 20 & -0.47 & 46 & -0.12 & 51 & -0.27 & 48 & -6.59 & 35 & -0.11 & \\
\hline & -4.40 & & -0.58 & & -0.30 & & -0.41 & & -0.16 & & -0.49 & & -0.18 & & -7.05 & \\
\hline
\end{tabular}

Note : $\mathrm{b}=$ basic, $\mathrm{e}=$ expanded basic $1, \mathrm{f}=$ expanded basic $2, \mathrm{~h}=\mathrm{hbo}, \mathrm{s}=$ showtime, $\mathrm{d}=$ disney, $\mathrm{c}=$ cinemax, $\mathrm{t}=$ the movie channel D:ICABLEIPROGRAMSIPOSTESTIVERSIONQIOUTPUT1.XLS 


\begin{tabular}{|c|c|c|c|c|c|c|c|c|c|}
\hline & $\begin{array}{l}\text { Base } \\
\text { Spec. }\end{array}$ & $\begin{array}{l}\text { Spec. } \\
2\end{array}$ & $\begin{array}{l}\text { Spec. } \\
11\end{array}$ & $\begin{array}{l}\text { Spec. } \\
13\end{array}$ & & $\begin{array}{l}\text { Base } \\
\text { Spec. }\end{array}$ & $\begin{array}{l}\text { Spec. } \\
2\end{array}$ & $\begin{array}{l}\text { Spec. } \\
11\end{array}$ & $\begin{array}{l}\text { Spec. } \\
13\end{array}$ \\
\hline \multirow[t]{2}{*}{ Parameter } & $\begin{array}{l}\text { Estimate } \\
\text { (Std. Err) }\end{array}$ & $\begin{array}{l}\text { Estimate } \\
\text { (Std. Err) }\end{array}$ & $\begin{array}{l}\text { Estimate } \\
\text { (Std. Err) }\end{array}$ & $\begin{array}{l}\text { Estimate } \\
\text { (Std. Err) }\end{array}$ & Parameter & \begin{tabular}{|l|} 
Estimate \\
(Std. Err)
\end{tabular} & $\begin{array}{l}\text { Estimate } \\
\text { (Std. Err) }\end{array}$ & $\begin{array}{l}\text { Estimate } \\
\text { (Std. Err) }\end{array}$ & $\begin{array}{l}\text { Estimate } \\
\text { (Std. Err) }\end{array}$ \\
\hline & \multicolumn{4}{|c|}{ Demand } & & \multicolumn{4}{|c|}{ Pricing } \\
\hline $\begin{array}{l}\text { Price } \\
\quad \alpha=\exp (\text { parameter })\end{array}$ & $\begin{array}{r}0.00 \\
(0.00)\end{array}$ & $\begin{array}{r}0.00 \\
(0.00)\end{array}$ & $\begin{array}{c}0.69 \\
(0.00)\end{array}$ & $\begin{array}{l}0.69 \\
(0.00)\end{array}$ & 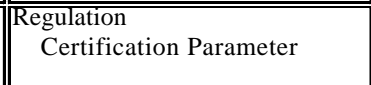 & $-\cdots--$ & ---- & $\begin{array}{r}0.00 \\
(0.00)\end{array}$ & $\begin{array}{c}0.00 \\
(0.00)\end{array}$ \\
\hline Constant Terms & & & & & Constant Terms & & & & \\
\hline Basic & $\begin{array}{c}0.00 \\
(0.00)\end{array}$ & $\begin{array}{l}0.00 \\
(0.00)\end{array}$ & $\begin{array}{l}18.72 \\
\text { (u.vo) }\end{array}$ & $\begin{array}{l}18.98 \\
\text { (u.vo) }\end{array}$ & Basic & $\begin{array}{c}0.00 \\
(0.00)\end{array}$ & $\begin{array}{c}0.00 \\
(0.00)\end{array}$ & $\begin{array}{l}7.35 \\
\text { (u.vo) }\end{array}$ & $\begin{array}{l}7.27 \\
(0.00)\end{array}$ \\
\hline Exp. Basic I & $\begin{array}{c}0.00 \\
\text { (u.vo) }\end{array}$ & $\begin{array}{l}0.00 \\
\text { (u.vo) }\end{array}$ & $\begin{array}{l}1.36 \\
(0.00)\end{array}$ & $\begin{array}{l}0.99 \\
\text { (u.vu) }\end{array}$ & Exp. Basic I & ---- & --- & --- & --- \\
\hline Exp. Basic II & (u.vo, & $\begin{array}{l}---- \\
\text { (u.vu }\end{array}$ & $\begin{array}{l}---- \\
\text { (v.vu) }\end{array}$ & $\begin{array}{l}----- \\
\text { (u.vou }\end{array}$ & Exp. Basic II & ----- & ----- & ---- & ----- \\
\hline $\begin{array}{l}\text { Broadcast Prog. } \\
\text { First Over-the-Air }\end{array}$ & 0.00 & 0.00 & -0.22 & -0.23 & $\begin{array}{l}\text { Broadcast Prog. } \\
\text { First Over-the-Air }\end{array}$ & ---- & ---- & ---- & ---- \\
\hline Dup. Over-the-Air & $\begin{aligned} 0.00 \\
\text { (u.vo) }\end{aligned}$ & $\begin{array}{l}0.00 \\
\text { (v.vov) }\end{array}$ & $\begin{array}{l}-0.10 \\
\text { (v.vo) }\end{array}$ & $\begin{array}{l}-0.11 \\
\text { (u.vo) }\end{array}$ & Dup. Over-the-Air & ---- & ----- & ----- & ----- \\
\hline $\begin{array}{l}\text { First on Basic } \\
\text { not available Over-the-Air }\end{array}$ & $\begin{array}{l}0.00 \\
(0.00)\end{array}$ & $\begin{array}{l}0.00 \\
(0.00)\end{array}$ & $\begin{array}{l}-0.25 \\
(0.00)\end{array}$ & $\begin{array}{l}-0.25 \\
(0.00)\end{array}$ & $\begin{array}{l}\text { First on Basic } \\
\text { not available Over-the-Air }\end{array}$ & $\begin{array}{r}0.00 \\
(0.00)\end{array}$ & $\begin{array}{l}0.00 \\
(0.00)\end{array}$ & $\begin{array}{l}-0.35 \\
(0.00)\end{array}$ & $\begin{array}{l}-0.35 \\
(0.00)\end{array}$ \\
\hline $\begin{array}{l}\text { Duplicate on Basic } \\
\text { not available Over-the-Air }\end{array}$ & $\begin{array}{c}0.00 \\
(0.00)\end{array}$ & $\begin{array}{l}0.00 \\
(0.00)\end{array}$ & $\begin{array}{l}0.13 \\
(0.00)\end{array}$ & $\begin{array}{l}0.12 \\
(0.00)\end{array}$ & $\begin{array}{l}\text { Duplicate on Basic } \\
\text { not available Over-the-Air }\end{array}$ & $\begin{array}{l}0.00 \\
(0.00)\end{array}$ & $\begin{array}{l}0.00 \\
(0.00)\end{array}$ & $\begin{array}{l}-0.21 \\
(0.00)\end{array}$ & $\begin{array}{l}-0.21 \\
(0.00)\end{array}$ \\
\hline Cable Programming & & & & & Cable Programming & & & & \\
\hline ESPN & $\begin{array}{c}0.00 \\
\text { (vovo) }\end{array}$ & $\begin{array}{l}0.00 \\
\text { (u.vo) }\end{array}$ & $\begin{array}{l}1.17 \\
\text { (u.vo) }\end{array}$ & $\begin{array}{l}1.03 \\
\text { (v.uv) }\end{array}$ & ESPN & $\begin{array}{c}0.00 \\
\text { (v.vo) }\end{array}$ & $\begin{array}{l}0.00 \\
\text { (v.uv) }\end{array}$ & $\begin{array}{c}0.61 \\
\text { (v.vu) }\end{array}$ & $\begin{array}{c}0.66 \\
\text { (v.uv) }\end{array}$ \\
\hline $\mathrm{CNN}$ & $\begin{array}{l}0.00 \\
\text { (u.ve) }\end{array}$ & $\begin{array}{l}0.00 \\
\text { (u.ve) }\end{array}$ & $\begin{array}{l}1.18 \\
\text { (v.vo) }\end{array}$ & $\begin{array}{l}1.30 \\
\text { (v.vo) }\end{array}$ & $\mathrm{CNN}$ & $\begin{array}{l}0.00 \\
\text { (v.vo) }\end{array}$ & $\begin{array}{l}0.00 \\
\text { (u.vo) }\end{array}$ & $\underset{\text { (u.vo) }}{2.17}$ & $\underset{\text { (u.vo) }}{2.10}$ \\
\hline WTBS & $\begin{array}{l}0.00 \\
\text { (u.vo) }\end{array}$ & $\begin{array}{l}0.00 \\
\text { (u.vo) }\end{array}$ & $\begin{array}{l}2.01 \\
\text { (u.vo) }\end{array}$ & $\begin{array}{l}1.86 \\
\text { (u.vo) }\end{array}$ & WTBS & $\begin{array}{l}0.00 \\
\text { (v.vo) }\end{array}$ & $\begin{array}{l}0.00 \\
\text { (u.vo) }\end{array}$ & $\begin{array}{l}-1.28 \\
\text { (u.vo) }\end{array}$ & $\begin{array}{l}-1.25 \\
\text { (u.vo) }\end{array}$ \\
\hline USA & $\begin{array}{l}0.00 \\
\text { (u.vo) }\end{array}$ & $\begin{array}{l}0.00 \\
\text { (u.vo) }\end{array}$ & $\begin{array}{l}2.16 \\
\text { (u.vo) }\end{array}$ & $\underset{t}{2.12}$ & USA & $\begin{array}{l}0.00 \\
\text { (v.vo) }\end{array}$ & $\begin{array}{l}0.00 \\
\text { (u.vo) }\end{array}$ & $\begin{array}{l}1.17 \\
\text { (v.vo) }\end{array}$ & $\begin{array}{l}1.16 \\
\text { (u.vo) }\end{array}$ \\
\hline The Discovery Channel & $\begin{array}{l}0.00 \\
\text { (v.vu, }\end{array}$ & $\begin{array}{l}0.00 \\
\text { (v.vu, }\end{array}$ & $\begin{array}{l}-0.09 \\
-0.001\end{array}$ & $\begin{array}{l}-0.11 \\
\text { (v.vu, }\end{array}$ & The Discovery Channel & $\begin{array}{l}0.00 \\
\text { (v.vu, }\end{array}$ & $\begin{array}{l}0.00 \\
\text { c.uve }\end{array}$ & $\begin{array}{c}0.21 \\
\text { (u.vo, }\end{array}$ & $\begin{array}{r}0.25 \\
\text { (v.uv) }\end{array}$ \\
\hline $\begin{array}{l}\text { Other Cable Networks } \\
\text { on Basic Service }\end{array}$ & $\begin{array}{c}0.00 \\
(0.00)\end{array}$ & $\begin{array}{c}0.00 \\
(0.00)\end{array}$ & $\begin{array}{l}0.26 \\
(0.00)\end{array}$ & $\begin{array}{l}0.26 \\
(0.00)\end{array}$ & $\begin{array}{l}\text { Other Cable Networks } \\
\text { on Basic Service }\end{array}$ & $\begin{array}{r}0.00 \\
(0.00)\end{array}$ & $\begin{array}{l}0.00 \\
(0.00)\end{array}$ & $\begin{array}{l}0.28 \\
(0.00)\end{array}$ & $\begin{array}{l}0.28 \\
(0.00)\end{array}$ \\
\hline $\begin{array}{c}\text { Other Cable Networks } \\
\text { on Expanded Basic Svcs. }\end{array}$ & ----- & ----- & ----- & $\begin{array}{l}0.31 \\
(0.00)\end{array}$ & \begin{tabular}{|c} 
Other Cable Networks \\
on Expanded Basic Svcs.
\end{tabular} & ----- & ---- & ---- & ---- \\
\hline $\begin{array}{l}\text { Premium Programming } \\
\text { HBO }\end{array}$ & $\begin{array}{c}0.00 \\
\text { (u.vo) }\end{array}$ & $\begin{array}{c}0.00 \\
(\text { (u. ou) }\end{array}$ & $\begin{array}{l}12.21 \\
\text { (v.vo) }\end{array}$ & $\begin{array}{l}12.19 \\
\text { (v.vo) }\end{array}$ & $\begin{array}{l}\text { Premium Programming } \\
\text { HBO }\end{array}$ & $\begin{array}{c}0.00 \\
(0.00)\end{array}$ & $\begin{array}{c}0.00 \\
(0.00)\end{array}$ & $\begin{array}{l}8.52 \\
\text { (u.vo) }\end{array}$ & $\begin{array}{c}8.52 \\
\text { (u.vo) }\end{array}$ \\
\hline Showtime & $\begin{array}{c}0.00 \\
\text { (v.ve) }\end{array}$ & $\begin{array}{l}0.00 \\
\text { (v.vo) }\end{array}$ & $\begin{array}{l}11.59 \\
\text { (v.vo) }\end{array}$ & $\begin{array}{l}11.58 \\
\text { (v.vo) }\end{array}$ & Showtime & $\begin{array}{c}0.00 \\
\text { (v.vo) }\end{array}$ & $\begin{array}{l}0.00 \\
\text { (u.vo }\end{array}$ & $\begin{array}{l}8.59 \\
\text { (u.vo) }\end{array}$ & $\begin{array}{l}8.59 \\
\text { (u.vo }\end{array}$ \\
\hline The Disney Channel & $\begin{array}{c}0.00 \\
\text { (v.vo) }\end{array}$ & $\begin{array}{l}0.00 \\
\text { (u.vo) }\end{array}$ & $\begin{array}{l}8.71 \\
\text { (v. vou }\end{array}$ & $\begin{array}{l}8.69 \\
\text { (v. vou }\end{array}$ & The Disney Channel & $\begin{array}{l}0.00 \\
\text { (u.vo) }\end{array}$ & $\begin{array}{l}0.00 \\
\text { (u.vo }\end{array}$ & $\begin{array}{l}7.13 \\
\text { (u.vo) }\end{array}$ & $\begin{array}{l}7.13 \\
\text { (u.vo) }\end{array}$ \\
\hline Cinemax & $\begin{array}{l}0.00 \\
\text { (v.vou) }\end{array}$ & $\begin{array}{l}0.00 \\
\text { (v.vou, }\end{array}$ & $\begin{array}{l}11.08 \\
(\text { v.vo })\end{array}$ & $\begin{array}{l}11.06 \\
\text { (v.vo) }\end{array}$ & Cinemax & $\begin{array}{c}0.00 \\
\text { (v.vou) }\end{array}$ & $\begin{array}{l}0.00 \\
\text { (v.vou }\end{array}$ & $\begin{array}{l}8.25 \\
\text { (v.vu) }\end{array}$ & $\begin{array}{l}8.25 \\
\text { (v.vo, }\end{array}$ \\
\hline The Movie Channel & $\begin{array}{c}0.00 \\
(0.00)\end{array}$ & $\begin{array}{l}0.00 \\
\text { (u.vo) }\end{array}$ & $\begin{array}{l}11.27 \\
(0.00)\end{array}$ & $\begin{array}{l}11.26 \\
\text { (v.vo) }\end{array}$ & The Movie Channel & $\begin{array}{c}0.00 \\
(0.00)\end{array}$ & $\begin{array}{l}0.00 \\
(\text { (u.vo })\end{array}$ & $\begin{array}{l}8.54 \\
(0.00)\end{array}$ & $\begin{array}{l}8.54 \\
(0.00)\end{array}$ \\
\hline $\begin{array}{l}\text { Other Programming } \\
\text { Other Programming }\end{array}$ & $\begin{array}{c}0.00 \\
\text { (u.vo) }\end{array}$ & $\begin{array}{c}0.00 \\
\text { (u.vou }\end{array}$ & $\begin{array}{l}0.04 \\
\text { (v. vou) }\end{array}$ & $\begin{array}{l}0.04 \\
\text { (v.vo) }\end{array}$ & $\begin{array}{c}\text { Other Programming } \\
\text { Other Programming }\end{array}$ & $\begin{aligned} 0.00 \\
\text { (u.vo) }\end{aligned}$ & $\begin{array}{l}0.00 \\
\text { (v.vo })\end{array}$ & $\begin{array}{c}0.08 \\
\text { (u.vo }\end{array}$ & $\begin{array}{c}0.08 \\
\text { (v.vo) }\end{array}$ \\
\hline $\begin{array}{c}\text { Demographics } \\
\text { DMA Rank }\end{array}$ & 0.00 & 0.00 & 0.00 & 0.01 & $\begin{array}{c}\text { Demographics } \\
\text { DMA Rank }\end{array}$ & 0.00 & 0.00 & $\begin{array}{l}-0.01 \\
-0.001\end{array}$ & -0.01 \\
\hline DMA Dummy & $\begin{array}{c}0.00 \\
\text { (u.vo) }\end{array}$ & $\begin{array}{c}0.00 \\
\text { (u.vo) }\end{array}$ & $\begin{array}{l}-0.34 \\
\text { (v.vo) }\end{array}$ & $\begin{array}{l}-0.34 \\
\text { (u.vo) }\end{array}$ & DMA Dummy & $\begin{array}{c}0.00 \\
\text { (u.vo) }\end{array}$ & $\begin{array}{c}0.00 \\
\text { (u.vo) }\end{array}$ & $\begin{array}{l}-3.05 \\
\text { (u.vo) }\end{array}$ & $\begin{array}{l}-3.02 \\
\text { (u.vo) }\end{array}$ \\
\hline$\%$ Population Aged 5-18 & 0.00 & 0.00 & -21.04 & -20.92 & Number of Subs. controlle & 0.00 & 0.00 & 0.00 & 0.00 \\
\hline$\%$ Population With Collegd & $\begin{array}{l}(0.00) \\
0.00\end{array}$ & $\begin{array}{l}(0.00) \\
0.00\end{array}$ & $\begin{array}{l}\text { (v.vo) } \\
5.23\end{array}$ & $\begin{array}{l}\text { (v.vo) } \\
4.92\end{array}$ & MSO Affiliated with Progr & $\begin{array}{l}(0.00) \\
0.00\end{array}$ & $\begin{array}{l}(0.00) \\
0.00\end{array}$ & $\begin{array}{l}\text { (u.ve) } \\
1.51\end{array}$ & $\begin{array}{l}\text { (u.vo) } \\
1.49\end{array}$ \\
\hline Median Income (thousand & 0.00 & $\begin{array}{l}0.00 \\
\text { u.vou }\end{array}$ & $\begin{array}{l}-0.11 \\
\text { (vovu }\end{array}$ & $\begin{array}{l}-0.11 \\
\text { (v.vo, }\end{array}$ & Homes Passed & $\begin{array}{r}0.00 \\
\text { (1). }\end{array}$ & $\begin{array}{c}0.00 \\
\text { covou, } \\
\end{array}$ & $\begin{array}{c}0.00 \\
\text { (vovo } \\
\end{array}$ & $\begin{array}{c}0.00 \\
\text { (u.vo } \\
\end{array}$ \\
\hline Price*Demographics & & & & & Log Likelihood Function & 0.00 & 0.00 & 0.00 & 0.00 \\
\hline$\alpha^{*}$ DMA Rank & ---- & 0.00 & 0.00 & 0.00 & Test of Overidentifying Restricti & 239.40 & 0.00 & 0.00 & 0.00 \\
\hline$\alpha^{*}$ DMA Dummy & ----- & 0.00 & -0.02 & -0.02 & |Number of Observations & 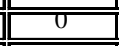 & $=0$ & $\overline{0}$ & $\overline{0}$ \\
\hline$\alpha * \%$ Population Aged 5-1 & ----- & $\begin{array}{l}(u . v 0) \\
0.00\end{array}$ & 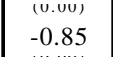 & 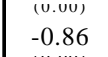 & & & & & \\
\hline$\alpha * \%$ Population With Coll & ----- & 0.00 & -0.11 & -0.13 & & & & & \\
\hline$\alpha^{*}$ Median Income (thousa & ---- & 0.00 & 0.00 & 0.00 & & & & & \\
\hline
\end{tabular}




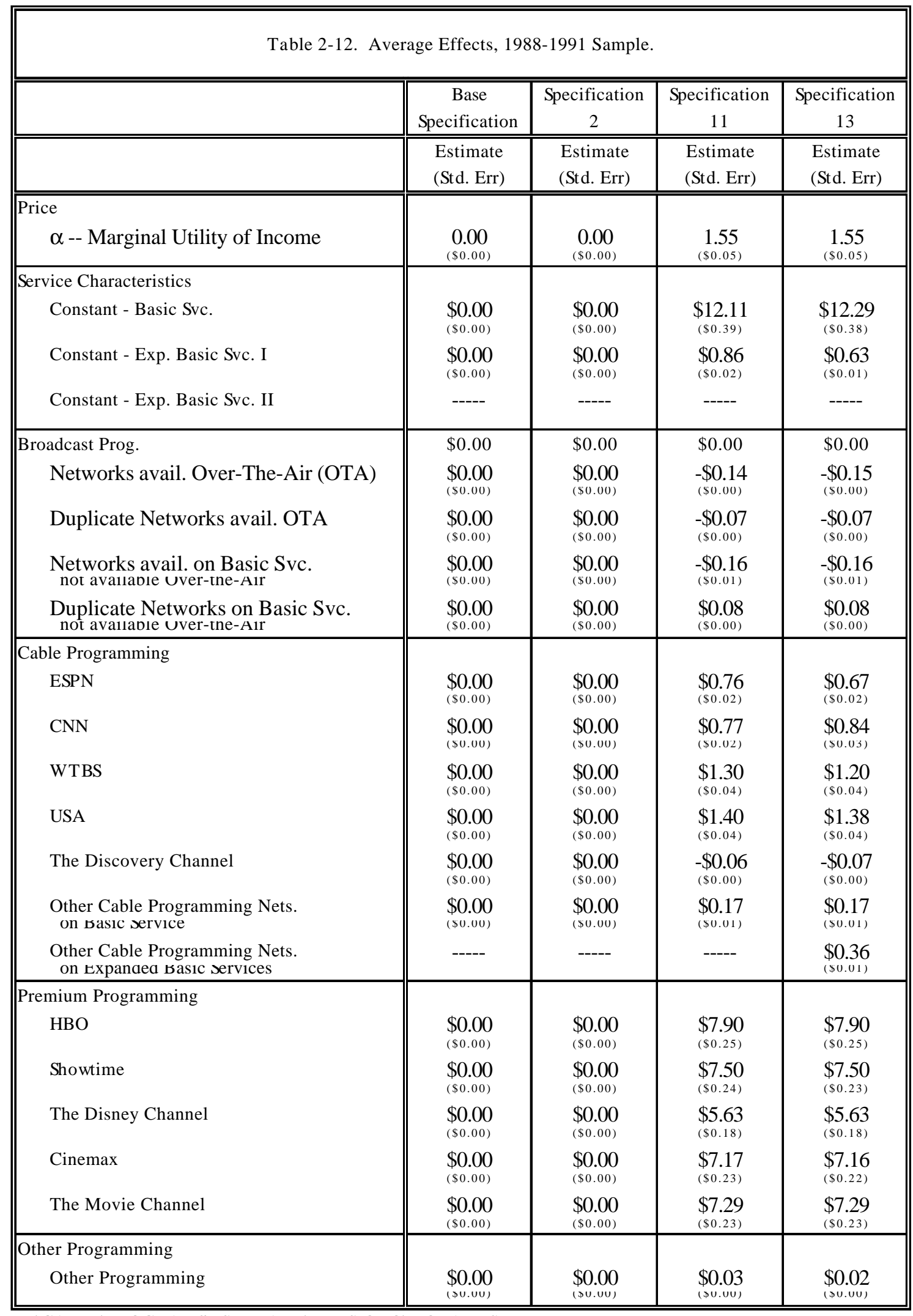

D:ICABLEIPROGRAMSIESTIMATEIVERSIONQIMOD1.XLS 


\begin{tabular}{|c|c|c|c|c|c|}
\hline \multicolumn{6}{|c|}{$\begin{array}{l}\text { Table 2-13. Welfare and Equivalent Price Effects } \\
\text { Changes in System Choice Sets By Type of Change }\end{array}$} \\
\hline & \multicolumn{4}{|c|}{ Welfare Effect } & \\
\hline & Mean & Std.Dev. & Min. & Max. & \\
\hline Demographics & $-\$ 0.25$ & $\$ 0.34$ & $-\$ 2.68$ & $\$ 2.06$ & \\
\hline Services & $\$ 0.91$ & $\$ 2.30$ & $-\$ 2.31$ & $\$ 9.53$ & \\
\hline \multicolumn{6}{|l|}{ Programming } \\
\hline New Programming & $\$ 0.38$ & $\$ 0.73$ & $-\$ 0.34$ & $\$ 6.96$ & \\
\hline Moving Programming & $-\$ 0.14$ & $\$ 0.91$ & $-\$ 6.53$ & $\$ 7.41$ & \\
\hline Prices & $-\$ 0.86$ & $\$ 2.01$ & $-\$ 8.50$ & $\$ 7.51$ & \\
\hline \multirow[t]{3}{*}{ Total } & $\$ 0.04$ & $\$ 1.63$ & $-\$ 3.67$ & $\$ 8.55$ & \\
\hline & \multicolumn{4}{|c|}{ Equivalent Price Effect } & $\begin{array}{c}\text { Price Change } \\
\text { Jan, 1989 - July, } 1995 \\
\end{array}$ \\
\hline & Mean & Std.Dev. & Min. & Max. & \\
\hline Demographics & $3.34 \%$ & $4.12 \%$ & $-20.27 \%$ & $22.91 \%$ & $4.71 \%$ \\
\hline Services & $-8.00 \%$ & $21.15 \%$ & $-92.91 \%$ & $79.97 \%$ & $-14.85 \%$ \\
\hline \multicolumn{6}{|l|}{ Programming } \\
\hline New Programming & $-4.54 \%$ & $10.66 \%$ & $-91.32 \%$ & $2.88 \%$ & \\
\hline Moving Programming & $1.17 \%$ & $13.85 \%$ & $-128.72 \%$ & $127.13 \%$ & $-6.16 \%$ \\
\hline Prices & $8.47 \%$ & $21.26 \%$ & $-55.83 \%$ & $110.02 \%$ & $16.83 \%$ \\
\hline Total & $0.08 \%$ & $20.49 \%$ & $-93.85 \%$ & $103.30 \%$ & $-2.20 \%$ \\
\hline Total CPI & $7.96 \%$ & $7.68 \%$ & $-5.73 \%$ & $18.49 \%$ & $14.60 \%$ \\
\hline
\end{tabular}

Notes:

1. Welfare Effect $=$ Average Expected Equivalent Variation associated with given change in market characteristic or choice elements

2. Equivalent Price Effect $=$ Percentage change in the price of Basic Service (in the 1988-1991 Sample) which would yield the estimated change in Equivalent Variation. This percentage then averaged across markets.

D:ICABLEIPROGRAMSIPOSTESTIVERSIONQIOUTPUT1.XLS 


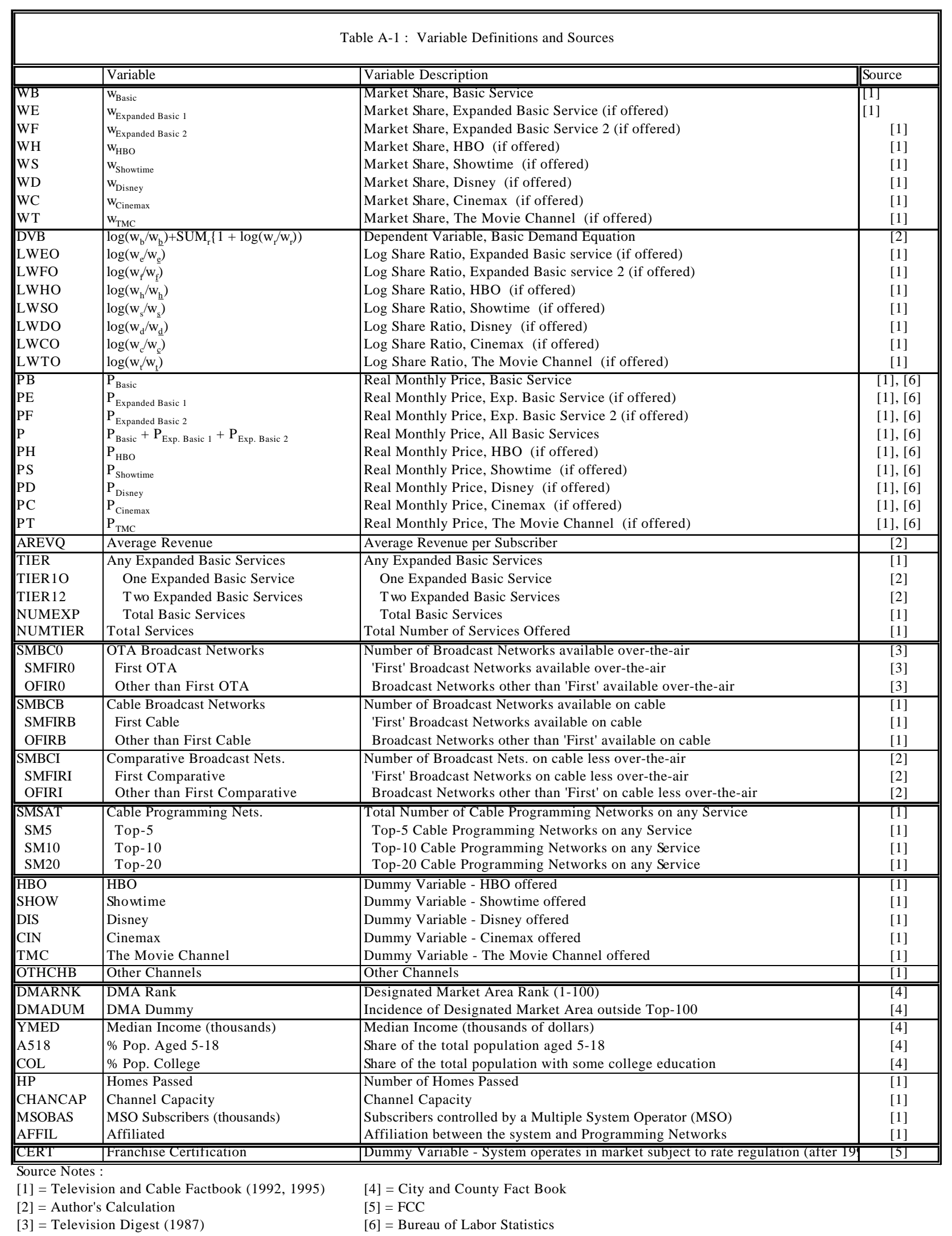




\begin{tabular}{|c|c|c|c|c|}
\hline \multirow[b]{2}{*}{ Condition } & \multirow[b]{2}{*}{ Description } & \multicolumn{2}{|c|}{ Pre-Act Sample } & \multirow{2}{*}{$\begin{array}{c}\text { Post-Act } \\
\text { Obs. } \\
\text { Lost }\end{array}$} \\
\hline & & \begin{tabular}{l||} 
Obs. \\
Lost
\end{tabular} & $\begin{array}{l}\text { Total } \\
\text { Obs. }\end{array}$ & \\
\hline & Total Observations & & "10202 & \\
\hline badpqb & Missing or zero price or quantity, Basic Service & 1549 & & 847 \\
\hline misscap & Missing channel capacity & 1468 & & 994 \\
\hline misshp & Missing homes passed & 2388 & & 2042 \\
\hline bigq & More subscribers than homes passed & 2505 & & 2164 \\
\hline zeromop & Zero or fewer Miles of Plant & 2064 & & 1555 \\
\hline badpqt & Missing or zero price or quantity, Expanded Basic Service & 514 & & 1035 \\
\hline dumtiers & Systems offering uncommon tiers & 7 & & 208 \\
\hline bigtier1 & Quantity for Expanded Basic 1 bigger than Basic & 57 & & 140 \\
\hline bigtier2 & Quantity for Expanded Basic 2 bigger than Basic & 2 & & 7 \\
\hline t2_no_t1 & Missing intermediate tier info & 0 & & 5 \\
\hline nomatier & Internal tier dates do not match & 3 & & 23 \\
\hline nomatpay & Internal pay dates do not match & 253 & & 308 \\
\hline nomatdat & Pay date does not equal tier date & 208 & & 4290 \\
\hline tooearly & Date before 9/1/93 & 739 & & 5285 \\
\hline missdate & Missing date & 2827 & & 2114 \\
\hline badbeg & Beginning date of $5 / 1 / 1$ & 1 & & 0 \\
\hline bctier & Broadcast Channels on Tiers & 165 & & 140 \\
\hline badstat & No Status for some stations & 0 & & 29 \\
\hline multaff & Multiple affiliates for some stations & 271 & & 817 \\
\hline noaff & No affiliation for some stations & 407 & & 356 \\
\hline badloc & No local broadcast information & 56 & & 50 \\
\hline badidsat & Bad tier identifier for network & & & 3 \\
\hline satdef1 & Programming offered on missing tier 2 & 142 & & 478 \\
\hline satdef2 & Programming offered on missing tiers & 579 & & 494 \\
\hline unbun & Systems only reported pay units & 0 & & 1072 \\
\hline mismat & No names for each price & 0 & & 120 \\
\hline badpqp & Missing price and/or quantity, Premium Services & 2677 & & 3015 \\
\hline nopaynam & No name given for some network, Premium Services & 6198 & & 93 \\
\hline missdemo & Missing Demographic Info & 41 & & 61 \\
\hline badshare & Shares outside $(0,1)$ & 489 & & 1124 \\
\hline missmso & Missing Multiple System Operator & 20 & & 45 \\
\hline negoth & 'Other' Channels Less Than 0 & 7600 & & 2311 \\
\hline & Total Lost & - & 8742 & \\
\hline & Remaining Data - Each Sample & $=$ & 1460 & $=$ \\
\hline & Remaining Data - Panel Sample & & & 344 \\
\hline
\end{tabular}




\begin{tabular}{|c|c|c|c|}
\hline \multicolumn{4}{|c|}{$\begin{array}{l}\text { Table A-3 : Comparability of Sample Data with Population of Cable Systems } \\
\qquad 1992-1995 \text { Sample }\end{array}$} \\
\hline Variable & Sample Data & Population Data & Source \\
\hline $\begin{array}{l}\text { Homes Passed } \\
\text { Market ShareBasic } \\
\text { Incidence of Premium Svcs. } \\
\text { Pay Units per Basic Sub. }\end{array}$ & \begin{tabular}{r|}
3,915 \\
$65.7 \%$ \\
$100.0 \%$ \\
0.45
\end{tabular} & $\begin{array}{r}\sim 8,195 \\
61.0 \% \\
\sim 75.6 \% \\
0.79 \\
\end{array}$ & $\begin{array}{l}(1),(3) \\
(1) \\
(2),(3) \\
(2)\end{array}$ \\
\hline $\begin{array}{l}\text { PriceBasic } \\
\text { Pricepremium }\end{array}$ & \begin{tabular}{l|}
$\$ 17.08$ \\
$\$ 10.27$ \\
\end{tabular} & $\begin{array}{l}18.85 \\
\$ 10.17 \\
\end{array}$ & $\begin{array}{l}(4) \\
(4)\end{array}$ \\
\hline $\begin{array}{l}\text { Revenue Shares: } \\
\text { Basic Revenue } \\
\text { Other Revenue } \\
\text { Premium Revenue }\end{array}$ & \begin{tabular}{l||}
$70.8 \%$ \\
$11.3 \%$ \\
$17.9 \%$
\end{tabular} & $\begin{array}{l}57.0 \% \\
19.0 \% \\
24.0 \% \\
\end{array}$ & $\begin{array}{l}(5) \\
(5) \\
(5) \\
\end{array}$ \\
\hline
\end{tabular}

Notes :

Pay Units are defined as the total of all subscriptions to premium services in each market.

PBasic is the price of basic service alone; it does not include the price of any expanded basic services, if offered.

PPremium is the average price of all premium services offered in each market

'Other' Revenue is defined as revenue from expanded basic services, pay-per-view services, equipment sales,

etc. In the sample data, only the revenue from expanded basic services is observed.

Sources: All Population Data taken from National Cable Television Association, Cable Television

Developments, June, 1993. Orginal Sources listed below.

(1) = Paul Kagan Associates, Marketing New Media,April 19, 1993, p.4

(2) = Paul Kagan Associates, The Kagan 1992 Census of Cable and Pay Television, vol. 1, p. 1. (\# Systems Offering Premium Services)

(3) = Warren Publishing, The Television and Cable Factbook, 1992 Edition. (\# Cable Systems)

(4) = Paul Kagan Associates, Inc., The Cable Television Financial Databook, June, 1992, p.2.

(5) = Paul Kagan Associates, Inc., The Cable Television Financial Databook, June, 1992, pp.5-6.

Cable/Data/Analyze/compare.95.xls 
Figure 2-1. Allocation of Programming to Services In the Cable Television Industry

Systems that Offer Expanded Basic Services

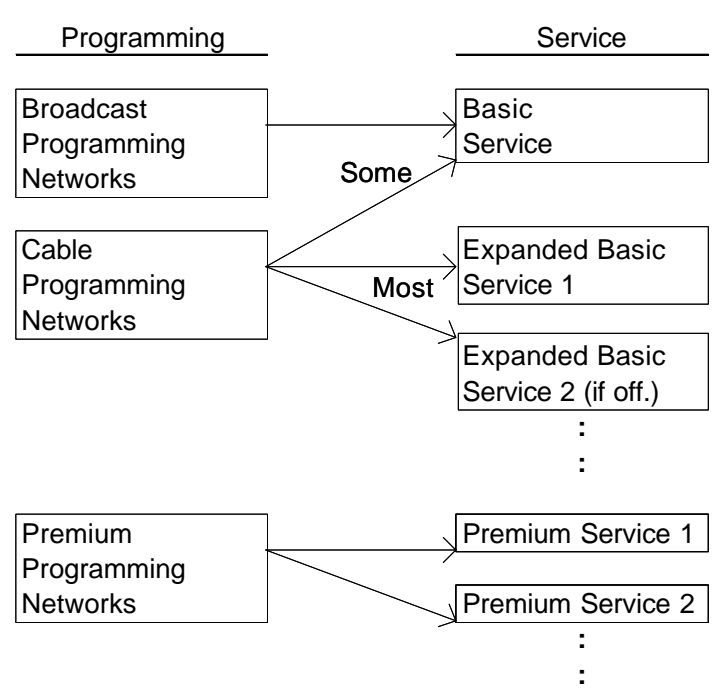

Systems that Do Not Offer an

Expanded Basic Service

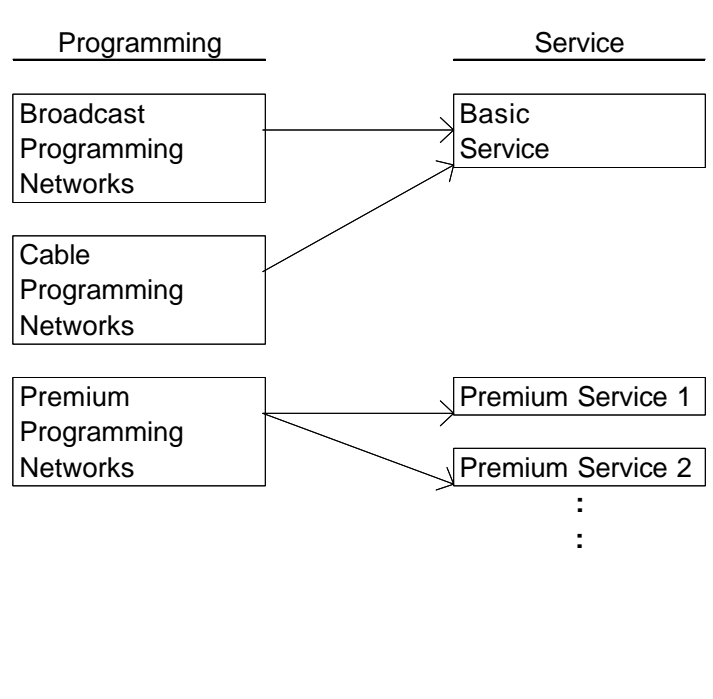


Figure 2-2. Price Indices for Cable Television Service

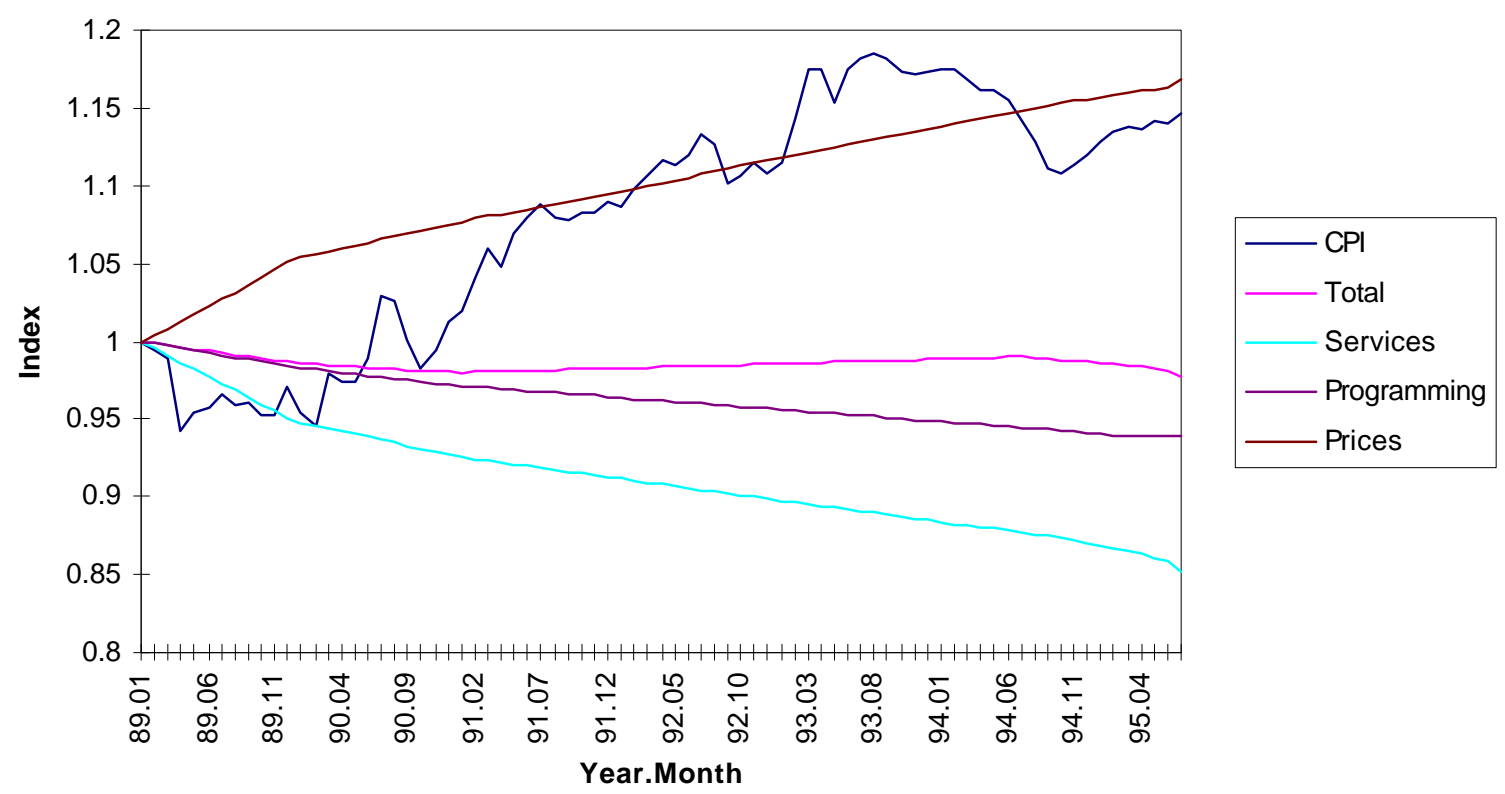

